\title{
问

\section{Methods of Measuring the Solubility and Viscosity of Lubricating Oil/Refrigerant Mixtures at High Discharge Pressures and Temperatures}

Nolan Van Gaalen

Dordt College, nolan.vangaalen@dordt.edu

Follow this and additional works at: https://digitalcollections.dordt.edu/faculty_work

Part of the Chemical Engineering Commons, and the Mechanical Engineering Commons

\author{
Recommended Citation \\ Van Gaalen, N. (1991). Methods of Measuring the Solubility and Viscosity of Lubricating Oil/Refrigerant \\ Mixtures at High Discharge Pressures and Temperatures. Retrieved from \\ https://digitalcollections.dordt.edu/faculty_work/132
}

This Dissertation is brought to you for free and open access by Dordt Digital Collections. It has been accepted for inclusion in Faculty Work Comprehensive List by an authorized administrator of Dordt Digital Collections. For more information, please contact ingrid.mulder@dordt.edu. 


\title{
Methods of Measuring the Solubility and Viscosity of Lubricating Oil/Refrigerant Mixtures at High Discharge Pressures and Temperatures
}

\begin{abstract}
The design and construction of a test facility and methodology for measuring the solubility and viscosity of lubricating oil/refrigerant mixtures at high pressures and temperatures are described. An auxiliary charging system, developed to provide precisely measured quantities of oil and refrigerant to the test facility, is also presented. The test facility was developed under the sponsorship and supervision of ASHRAE which funded this research project (RP-580); The solubility, viscosity and density of mixtures of R-22 and of R-502 with commonly used 150 SUS lubricants have been measured by using this facility. Specifically, results for liquid mixtures of $10 \%$ to $40 \%$ refrigerant (by mass) in a 150 SUS naphthenic oil and in a 150 SUS alkylbenzene are reported over the temperature range of 100 degrees $\mathrm{F}$ (38 degrees $\mathrm{C}$ ) to 300 degrees $F$ ( 149 degrees $C$ ). The oil/refrigerant mixtures for $\mathrm{R}-22$ were miscible over the complete range tested, while for the R-502/naphthenic oil mixtures, two coexistent liquid phases were encountered in tests at the higher refrigerant concentrations; The property test results are presented in graphical form as well as in the form of empirical correlations based on a nonlinear regression analysis of the experimental data. Comparisons with the limited data previously published in the open literature show reasonable agreement.
\end{abstract}

\section{Keywords}

ASHRAE, compressor design, lubricating oil, refrigerant mixtures, viscosity

\section{Disciplines}

Chemical Engineering | Mechanical Engineering

\section{Comments}

- A dissertation submitted to the graduate faculty of lowa State University in partial fulfillment for the degree of DOCTOR OF PHILOSOPHY

- Dr. Michael B. Pate, Committee Chairperson

- C) 1991 Nolan A. Van Gaalen 
Methods of Measuring the Solubility and Viscosity of Lubricating Oil/Refrigerant Mixtures

at High Discharge Pressures and Temperatures

\author{
by \\ Nolan A. Van Gaalen \\ A Dissertation Submitted to the \\ Graduate Faculty in Partial Fulfillment of the \\ Requirements for the Degree of \\ DOCTOR OF PHILOSOPHY
}

Major: Mechanical Engineering

\title{
Approved:
}

Signature was redacted for privacy.

In Charge of Major Work

Signature was redacted for privacy.

For the Major Department

Signature was redacted for privacy.

For the Graduate College

Iowa State University

Ames, Iowa

1991 
TABLE OF CONTENTS

ACKNOWLEDGEMENTS $\ldots \ldots \ldots \ldots \ldots \ldots \ldots$

CHAPTER 1. INTRODUCTION $\ldots \ldots \ldots \ldots \ldots \ldots$

CHAPTER 2. OIL/REFRIGERANT TEST FACILITY $\ldots \ldots \ldots 4$

Design of Experimental Apparatus . . . . . . . . . . 4

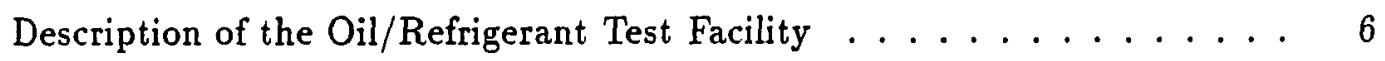

Description of the Oil/Refrigerant Charging Station . . . . . . . 19

Summary . . . . . . . . . . . . . . . . 23

CHAPTER 3. EXPERIMENTAL PROCEDURES AND DATA

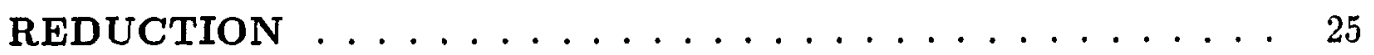

General Experimental Procedures . . . . . . . . . . . . . . . 25

System Calibration Check . . . . . . . . . . . . . . . 30

Data Reduction . . . . . . . . . . . . . . . 39

Summary . . . . . . . . . . . . . . . . . . . 42

CHAPTER 4. R-22 AND OIL SOLUTION PROPERTY RESULTS 43

Results and Discussion . . . . . . . . . . . . 43

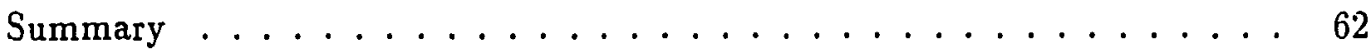

CHAPTER 5. R-502 AND OIL SOLUTION PROPERTY RESULTS 66 
Results and Discussion ................. 6 i

Summary $\ldots \ldots \ldots \ldots \ldots \ldots \ldots \ldots \ldots$

CHAPTER 6. CONCLUSIONS AND RECOMMENDATIONS . . 88

Recommendations for Future Work . . . . . . . . . . . . . . 89

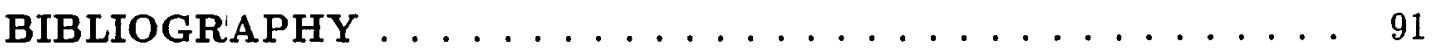

APPENDIX A. TEST FACILITY CONSTRUCTION DETAILS . . 93

APPENDIX B. UNCERTAINTY ANALYSIS . . . . . . . . . 103

Uncertainties of the Pressure, Temperature, and Viscosity Data . . . . . 103

Uncertainty of the Liquid Density . . . . . . . . . . . . . 105

Uncertainty of the Liquid Composition . . . . . . . . . . . . . 114

APPENDIX C. LISTING OF EXPERIMENTAL DATA . . . . . 118 


\section{LIST OF TABLES}

Table 2.1: Summary of instrumentation ranges and precision . . . . . 18

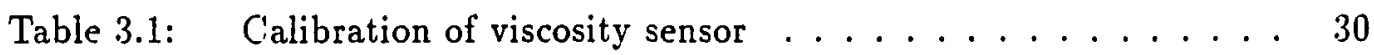

Table 4.1: Coefficients for Empirical Correlations of Viscosity, Pressure, and Density Data for R-22/oil Solutions . . . . . . . 45

Table 5.1: Coefficients for empirical correlations of viscosity, pressure, and density data for R-502/oil solutions . . . . . . . 68

Table A.1: List of test facility components . . . . . . . . . . . 98

Table A.2: List of charging station components . . . . . . . . . . . 101

Table C..1: Experimental solubility (vapor pressure) data for R-22/150 SUS naphthenic oil solutions .............. 120

Table C.2: Experimental viscosity data for R-22/150 SUS naphthenic oil solutions ..................... 123

Table C.3: Experimental density data for R-22/150 SUS naphthenic oil solutions ...................... 125

Table C.4: Experimental solubility (vapor pressure) data for R-22/150 SUS alkylbenzene solutions . . . . . . . . . . 127 
Table C..5: Experimental viscosity data for R-22/150 SLiS alkylbenzene solutions ....................... 130

Table C.6: Experimental density data for R-22/150 SUTS alkylbenzene so-

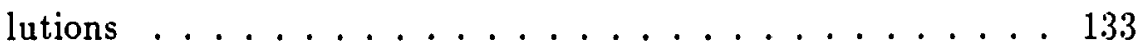

Table C.7: Experimental solubility (vapor pressure) data for R-502/150 SUS naphthenic oil solutions $\ldots \ldots \ldots \ldots$

Table C.8: Experimental viscosity data for R-502/150 SUS naphthenic oil solutions $\ldots \ldots \ldots \ldots \ldots \ldots$

Table C.9: Experimental density data for R-502/150 SUS naphthenic oil solutions ..................... 140

Table C..10: Experimental solubility (vapor pressure) data for R-502/150 SUS alkylbenzene solutions . . . . . . . . . . . . . . . 142

Table C.11: Experimental viscosity data for R-502/150 SLiS alkylbenzene solutions ...................... 144

Table C.12: Experimental density data for R-502/150 SUS alkylbenzene solutions ................... 146 


\section{LIST OF FIGURES}

Figure 2.1: Oil/refrigerant test facility .............

Figure 2.2: $\quad$ Test cell assembly schematic . . . . . . . . . . . . 9

Figure 2.3: $\quad$ Oil/refrigerant test facility schematic . . . . . . . . . 10

Figure 2.4: Viscosity-temperature sensor body . . . . . . . . . . . 14

Figure 2.5: Oil/refrigerant charging facility . . . . . . . . . . 20

Figure 2.6: Oil/refrigerant charging facility schematic . . . . . . . 21

Figure 3.1: $\quad$ R-22 vapor pressure data . . . . . . . . . . . 31

Figure 3.2: Solubility data for mixtures of R-22 and a 150 SUS naphthenic

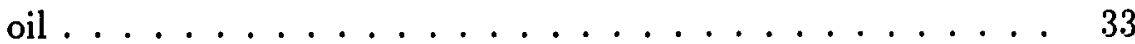

Figure 3.3: Viscosity data for mixtures of R-22 and a 150 SUS naphthenic

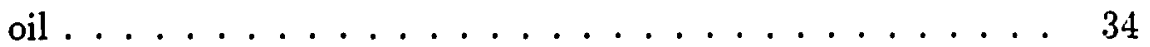

Figure 3.4: Test of repeatability of solubility measurements for $30 \% \mathrm{R}-22$ in a 150 SUS naphthenic oil .................. 35

Figure 3.5: Test of repeatability of viscosity measurements for $30 \% \mathrm{R}-22$ in a 150 SUS naphthenic oil ............ 36

Figure 3.6: Solubility data for mixtures of R-22 and a 150 SUS naphtnenic oil - comparison with literature ........... 3 T 
vii

Figure 3.T: Viscosity data for mixtures of R-22 and a 150 SL'S naphthenic oil - comparison with literature ........... 38

Figure 4.1: Goodness-of-fit of pressure correlation with experimental data for solutions of R-22 in a 150 SUS naphthenic oil . . . . . . 46

Figure 4.2: Goodness-of-fit of viscosity correlation with experimental data for solutions of R-22 in a 150 SUS naphthenic oil . . . . . 47

Figure 4.3: Goodness-of-fit of pressure correlation with experimental data for solutions of R-22 in a 150 SUS alkylbenzene . . . . . . . 48

Figure 4.4: Goodness-of-fit of viscosity correlation with experimental data for solutions of R-22 in a 150 SUS alkylbenzene . . . . . . . 49

Figure 4.5: Solubility of R-22 in a 150 SUS naphthenic oil . . . . . . 50

Figure 4.6: Absolute viscosity of R-22 in a 150 SUS naphthenic oil . . . 51

Figure 4.T: Density of R-22 in a 150 SUS naphthenic oil . . . . . . 52

Figure 4.8: Viscosity-temperature-pressure chart for solutions of R-22 in a 150 SUS naphthenic oil . . . . . . . . . . . . 54

Figure 4.9: Ciorrelation of test results compared with manufacturer's solubility data for solutions of R-22 in a 150 SUS naphthenic oil ........................ 56

Figure 4.10: Solubility of R-22 in a 150 SUS alkylbenzene . . . . . . 57

Figure 4.11: Absolute viscosity of R-22 in a $150 \mathrm{SUS}$ alkylbenzene . . . 58

Figure 4.12: Density of R-22 in a 150 SUS alkylbenzene . . . . . . . 59

Figure 4.13: Viscosity-temperature-pressure chart for solutions of R-22 in a 150 SUS alkylbenzene . . . . . . . . . . . . 60 
viii

Figure 4.14: C'orrelation of test results compared with previously reported solubility data for solutions of R-22 in a 150 SUS alkylbenzene 61

Figure 4.15: C'orrelation of test results compared with estimates of viscosity data for solutions of R-22 in a $150 \mathrm{SLiS}$ alkylbenzene . . . 63

Figure 4.16: Comparison of the solubility of R-22 in a 150 SUS naphthenic oil and in a 150 SUS alkylbenzene . . . . . . . . . . 64

Figure 4.17: Comparison of the viscosity of R-22 in a 150 SUS naphthenic oil and in a 150 SUS alkylbenzene . . . . . . . . . 65

Figure 5.1: Goodness-of-fit of pressure correlation with experimental data for solutions of R-502 in a 150 SUS naphthenic oil . . . . . 69

Figure 5.2: Goodness-of-fit of viscosity correlation with experimental data for solutions of R-502 in a 150 SUS naphthenic oil . . . . 70

Figure 5.3: Goodness-of-fit of pressure correlation with experimental data for solutions of R-502 in a 150 SUS alkylbenzene . . . . . 71

Figure 5.4: Goodness-of-fit of viscosity correlation with experimental data for solutions of R-502 in a $150 \mathrm{SUS}$ alkylbenzene . . . . . 72

Figure 5.5: Solubility of R-502 in a 150 SUS naphthenic oil . . . . . . 74

Figure 5.6: Absolute viscosity of R-502 in a 150 SUS naphthenic oil . . . 75

Figure 5.7: Density of R-502 in a 150 SUS naphthenic oil . . . . . . 76

Figure 5.8: Viscosity-temperature-pressure chart for solutions of R-502 in a 150 SUS naphthenic oil ................. 78

Figure 5.9: Correlation of test results compared with manufacturer's solubility data for solutions of R-502 in a 150 SUS naphthenic

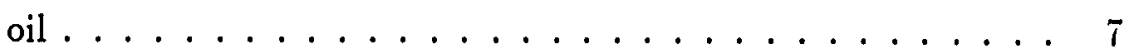


Figure 5.10: Solubility of R-502 in a 150 SUS alkylbenzene . . . . . . 80

Figure 5.11: Absolute viscosity of R-502 in a 150 SUS alkylbenzene . . . 81

Figure 5.12: Density of R-502 in a 150 SUS alkylbenzene $\ldots \ldots . . .82$

Figure 5.13: Viscosity-temperature-pressure chart for solutions of R-502 in a 150 SUS alkylbenzene . . . . . . . . . . . 83

Figure 5.14: Correlation of test results compared with previously reported solubility data for solutions of R-502 in a 150 SUS alkylbenzene 84

Figure 5.15: Comparison of the solubility of R-502 in a 150 StS naphthenic oil and in a 150 SUS alkylbenzene . . . . . . . . 86

Figure 5.16: Comparison of the viscosity of R-502 in a $150 \mathrm{SUS}$ naphthenic oil and in a 150 SUS alkylbenzene .......... 87

Figure A.1: Working drawing of pressure vessel . . . . . . . 95

Figure A.2: Window frame details . . . . . . . . . . . . 96

Figure A.3: Window assembly details .............. 9 T 


\section{ACKNOWLEDGEMENTS}

This study was sponsored by ASHRAE as Research Project RP-580. The support of ASHRAE and the advice of the RP-580 Monitoring C'ommittee are gratefully acknowledged. In particular, I wish to thank Jack O'Brien, Kanaya Sanvordenker. Glenn Short, and C'arl Speich, for their interest, encouragement, and helpful advice. In the early stages of the project, Ken Puetzer and Paul Tietze also served on this committee. Thanks are also extended to Witco Corp. (Sonneborn Division) and to Shrieve Chemical $\mathrm{C} o$. for the donation of lubricating fluids for testing.

Beyond this, I am grateful to Dr. Michael Pate, without whose insight, generosity, and moral support, this project would not have been completed. Throughout this research project, he has been an effective teacher, technical advisor, and counsellor for me, especially during the more difficult challenges encountered during this work. I also wish to thank Dr. John Eggebrecht, Dr. Jerry Hall, Dr. Ron Nelson, and Dr. Howard Shapiro, who served on my doctoral committee and reviewed the dissertation.

A special acknowledgement is due to Steve Zoz, who helped to design and build the oil/refrigerant charging station and provided much technical assistance in both the construction and operation of the test facility. I have also benefitted from interactions with other graduate student colleagues, especially Joe Huber and Steve Eckels, 
who readily shared their computer systems expertise and practical laboratory experience with me. I will remember with appreciation the philosophical, as well as technical, discussions with them and with "Rajan" Natarajan, Halim Wijaya. Dick Rusk. Bob Bittle, Don Gauger, and Steve Crown. For enthusiastically and frequently sharing the tastes of China, my family and I heartily thank Liang Yong and Ping Liu and their families.

I owe more than I can say to my wife Dorenda, who has lovingly supported and encouraged me in many ways through both the joys and frustrations of our time at Iowa State University, and has provided more than her share of the care and nurture of our daughter Joelle, while also pursuing her studies.

Finally, those who know me well will understand my ready acknowledgement of the blessings of the Lord. Believing that all of reality has an ultimate meaning when seen in reference to a Creator God who also sustains and redeems it, I have tried to view and do my work also within that context. Accordingly, one aspect of the relevance of this work, as I see it, is the extent to which it somehow contributes to better stewardship of energy resources and the environment within the refrigeration industry in its transition to alternative working fluids. 


\section{CHAPTER 1. INTRODUCTION}

Recent advances in screw and rolling piston compressor design have resulted in a need for data on the viscosity and solubility of oil/refrigerant mixtures at high pressures and temperatures. Data on the viscosity and solubility of oil/refrigerant pairs exist in the literature for a limited pressure and temperature range. For example, ASHRAE (1990) has published data from various sources that provide viscosities of these mixtures up to a maximum temperature of $140^{\circ} \mathrm{F}\left(60^{\circ} \mathrm{C}\right)$. Further, for some important combinations of oil and refrigerants, data at any conditions are hard to find or unavailable in the open literature. This is increasingly important as the industry searches for alternative refrigerants and appropriate lubricants. An ASHRAE-sponsored research project, RP-444 (Spauchus 1987), documented the published works in this area, concluding that fewer than 20 references exist on the viscosities of oil/refrigerant mixtures.

Responding to this need for data, ASHRAE sponsored a research project, RP580 , to develop a method for measuring the solubility and the viscosity of oil/refrigerant mixtures at high pressures and temperatures. This need was recognized by ASHRAE as early as 1977 when TC: 3.4 (Lubrication) sponsored a Forum at the ASHRAE Winter Meeting to discuss industrial needs for expanded data on oil/refrigerant mixtures. The early 1980's saw the formation of a consensus between 
TC' 3.4 and TC' 8.1 (Positive Displacement C'ompressors), culminating in a joint work statement recommending "a study to increase the state of the art of solubility and viscosity relationships for lubricating oil/refrigerant mixtures."

The ensuing research project, RP-444, was completed in 1986 and a paper summarizing its findings was presented in 1987 (Spauchus and Speaker 1987). This research included a survey of the existing solubility and viscosity data. finding that a "lack of uniformity in experimental data and data reporting;" especially with regard to systems of units and manner of presentation, made comparison of the results difficult. The researchers also reviewed the available experimental methods of determining this data and studied algorithms that could be used to correlate viscosity data, discovering that "reliable results can be obtained by various methods and equipment. No single method or apparatus has been identified that simplifies the measurements and readily extends the range of the viscosity data that can be acquired." They therefore concluded that there existed a "need for experimental studies by validated means on selected [oil/refrigerant] solutions to serve as models for the generation of a complete data base."

Following the conclusion of RP-444, ASHRAE TC's 3.4 and 8.1 jointly issued a work statement titled "Methods of Measuring the Solubility and Viscosity of Lubricating Oil/Refrigerant Mixtures at High Discharge Pressures and Temperatures." This document outlined the scope of the present research project, RP-580. The objectives of this research project included the development of a methodology for "measurement of solubility and viscosity data for common oil/refrigerant mixtures to static pressures of [at least] 450 psia and temperatures of 150 degrees C'elsius." The apparatus was to meet the criteria of high reproducibility, engineering accuracy, 
ease of construction, reasonable cost, and, if feasible, commercial availability. The correctness of the results was to be proven by tests using several refrigerants and commonly used lubricants. The data sets for the chosen oil/refrigerant pairs were to be extended to the maximum pressure and temperature limits of 450 psia ( $3.1 \mathrm{MPa})$ and $300^{\circ} \mathrm{F}\left(150^{\circ} \mathrm{C}\right)$.

Consultations with the monitoring committee established that four oil/refrigerant pairs were to be studied so that the results could be compared with existing data in order to prove the methodology. These pairs were:

1. R-22 and a 150 SUS naphthenic mineral oil

2. R-22 and a 150 SUS alkylbenzene lubricant

3. R-502 and a 150 SUS naphthenic mineral oil

4. R-502 and a $150 \mathrm{SL}$ S alkylbenzene lubricant

The following chapters discuss the test facility and the methodology which has been developed to meet the above research objectives. Results for the oil/refrigerant pairs studied are presented in the form of graphs and empirical correlations and compared with the limited existing data. Additionally, appendices contain detailed construction information and drawings, an uncertainty analysis, and a tabulation of the actual data points. 


\section{CHAPTER 2. OIL/REFRIGERANT TEST FACILITY}

The experimental apparatus described in this chapter includes a multipurpose test cell capable of withstanding and controlling the high temperatures and pressures present in the oil/refrigerant mixtures undergoing experimental tests. Additional equipment is an auxiliary flow loop for measuring liquid viscosity and for sampling. Transducers for measuring viscosity, temperature, and pressure are installed in the flow loop and the test cell. The facility was designed to measure solubility, viscosity, and density for any oil/refrigerant mixture over a normal operating temperature range of $70^{\circ} \mathrm{F}\left(20^{\circ} \mathrm{C}\right)$ to $300^{\circ} \mathrm{F}\left(150^{\circ} \mathrm{C}\right)$, and at pressures up to 500 psia $(3.5 \mathrm{MPa})$. By interfacing an appropriate cooling unit, the test facility can also be used to evaluate oil/refrigerant mixtures at low temperatures, e.g., $-40^{\circ} \mathrm{F}\left(-40^{\circ} \mathrm{C}\right)$.

\section{Design of Experimental Apparatus}

The design of the test facility began with general requirements that were then used to develop detailed specifications to guide the actual construction of the test facility. These design criteria, equipment and instrumentation descriptions, and operating procedures are given in the following sections. 


\section{General requirements}

The general requirements used to guide the design of the test facility were:

1. Construction with commercially available components and/or readily manufacturable parts.

2. Wide mixture concentration range ( 0 to $100 \%$ refrigerant).

3. Temperatures from $140^{\circ} \mathrm{F}\left(60^{\circ} \mathrm{C}\right)$ to approximately $300^{\circ} \mathrm{F}\left(150^{\circ} \mathrm{C}\right)$.

4. Pressures up to 500 psia $(3.5 \mathrm{MPa})$.

\section{Detailed specifications}

The detailed specifications developed to meet the general requirements were:

1. Batch-type operation, with sufficient liquid to supply viscometer and adequately submerge temperature probes.

2. Overall volume sufficient to (a) contain the addition of refrigerant up to liquid concentrations of $40 \%$ refrigerant / $60 \%$ oil at all expected densities, (b) provide for thermal expansion of the liquid due to heating, and (c) mount a temperature probe in a vapor space.

3. Cylindrical test cell to allow for ease of manufacture from pipe stock. Minimum diameter to contain internal probes and sufficient liquid, ensuring most rapid attainment of equilibrium and uniform temperature profile upon heating.

4. Wall thickness sufficient to safely withstand internal pressure and to permit the machining of appropriately sized O-ring grooves used to seal the ends. 
5. Test cell material to be stainless steel. type 304, for toughness and chemical stability in normal operation.

6. Two independent measurements of liquid temperature, one measurement of vapor temperature and several measurements of test cell wall temperature to check thermal gradients.

7. Pressure, viscosity, and mixture composition determination of highest practical accuracy.

8. Uniform mixing ensured by pumping action.

\section{Description of the Oil/Refrigerant Test Facility}

On the basis of these general and specific considerations, the necessary equipment was designed and built. The major components, including the test cell. the viscometer and sampling loops, and a temperature control flow loop, are housed in an enclosure as shown in Figure 2.1. These system components, as well as the instrumentation for data acquisition and an auxiliary charging system to inject fluids into the test cell, are described in the following sections.

\section{Test cell}

The test cell is a cylinder constructed of Schedule 120 Type 304 stainless steel pipe, with an outside diameter of $5.563 \mathrm{in}$. (141.3 mm), a wall thickness of 0.500 in. $(12.7 \mathrm{~mm})$, and a corresponding inside diameter of $4.563 \mathrm{in}$. $(115.9 \mathrm{~mm})$. The height of the internal volume is $18 \mathrm{in}$. $(457.2 \mathrm{~mm})$. The test cell stands upright on one end. Two diametrically opposite slots $12.5 \mathrm{in}$. $(317.5 \mathrm{~mm})$ in length were 


$$
\text { Pyil| }
$$


machined through the cylinder wall. Windows bolted into position over these slots allow for visual inspection of the contents at all times and under all test conditions. A schematic drawing of the test cell is provided in Figure 2.2 while detailed line drawings are provided in Appendix A.

Machined end plates $1 \mathrm{in}$. $(25.4 \mathrm{~mm})$ thick are bolted onto flanges welded to the pipe section at each end. O-rings at each end, seated in machined grooves in the wall of the pipe section, provide the pressure (and vacuum) seals. Because none of the weld joints are exposed to the contents of the test cell, this method of construction obviates the need for inspection of welds for leakage that would be required by other designs. The height of the test cell is sufficient to accommodate the addition of $40 \%$ (by mass) refrigerant to the initial oil charge, while still reserving a minimum vapor space at all expected densities and at maximum charge conditions.

Entering the test cell through the top end plate are three temperature probes and a heating/cooling coil, as depicted in Figure 2.2. Also provided in the top plate are ports for pressure measurement and pressure relief, as well as for filling and evacuation of the test cell. Two ports machined into the bottom plate allow for the exit and return of fluid to/from the external viscometer and sampling loops, as shown in Figure 2.3. Actual volumes of the test cell and associated loops were determined and the scales on the windows calibrated by injecting precise amounts of R-113 from the charging system, which had been previously calibrated. With both windows mounted on the test cell and with the viscometer and sample loops full, the overall volume was measured as 316.5 in. $^{3} \pm 1.2$ in. $^{3}(5190 \mathrm{~mL} \pm 20 \mathrm{~mL})$. Liquid and vapor volumes were correlated with liquid level height as measured on the scales.

The temperature, and hence pressure, of the solution under test is controlled by 


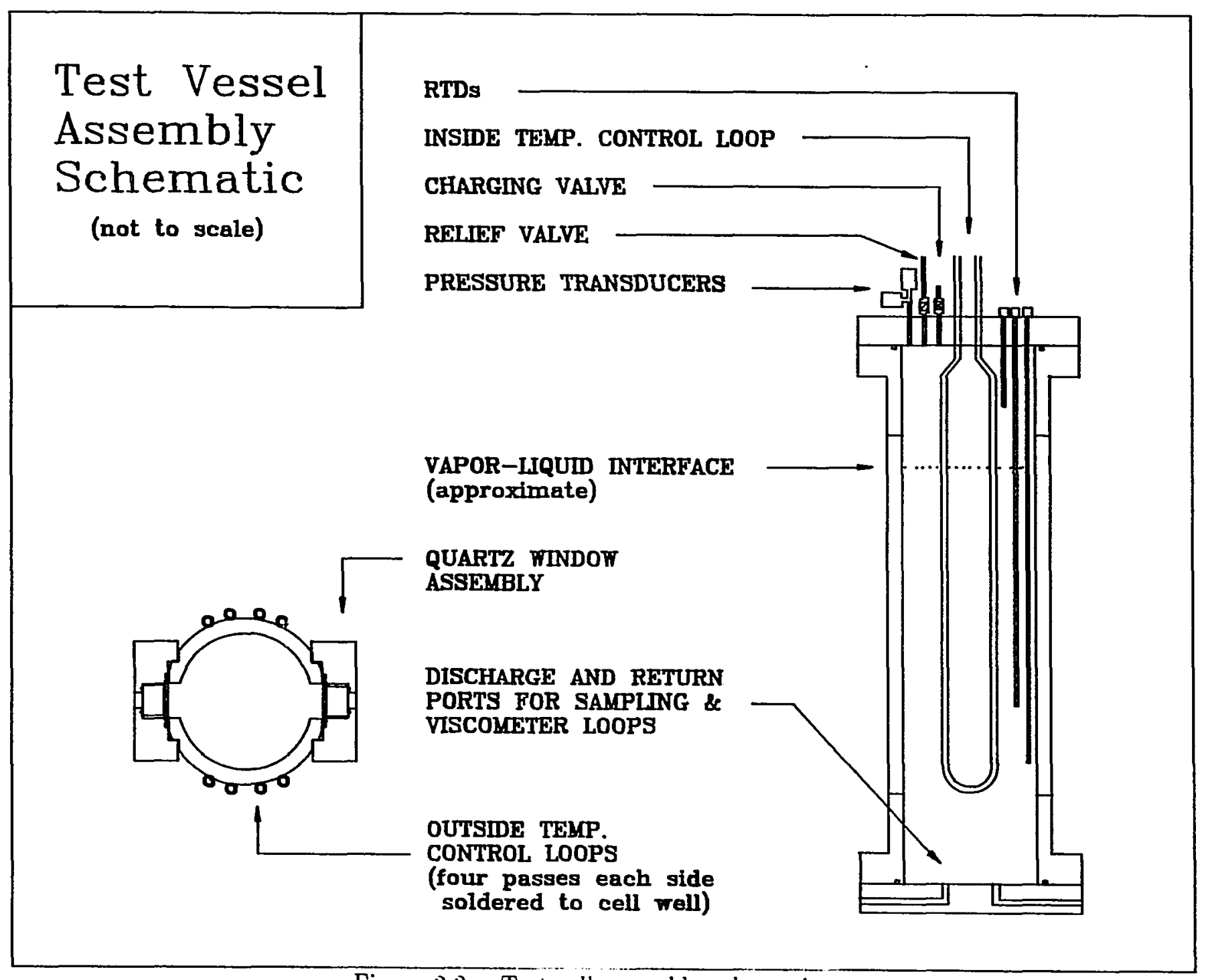

Figure 2.2: Test cell assembly schematic 


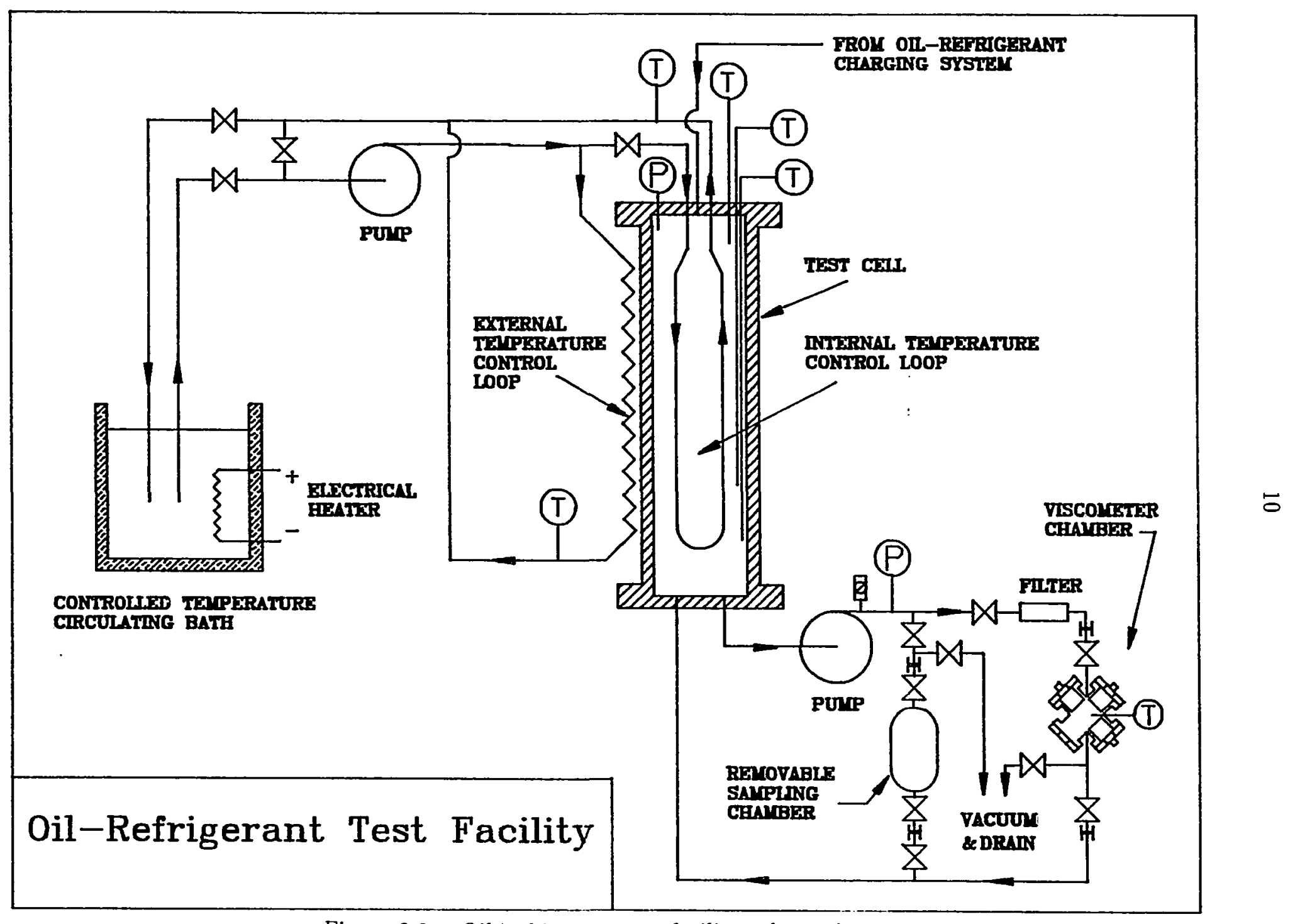

Figure 2.3: Oil/refrigerant test facility schematic 
a temperature control flow loop having coils soldered onto the exterior of the test cell and by a portion of the loop immersed in the test cell. A heating fluid is supplied to this loop by a circulating bath. Uniform heating of a large surface area minimizes the thermal gradients in the oil/refrigerant mixture. Fiberglass insulation, 2 in. 150 $\mathrm{mm}$ ) thick around the test cell, minimizes heat loss to the environment. A walled enclosure, described elsewhere, also reduces heat losses.

\section{Windows}

In order to view the contents of the test cell for the purposes of detecting the presence of more than one liquid phase and for density determinations, as well as aiding the charging of the test cell, two diametrically opposite vertical windows were provided in the test cell wall. The viewing slots are 12 in. $(304.8 \mathrm{~mm})$ long and 0.50 in. $(12.7 \mathrm{~mm}$ ) wide (see Figure 2.1). Calibrated scales fastened to the retainer plates adjacent to the viewing slots enable measurement of the height of the liquidvapor interface to within $\pm 1 / 32$ inch. This permits determination of the volumes of liquid and vapor present to within $\pm 9 \mathrm{~mL}$, or less than $0.2 \%$ of the total cell volume. Quartz pieces set on $\mathrm{O}$-rings and held in place by retainer plates provide the pressure seal. A stainless steel backing plate holds the quartz against the O-ring in the slot. The whole assembly is then bolted onto the test cell and sealed by another (larger) O-ring compressed between the test cell wall and the window assembly. The O-ring material must be compatible with the oil/refrigerant mixtures to which it will be exposed. Neoprene $\mathrm{O}$-rings were used with the R-22/oil mixtures. Viton O-rings have also proven satisfactory in later work, including the studies of R-502/oil mixtures also reported here. Epichlorhydrin, if available, may also prove to be quite widely 
compatible. After installation, a hydrostatic test to $500 \mathrm{psi}(3.5 \mathrm{MPa})$ conducted at ambient temperature proved that the windows were leak-tight. Additional pressure tests with nitrogen gas at 500 psi $(3.5 \mathrm{MPa})$ also showed no leaks.

\section{Temperature control flow loop}

A flow loop for controlling the temperature of the test cell is installed. Figure 2.3 shows a schematic diagram of this loop. The loop has two coils of $0.375 \mathrm{in} .(9.525$ $\mathrm{mm}$ ) OD Type 304 stainless steel tubing in parallel: one soldered in place around the test cell wall and the other immersed in the test cell through the top plate. The exterior portion of this loop is further divided into two parts, with each part heating one side of the test cell. The interior portion also bifurcates to provide more thermal contact area. The routing of these internal loop portions was arranged so that they did not obstruct the view through the windows.

A circulating bath maintains the desired temperature of the heating fluid by controlling a $3-\mathrm{kW}$ heating element. The heating fluid is a poly-alpha-olefin (PAO), used from $140^{\circ} \mathrm{F}\left(60^{\circ} \mathrm{C}\right)$ to $300^{\circ} \mathrm{F}\left(150^{\circ} \mathrm{C}\right)$. While the viscosity of PAO at the lower end of this temperature range, $140^{\circ} \mathrm{F}\left(60^{\circ} \mathrm{C}\right)$, is high $(6-7 \mathrm{cp})$ for achieving turbulent flow in the loop with the circulating bath pump, it performs well at higher temperatures in an open system because of its decreasing viscosity and extremely low volatility. The steady-state temperature of the contents of the test cell is indirectly controlled by setting the temperature of the heating fluid in the flow loop. Operating experience has shown that adequate heating of the test cell is provided by this arrangement. Steady-state conditions are typically achieved from one to two hours after a $18^{\circ} \mathrm{F}$ $\left(10^{\circ} \mathrm{C}^{\prime}\right)$ change in the circulating bath temperature setpoint. To monitor the magni- 
tude of thermal gradients, copper-constantan (Type $T$ ) thermocouples were installed in the flow loop as well as on seven different locations on the outer surface of the test cell. At equilibrium, surface temperature differences are on the order of a few degrees. However, since the liquid inside is well stirred, its temperature is more uniform as measured by the internal resistance temperature detectors (RTD). An average of these liquid temperatures is used in the reporting of the liquid density data.

\section{Viscometer}

Three commercially available viscosity sensors were procured for installation in the auxiliary viscometer loop (CAS 1989). An early version of this viscosity measuring technology was used as a means of measuring the concentration of oil in the liquid line of a refrigeration system as part of a previous ASHRAE-sponsored research project, RP-356 (Baustian et al. 1988). The viscosity sensor operation is based on a movable piston drawn through the fluid in the internal cavity by an applied electromagnetic field. Figure 2.4 provides a schematic drawing of the internal details (C:AS 1989). The time elapsed as the piston travels through a known distance is a measure of the viscosity of the fluid. The associated circuit card provides electronics for control and sensing, giving a 0 to 2 volt d.c. signal correlated to viscosity. The uncertainty of the viscosity data is $\pm \mathbf{2 . 0 \%}$ of the reading. Each sensor also contains an RTD for measurement of the local temperature, which is used in the reporting of the viscosity data. Because of internal self-heating in the viscometer which arises from the dissipation of electrical energy in the drive coils of the sensor, this RTD reading is somewhat higher than the temperatures indicated by the RTDs in the test cell during steady-state operation. This is especially true at the lower end of the 


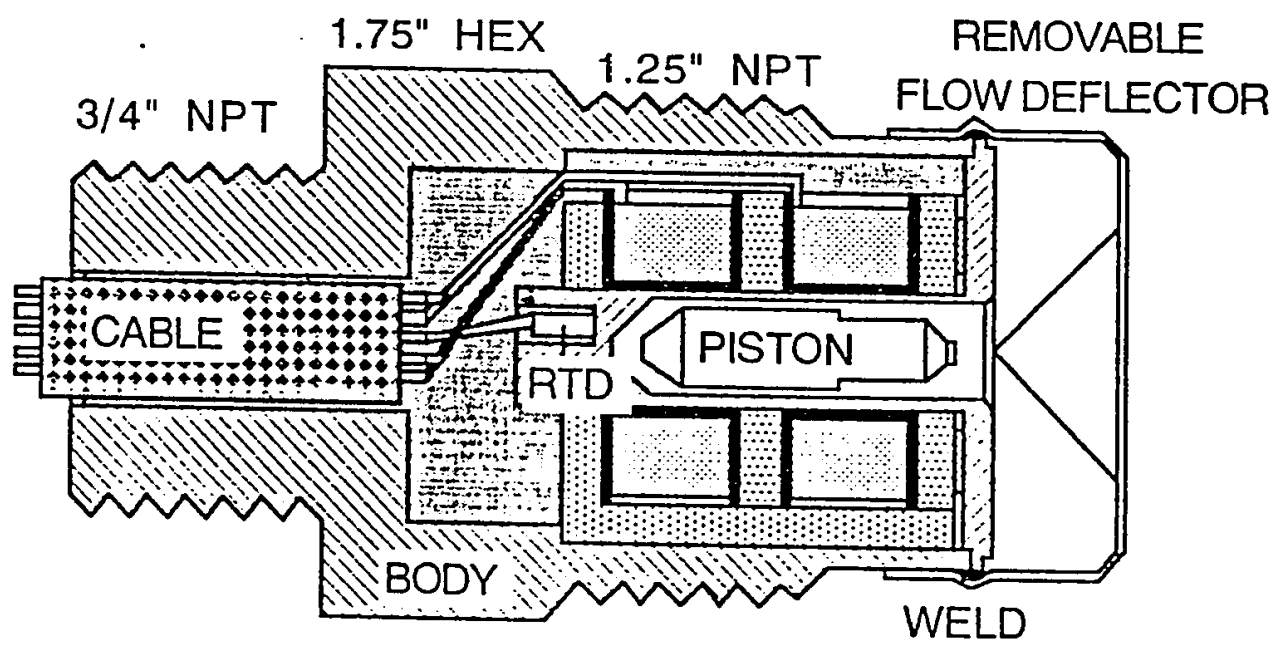

Figure 2.4: Viscosity-temperature sensor body 
investigated temperature range. For example, at $40^{\circ} \mathrm{C}$ the difference is about 3 $4^{\circ} \mathrm{C}$, depending on the particular viscosity sensor. This difference decreases to about zero at temperatures of $90^{\circ} \mathrm{C}$ and beyond.

The three viscosity sensors that are installed in the viscometer chamber have viscosity ranges of $0.1-2 \mathrm{cp}, 1-20 \mathrm{cp}$, and $10-200 \mathrm{cp}$, respectively. Because these ranges overlap, some limited redundant measurements of viscosity are possible, thus increasing the confidence in the validity of the calibrations of each sensor. Use of multiple sensors reduces the downtime that would otherwise be required to change the internal piston of a single sensor to the desired measurement range. Pistons are available from the manufacturer for viscosities up to $5000 \mathrm{cp}$, should they be necessary for measurements at low temperatures where the oil/refrigerant solutions may be very viscous. These solutions are assumed to be "Newtonian" fluids in which the viscosity is independent of shear rate. Discussions with experienced users of these fluids confirmed that this assumption is reasonable.

The viscosity of the liquid is measured outside the test cell in an auxiliary flow loop. Because internal self-heating in the drive coils of the viscometer tends to cause vapor to flash from the equilibrium liquid mixture, it was necessary to construct an external flow loop through which compressed liquid could be pumped to the viscometer for measurement and then returned to the test cell. In this manner, stable and repeatable viscosity readings were achieved. The viscosity test loop complements the test cell, which sets the conditions of concentration, temperature, and pressure at desired values, prior to measuring viscosity. Taking liquid from the test cell, a pump raises the pressure of the liquid without noticeably affecting the temperature. Since a small increase in pressure has a negligible effect on liquid viscosity, this pressurization 
provides a means of preventing vapor formation in the viscometer. Early operating experiences with a different viscometer-mounting configuration showed that vapor formation is disruptive to stable and accurate operation of the viscometer.

As shown in Figures 2.1 and 2.3, a magnetically driven positive-displacement gear pump with a variable-speed motor moves the fluid through this loop to the viscometer chamber and back to the test cell. Variable-speed control allows for adjustment of flow from almost zero to about $1.5 \mathrm{gpm}(0.095 \mathrm{~L} / \mathrm{s})$, which provides for sufficient pressurization of the liquid in the loop while limiting uncontrolled heating of the fluid due to the addition of pumping power. A valve between the viscometer chamber and the discharge to the test cell can be adjusted, along with the flow rate, to produce the required pump discharge pressure at a reasonable flow rate. A pressure gauge is installed at the pump discharge to monitor the pressure increase. A pressure relief valve set to open at 500 psig $(3.5 \mathrm{MPa})$ is installed just downstream of the pump discharge to provide a safe release of fluid if the downstream flow is inadvertently blocked by the closing of a valve or other restriction.

The chamber that holds the viscometers is constructed from a $1.25 \mathrm{in}$. NPT $(31.75 \mathrm{~mm})$ stainless steel pipe cross. Each of the viscosity sensors thread into a branch of the pipe cross. The fourth branch is plugged for possible future use. Passing over an in-line RTD, which provides a check of the temperature, fluid enters the chamber through a fitting in the side of the pipe cross, flowing around the active portion of the viscosity sensors before returning to the test cell through the $0.25 \mathrm{in}$. $(6.35 \mathrm{~mm})$ diameter return line.

The inlet and exit lines contain valves to isolate the chamber for removal or disassembly. A vacuum/drain port is connected to the return line to allow removal of 
fluid after isolation of the chamber from the test cell before disassembly and to enable the necessary evacuation of the chamber after reinstallation into the loop. The total volume of the fluid contained in this loop is $3.51 \mathrm{in} .{ }^{3}(57.5 \mathrm{~mL})$, about $1.2 \%$ of the total system volume.

\section{Sampling loop}

A 4.6 in. ${ }^{3}(75 \mathrm{~mL})$ sampling cylinder is connected in parallel with the viscometer and may be independently isolated and removed from the system for measurements of the liquid composition. The sampling loop was assembled with this cylinder and two union bonnet valves on each side, as illustrated in Figure 2.3. The outer valves may be closed to isolate the chamber from the rest of the system, and the inner valves are closed to ensure that no fluid escapes from the sampling cylinder when it is removed. A vacuum/drain port is also provided. The total volume of the sampling loop is 5.0 in. ${ }^{3}(82 \mathrm{~mL})$. Since this is about $1.6 \%$ of the total system volume, disturbances of test cell conditions are minimized during sampling.

\section{Equipment enclosure}

Although all components of the facility are insulated, a frame and panel enclosure consisting primarily of steel framing, plywood, fiberglass ductboard, and plexiglass viewports was constructed to provide additional isolation from the room environment. This provides greater thermal uniformity and stability as well as affording a measure of protection to operators in the event of a high-pressure leak of the hot oil/refrigerant mixture. At the same time, the enclosure was designed to allow accessibility and visibility for proper operation and monitoring. 
Table 2.1: Summary of instrumentation ranges and precision

\begin{tabular}{||lcc||}
\hline Instrument & Range & Precision \\
\hline Bonded Strain Gauge Pressure Transducer & $0-500 \mathrm{psia}$ & $\pm 0.75 \mathrm{psia}$ \\
$(0-3.5 \mathrm{MPa})$ & $( \pm 5.1 \mathrm{kPa})$ \\
Variable Capacitance Pressure Transducer & $0-500 \mathrm{psia}$ & $\pm 0.55 \mathrm{psia}$ \\
& $(0-3.5 \mathrm{MPa})$ & $( \pm 3.8 \mathrm{kPa})$ \\
Viscometer & $0.1-2000 \mathrm{cp}$ & $\pm 2 \% \mathrm{rdg}$ \\
Platinum RTD and Signal Conditioner & $-.50^{\circ} \mathrm{C}- \pm 1.50^{\circ} \mathrm{C}$ & $\pm 0.1^{\circ} \mathrm{C}$ \\
& $\left(-58^{\circ} \mathrm{F}-+302^{\circ} \mathrm{F}\right)$ & $\left( \pm 0.2^{\circ} \mathrm{F}\right)$ \\
Copper-constantan Thermocouple & $-270^{\circ} \mathrm{C}-+400^{\circ} \mathrm{C}$ & $\pm 0.2^{\circ} \mathrm{C}$ \\
& $\left(-4.55^{\circ} \mathrm{F}-+750^{\circ} \mathrm{F}\right)$ & $\left( \pm 0.4^{\circ} \mathrm{F}\right)$ \\
Concentration Measurements & $0-100 \%$ & $\pm 1 \%$ \\
\hline
\end{tabular}

\section{Data acquisition}

Viscosities, temperatures, and pressures are recorded by computerized data acquistion methods. A microcomputer controls a digital multimeter and a switching unit that provides a sufficient number of channels to monitor all signals generated by the installed sensors. Table 2.1 gives a summary of the range and precision of the sensors.

A bonded strain gauge pressure transducer is in contact with the test cell contents via a port machined into the top plate. A second pressure transducer employs a capacitance-sensing element. The calibrations of these pressure transducers were checked with the use of a dead-weight pressure tester. These calibration checks indicated that the output signals of both transducers were linear with pressure, matching the factory calibrations. The uncertainty in the pressure data is $\pm 0.75 \mathrm{psi}(5.2 \mathrm{kPa})$. 
Three platinum RTDs independently track the temperature of the liquid contained in the test cell, and another monitors the vapor space temperature. A fifth RTD is inserted into the pipe cross containing the viscometers. These RTDs were calibrated after connection with current transmitters, the required load resistors, and a power supply. The signal conditioners used with the RTDs linearize the response, providing a 4- to $20-\mathrm{mA}$ signal that is linear over the temperature range $-58^{\circ} \mathrm{F}$ ($\left.50^{\circ} \mathrm{C}^{\prime}\right)$ to $300^{\circ} \mathrm{F}\left(150^{\circ} \mathrm{C}\right)$. This signal produces a 1- to 5 -volt output when measured across a 250-ohm load resistor, which is monitored by the data acquisition equipment. The calibration of output voltage vs. temperature showed that all of these RTDs provide a linear response. The uncertainty of these temperature measurements is $\pm 0.2^{\circ} \mathrm{F}\left(0.1^{\circ} \mathrm{C}\right)$.

Nine type- $T$ thermocouples are affixed to the exterior surface of the test cell, below the layer of insulation, to monitor thermal gradients in the wall. These thermocouples are connected through a switch to an electronic ice-point reference junction. and the output is monitored by the digital voltmeter. These temperature readings have an estimated uncertainty of $\pm 0.4^{\circ} \mathrm{F}\left(0.2^{\circ} \mathrm{C}\right)$

\section{Description of the Oil/Refrigerant Charging Station}

A charging station was designed to inject precise amounts of both refrigerant and lubricant into the test cell. As shown in Figures 2.5 and 2.6, oil and refrigerant are injected by separate, parallel systems. Both the oil and refrigerant sides employ stainless steel cylinders of 37.7 in. ${ }^{3}(617.8 \mathrm{~mL})$ having a 2 -in. $(50.8 \mathrm{~mm})$ bore with a 12 -in. (304.8 mm) stroke and of $4.4 \mathrm{in}^{3}(72.4 \mathrm{~mm})$ having a 0.75 in. $(19.05 \mathrm{~mm})$ bore and a 10 -in. $(254.0 \mathrm{~mm})$ stroke. The cylinder displacements were calibrated 


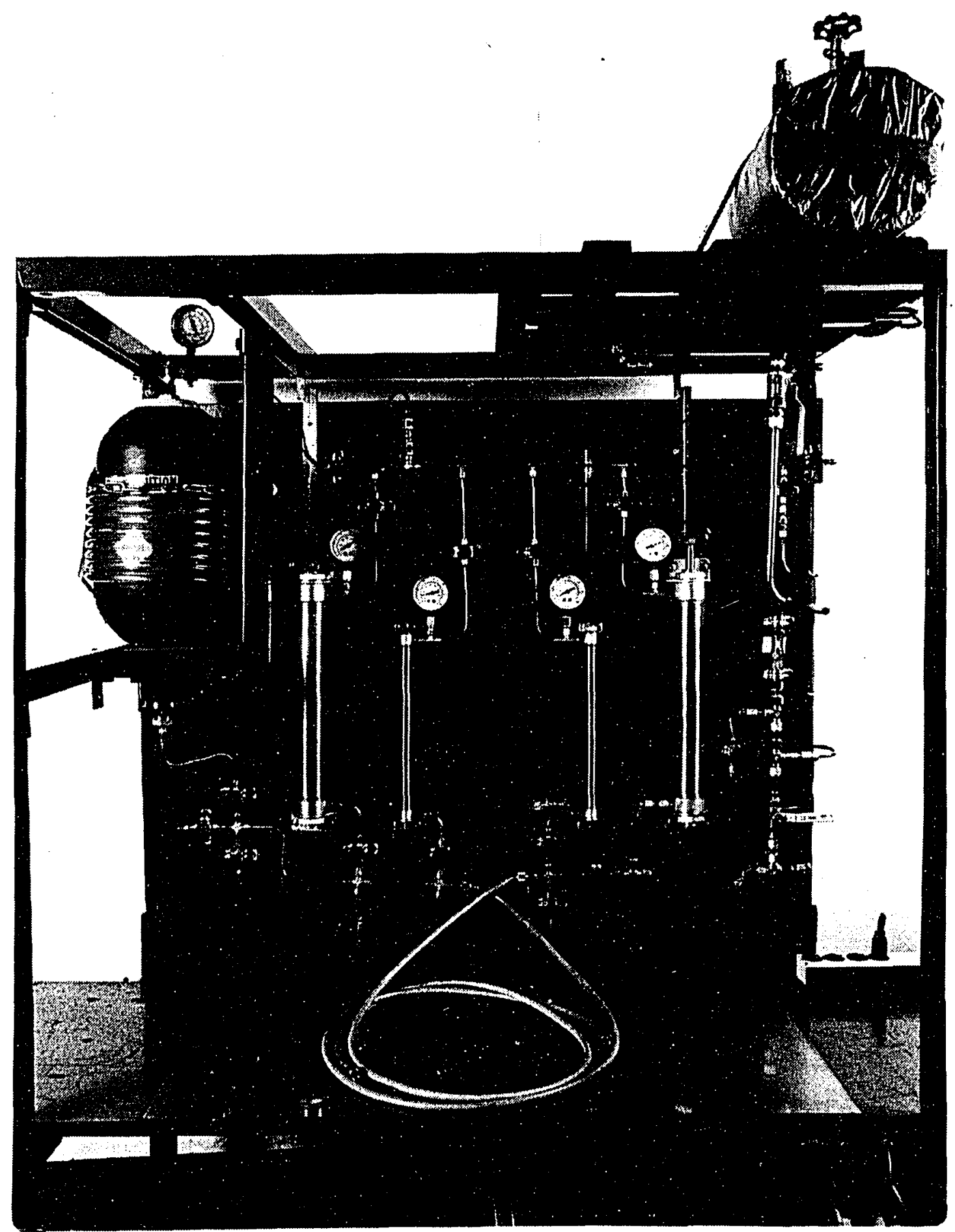

Figure 2.5: Oil/refrigerant charging facility 


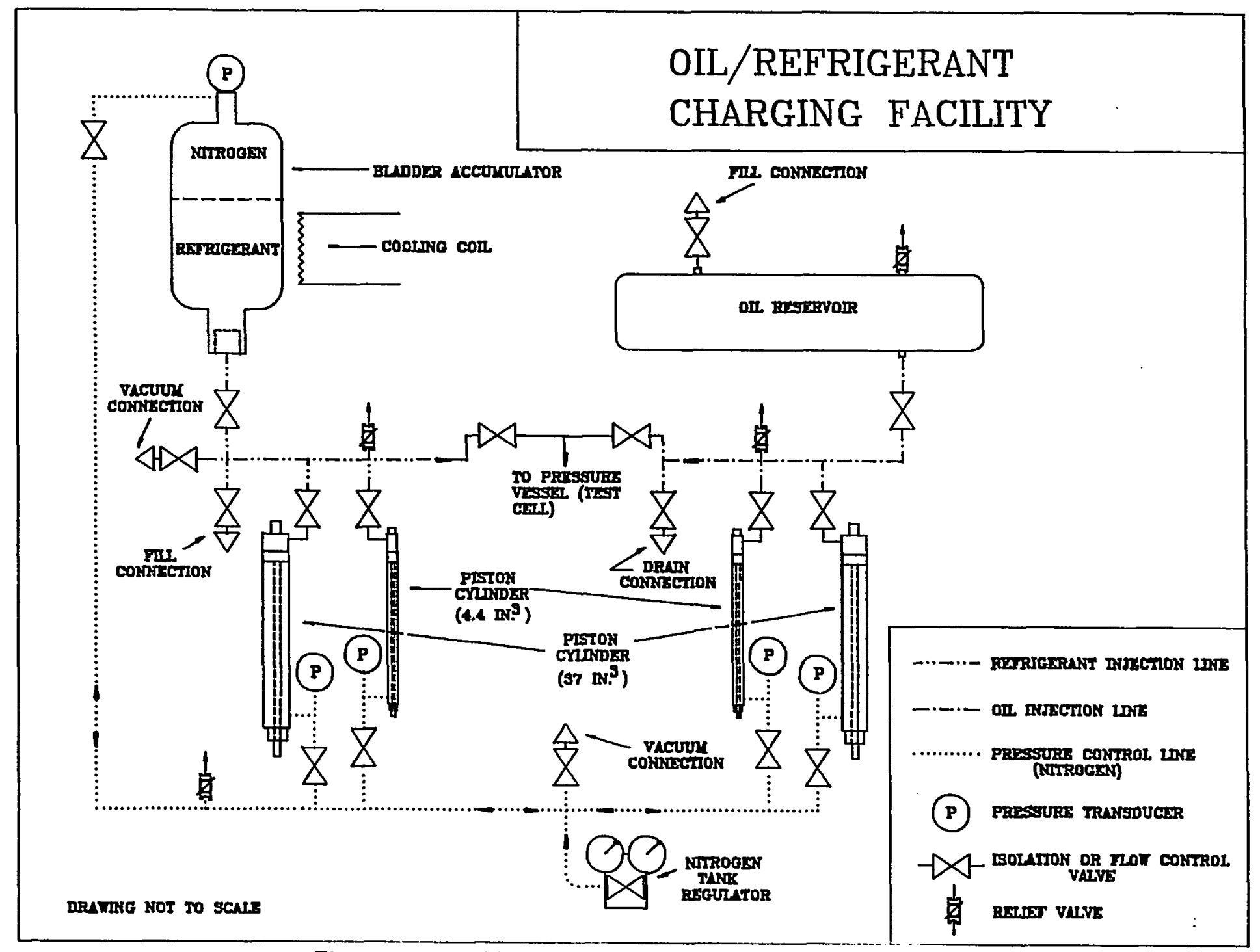

Figure 2.6: Oil/refrigerant charging facility schematic 
with the use of R-113, and they agree with the above values to within $=0.1$ in. ${ }^{3}$ ( 2 $\mathrm{mL})$. The commercially available cylinders are in two different sizes to allow injection of initial and additional amounts of either oil or refrigerant in suitable quantities to give the desired concentration increments.

A $2.5 \mathrm{gal}(9.5 \mathrm{~L})$ bladder accumulator rated for a maximum pressure of $3000 \mathrm{psi}$ $(20.7 \mathrm{MPa})$ serves as a refrigerant reservoir for filling the cylinders on the refrigerant side. Since initial property testing is for R-22 and R-502, a butyl bladder that is compatible with both refrigerants is installed in the accumulator. However. other bladder types can be installed depending on the refrigerant being tested. Initially, the bladder of the accumulator is pressurized with nitrogen to about half the refrigerant saturation pressure. The accumulator is then partially filled with liquid refrigerant from a commercial supply can. A cooling loop wrapped around the accumulator aids the filling process by maintaining a pressure gradient between the supply can at room temperature and the accumulator at a lower temperature where any refrigerant vapor present condenses. The bladder is then further pressurized with nitrogen to ensure that only liquid refrigerant is contained in the accumulator. This pressure is also used to force refrigerant out into the injection cylinders.

The presence of a "solid" charge of subcooled liquid in the injection cylinder is checked by applying nitrogen pressure well above the vapor pressure of the refrigerant and ensuring no rod movement. The cylinder contents are then discharged to the test cell through $0.25 \mathrm{in}$. $(6.35 \mathrm{~mm})$ diameter lines and a connecting refrigeration hose by application of pressurized nitrogen gas to the rod side of the cylinder as the charging valve on the test cell is opened. A partial injection of a given volume can be made by determining in advance the required displacement and then moving the 
rod to the appropriate position on a scale mounted directly behind the rod.

On the oil side, an oil reservoir was made from an altered 6 in. $(152.4 \mathrm{~mm})$ diameter by 30 in. ( $762 \mathrm{~mm})$ long horizontal liquid receiver. The volume of this reservoir is approximately 850 in. ${ }^{3}(13.9 \mathrm{~L})$. The oil reservoir is insulated and equipped with a heating tape, a thermocouple, and a thermostat. The contents can thus be heated as a vacuum is applied in order to liberate dissolved air and water vapor. The removal of air and water vapor from the oil is especially important prior to injection for testing. Since the vapor pressures of the naphthenic oil are very low, heating the oil to only $150^{\circ} \mathrm{F}\left(65^{\circ} \mathrm{C}\right)$ under a vacuum of approximately $29 \mathrm{in}$. $\mathrm{Hg}(3 \mathrm{kPa}$ absolute pressure $)$ will not remove the "light ends" of the oil. Thus, the oil properties are substantially unchanged. The unpressurized oil supply tank fills the empty, evacuated cylinders by gravity feed through $0.5 \mathrm{in}$. $(12.7 \mathrm{~mm})$ lines until the oil completely fills the cylinders. Again, pressurization of the rod side of the cylinder forces the lubricant through the connections to the test cell. Separate pressure gauges on each cylinder along with strategically placed pressure relief valves assist the safe operation of the system.

\section{Summary}

A versatile oil/refrigerant test facility has been developed to provide critically needed property data, especially at high pressures and temperatures, for a wide variety of oil/refrigerant mixtures. Incorporating a commercially available viscometer, as well as windows for observation of the contents, it can be used for determination of the solubility, viscosity, and density of these mixtures. Precise and convenient charging of mixtures with refrigerant compositions ranging from 0 to $100 \%$ is provided by a separate charging station. Operating temperature and pressure ranges for the 
test facility are $70^{\circ} \mathrm{F}\left(20^{\circ} \mathrm{C}^{\prime}\right)$ to $300^{\circ} \mathrm{F}\left(1.50^{\circ} \mathrm{C}\right)$, and 0 to 500 psia $(0$ to $3.5 \mathrm{MPa})$, respectively. The viscosity measurement range is from $0.1 \mathrm{cp}$ to $200 \mathrm{cp}$.

The following chapters outline the experimental methods and provide experimental results of mixtures of R-22 in a $150 \mathrm{SUS}$ naphthenic oil and in a $150 \mathrm{SLS}$ alkylbenzene lubricant as well as mixtures of R-502 in both of these same oils. 


\section{CHAPTER 3. EXPERIMENTAL PROCEDURES AND DATA REDUCTION}

In addition to, and concurrent with, the development of the test facility, procedures were developed for accurate and convenient measurement of the solubility, viscosity and density of a wide range of oil/refrigerant solutions. This chapter provides a discussion of the experimental procedures that were employed to collect the data discussed in later chapters.

\section{General Experimental Procedures}

The methods used to charge and operate the test facility vary, depending on the range of compositions and conditions desired in a particular test. A typical operating procedure for collecting viscosity and solubility data over a range of liquid-phase compositions and temperatures involves several operations. These operations, which are described in more detail later in this chapter, include evacuation of the test cell and auxiliary flow loops, injection of the necessary oil and refrigerant quantities, operating the gear pump to provide good mixing, heating the test cell and contents to the desired temperature, checking to ensure steady-state conditions, and taking the data. Prior to injecting another incremental charge to change the liquid concentration, cooling of the vessel contents to room temperature is required. 
All measurements of pressure, temperature, and viscosity are done under programmed control of the data acquisition system described earlier. C'areful recording of liquid level as the temperature changes allows for the calculation of liquid density at each test condition. As explained more fully below, this also permits a calculation of the actual liquid composition, which varies slightly with temperature because of variation in vapor and liquid densities.

\section{Rig cleansing}

Prior to the injection of any fluid for testing, the test cell and auxiliary loops are rinsed and cleaned with a sufficient amount of R-113 (or other solvent compatible with the O-ring material in the cell) to remove traces of any oil that had been previously tested. The $\mathrm{O}$-rings that seal the windows may also be replaced at this time if a failure to hold a vacuum or set pressure indicates that this is necessary.

\section{Data measurement}

The cell and auxiliary loops are then evacuated, and the connecting hoses from the charging station are attached to a valve on the test cell. Measured amounts of refrigerant and oil are injected to provide the desired volume and concentration of liquid. The circulating pump aids mixing of the two fluids as they are charged. The contents are then heated to desired temperatures whereupon pressures, temperatures, viscosity, and height of the liquid-vapor interface are read after checking to ensure steady-state operation. The reported pressure is the average of the pressures indicated by the two transducers. This solubility pressure is reported at a liquid-vapor interface temperature, taken to be the average of the temperature of the RTD in contact with 
vapor only and the average liquid temperature. The average liquid temperature is the mean of the temperatures of the RTDs immersed in liquid in the test cell and the RTD in the flow loop pipe cross containing the viscometers. The liquid density is reported at this temperature. The viscosity is reported at the temperature measured by an RTD inside the viscometer, which is generally slightly higher than the average liquid temperature due to the internal self-heating of the viscometer as discussed in C'hapter 2. At each measurement point, 20 consecutive viscosity readings are recorded and the mean and standard deviation are computed. The acceptable scatter, defined as the standard deviation divided by the mean, is taken as $1 \%$ or less. Once the limiting pressure of $500 \mathrm{psia}(3.5 \mathrm{MPa})$ is approached, the contents are allowed to cool. More data are then collected at several steady-state test points during the cooldown phase.

A special precaution is in order when testing refrigerant blends or azeotropes such as $R-502$. In tests with these fluids, the vapor space should be minimized to ensure that the refrigerant remains dissolved in the liquid in its azeotropic (or blended) proportions. Otherwise, given a large vapor space, the more volatile component of the azeotrope will tend to concentrate in the vapor space and the other component will be preferentially dissolved in the liquid, thus effecting a partial separation of the azeotrope into its components. In this case, the refrigerant would not be present in the liquid in its azeotropic proportions, and the compositions of both the vapor phase and the liquid phase would be unknown. In summary, if the vapor space is limited, one can more safely assume that the liquid contains the refrigerant in its azeotropic composition. 


\section{Oil/refrigerant sample evaluation}

After the solubility and viscosity data for a given mixture have been collected over the desired temperature range, the sample cylinder is isolated and removed so that the mass fraction of refrigerant in the liquid can be determined. The procedure for determining the composition of an oil/refrigerant mixture by sampling is as follows:

- The full sample cylinder is weighed.

- One valve is cracked to carefully vent off the refrigerant.

- The cylinder is heated and the remaining refrigerant is evacuated.

- The chamber, now containing only oil, is weighed.

- Using a suitable solvent, the oil is removed.

- The empty chamber is weighed.

- The net weights of the oil and the mixture, as well as the refrigerant, are found by differences, and the mixture composition is calculated (to an estimated uncertainty of $\pm 1 \%)$.

The temperature, pressure, and liquid level at which the sample was removed are also noted. At this point oil may be injected into the test cell or refrigerant may be added (or vented) to alter the concentration for another set of data. 


\section{Mixture concentration and density determination}

The actual concentration and the density of the liquid is calculated as follows for each test condition. Since the vapor mass varies along with slight variations in the volume as the temperature and pressure change, the refrigerant vapor density changes. This also means that the liquid concentration varies slightly as the temperature and pressure change. Generally, the overall variation in refrigerant concentration as temperature and pressure were changed during any particular test was less than $2 \%$. The vapor density is calculated from temperature and pressure by a computerized property routine based on work by Reynolds (1979). However, it should be noted that any accurate property relation or table could also have been used. With this density and the vapor volume determined from the level of the vapor-liquid interface, the mass of refrigerant in the vapor is calculated. Since the total mass of oil and refrigerant charged is known, the mass of refrigerant in the liquid is calculated by subtracting the mass of the vapor from the total mass of refrigerant in the cell. A ratio of the mass of refrigerant in the liquid to the total liquid mass determines the resulting liquid composition at each test condition. As noted earlier, the liquid is also sampled at one temperature during each run to check the composition at that test condition.

With the known masses of oil and refrigerant and the observed level of the liquid, the liquid densities are calculated for each test point. It should be noted that these densities are determined from test data, and are not calculated using the ideal mixing assumption. As a point of comparison, the liquid density at the sampling temperature is also determined from the net mass of the liquid sample and the known volume of the sampling chamber. 
Table 3.1: C'alibration of viscosity sensor

\begin{tabular}{|c|rr|ccc|}
\hline Liquid & \multicolumn{2}{|c|}{$\begin{array}{c}\text { Temperature } \\
\left({ }^{\circ} \mathrm{C}\right)\end{array}$} & $\begin{array}{c}\text { Measured Value } \\
(\mathrm{F})\end{array}$ & $\begin{array}{c}\text { Published Value } \\
(\mathrm{cp})\end{array}$ & $\begin{array}{c}\% \text { Diff. } \\
( \pm 0.5 \%)\end{array}$ \\
\hline K3 & 100.0 & 212.0 & 0.892 & 0.878 & +2 \\
Calibration & 86.9 & 188.4 & 1.04 & 1.04 & 0 \\
Fluid & 66.6 & 151.9 & 1.40 & 1.39 & +1 \\
& 52.0 & 125.6 & 1.79 & 1.77 & +1 \\
& 48.0 & 118.4 & 1.94 & 1.92 & +1 \\
\hline K6 & 110.5 & 230.9 & 1.23 & 1.23 & 0 \\
C'alibration & 97.1 & 206.8 & 1.55 & 1.50 & +3 \\
Fluid & 87.1 & 188.8 & 1.77 & 1.75 & +1 \\
& 79.8 & 175.6 & 2.05 & 1.99 & +3 \\
& 70.5 & 158.9 & 2.38 & 2.37 & +0 \\
\hline
\end{tabular}

\section{System Calibration Check}

The calibrations of the instruments were checked by running tests with pure R-22 and with two ASTM standard calibration fluids whose properties were readily available. Figure 3.1 shows that vapor pressures of pure R-22 were measured to within $0.7 \%$ of the saturation pressures published by ASHRAE (1989). The data in Table 3.1 also indicate close agreement between published viscosities and those measured by one of the viscosity sensors used in the tests reported here. Since the agreement is generally within the uncertainty band of the instrumentation, as discussed earlier, confidence in the accuracy of the results presented here is warranted.

\section{Repeatability}

Prior to more extensive studies of the oil/refrigerant pairs mandated by the monitoring committee, repeatability studies of the test facility were undertaken using mixtures of R-22 in a 150 SUS naphthenic oil. Presented here are data for nominal 


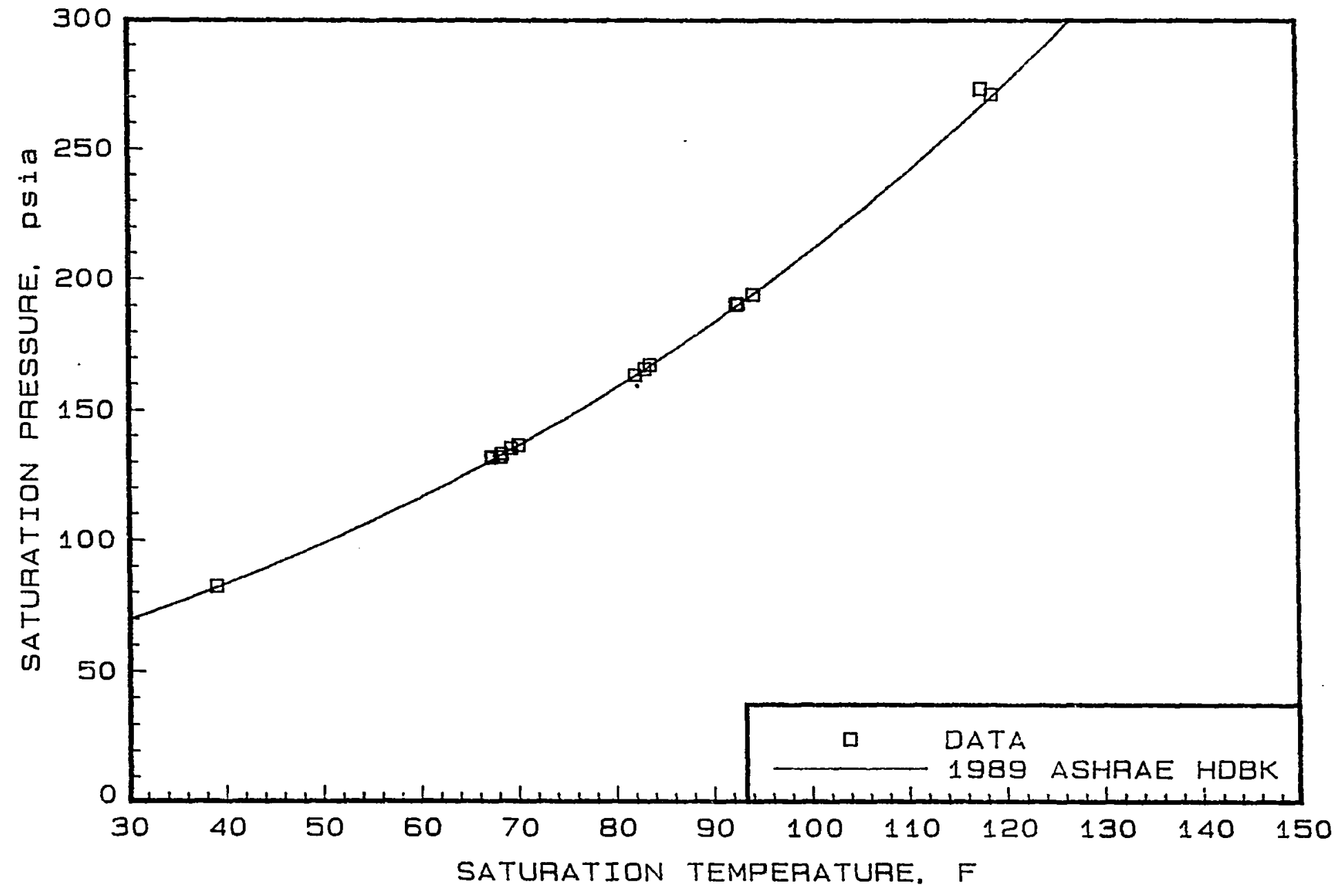

Figure 3.1: R-22 vapor pressure data 
approximate concentrations of $10 \%$ to $40 \%$ R-22 (by mass) in oil, over a temperature range from about $70^{\circ} \mathrm{F}\left(20^{\circ} \mathrm{C}\right)$ to $300^{\circ} \mathrm{F}\left(150^{\circ} \mathrm{C}\right)$. Figures 3.2 and 3.3 show the raw data for solubility and viscosity of each mixture composition with second order curve fits applied. The data sets for most of the compositions shown include results from at least two separate test runs involving separate refrigerant and oil charging operations. These data show good repeatability, as can be inferred from the plots. This is further highlighted in Figures 3.4 and 3.5. where the solubility and riscosity results for several repeatability test runs are plotted for an R-22 concentration of $30 \%$.

\section{Comparison with past work}

Comparison of these experimental data with previously published work is possible over a limited range of conditions. Solubility data from the manufacturer's literature are plotted along with the experimental results for the $10 \%$ and $30 \% \mathrm{R}-22$ concentrations in Figure 3.6. Viscosity data for these mixtures were not available from the manufacturer. However, ASHRAE (1986) provides some limited viscosity data for 0 to $30 \%$ R-22 in a 150 SUS naphthenic oil for temperatures up to $140^{\circ} \mathrm{F}$ $\left(60^{\circ} \mathrm{C}\right)$. Figure 3.7 shows a comparison of the ASHRAE data with the experimental data measured in this study for a refrigerant concentration of $30 \% \mathrm{R}-22$. The differences that exist are possibly due to changes in the feedstocks and processing of the oil in the years since the manufacturer's data were first generated. 


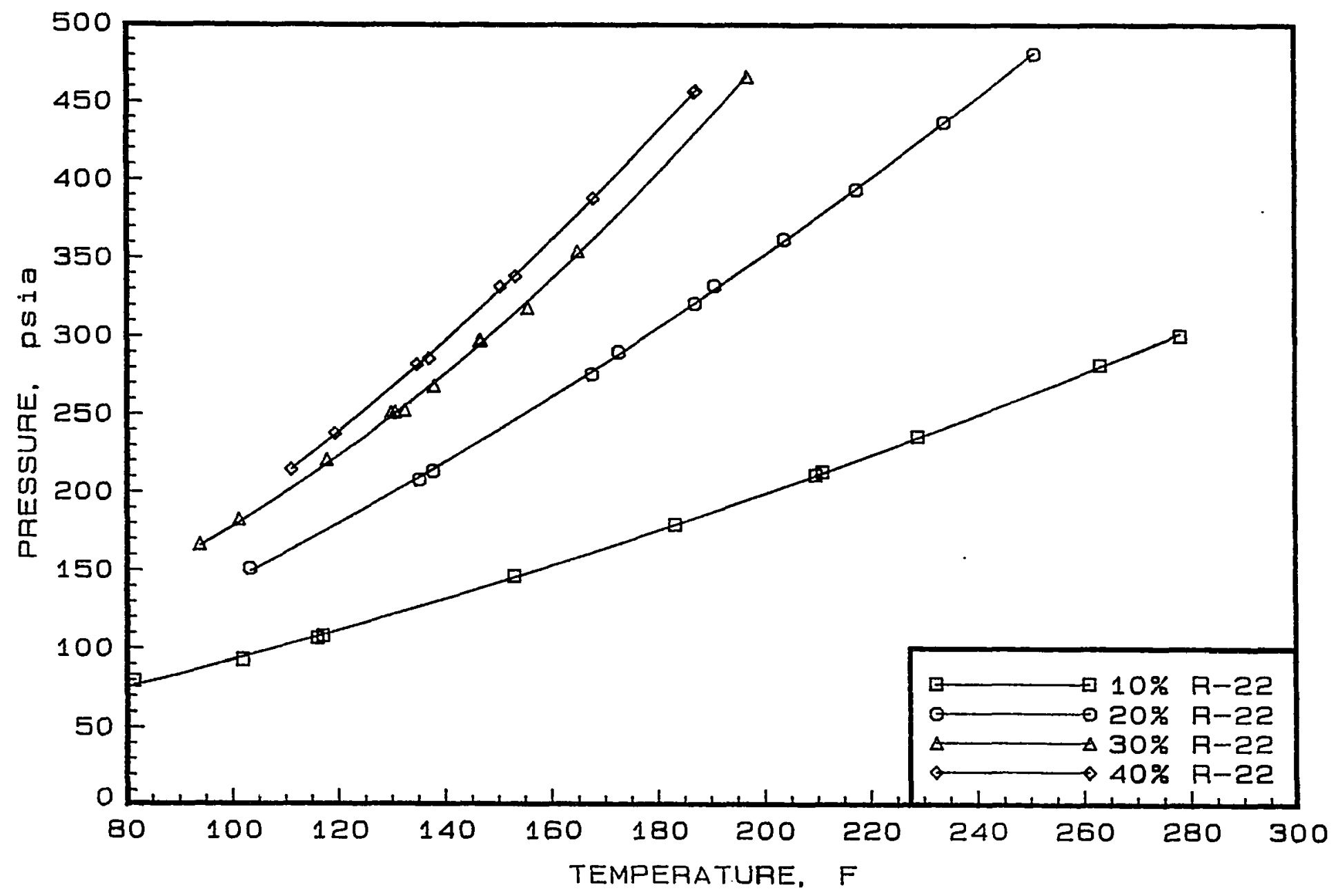

Figure 3.2: Solubility data for mixtures of R-22 and a 150 SIS naphthenic oil 


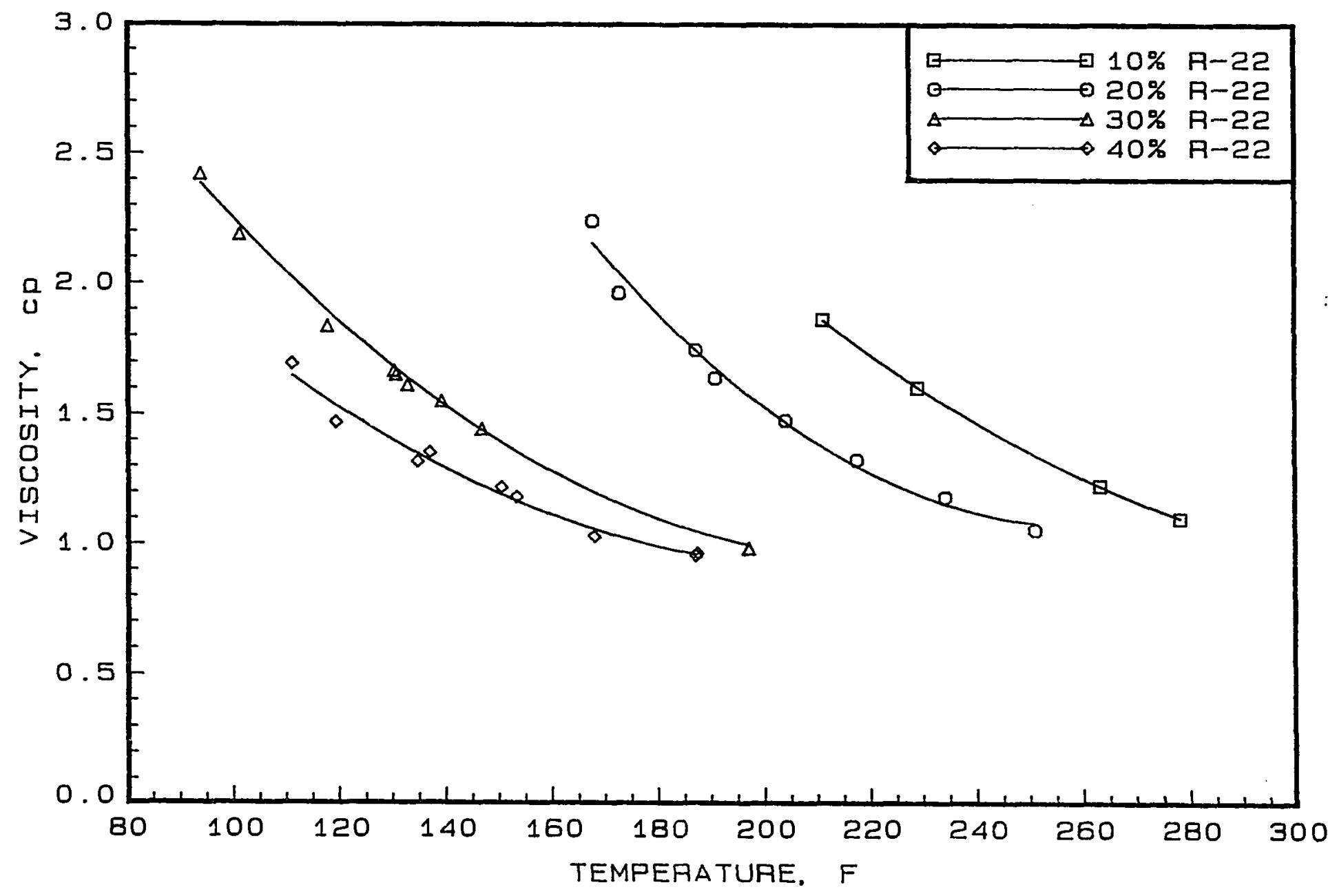

Figure 3.3: Viscosity data for mixtures of R-22 and a 150 SUS naphthenic oil 


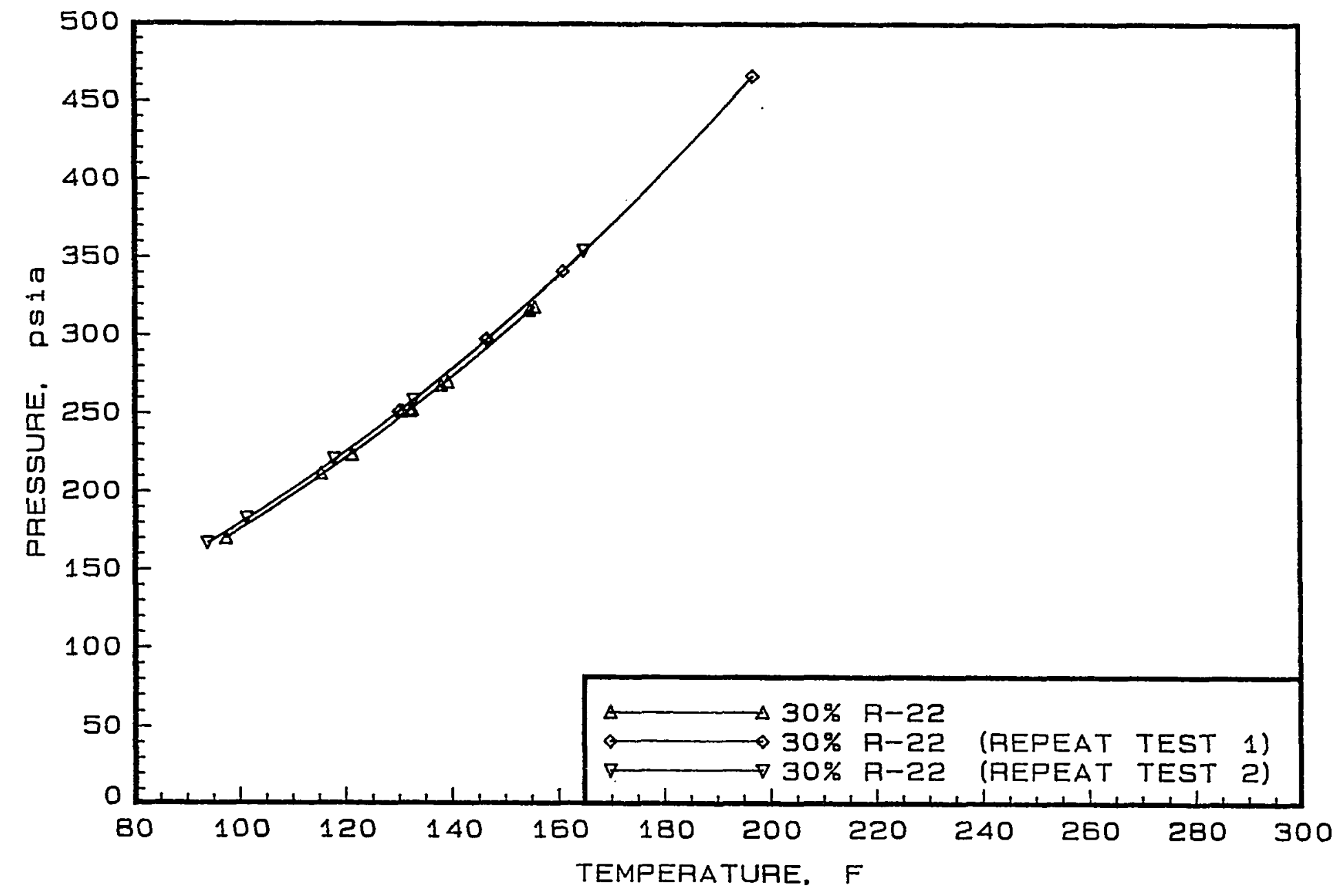

Figure 3.4: Test of repeatability of solubility measurements for $30 \%$ R- 22 in a 150 SUS naphthenic oil 


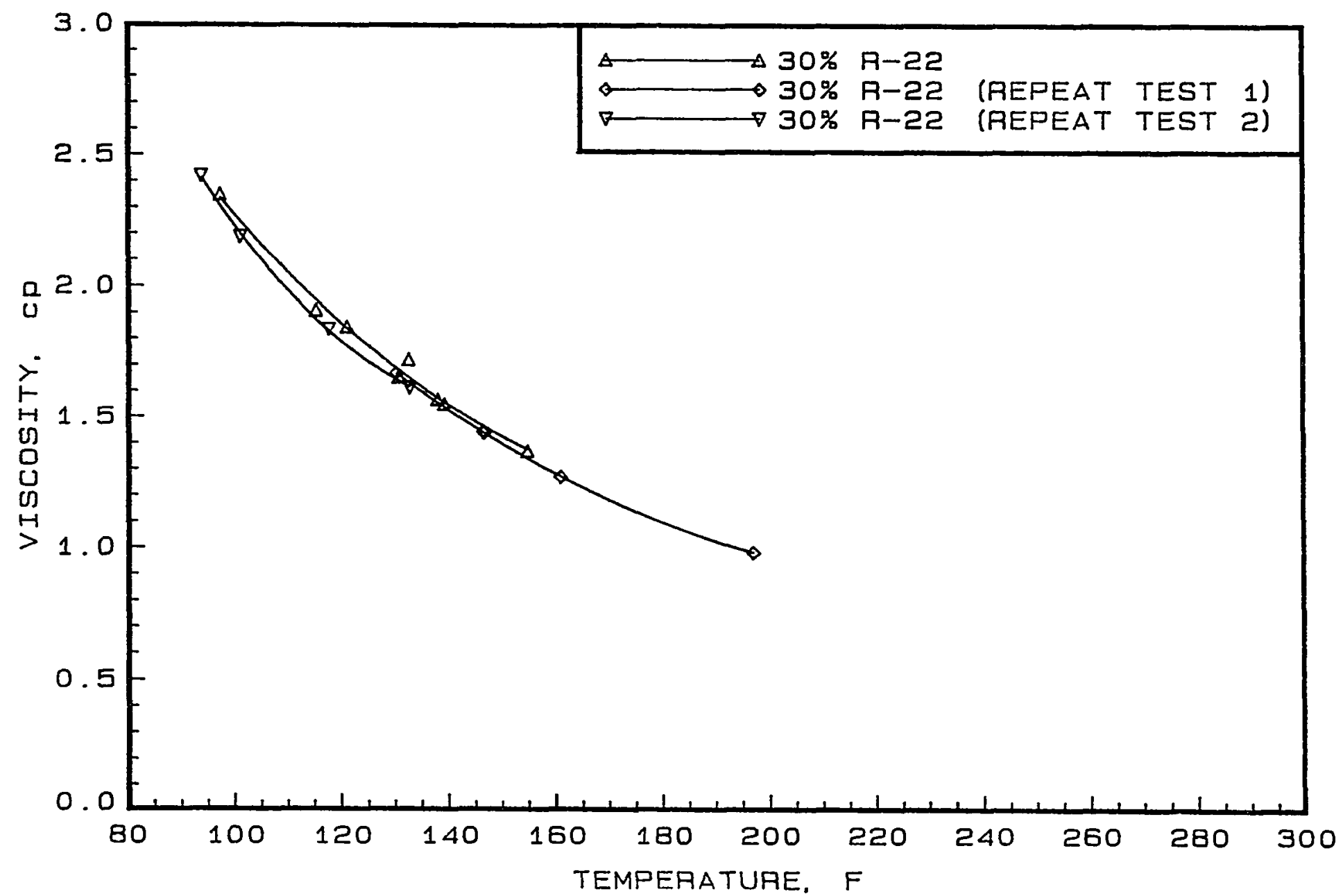

Figure 3.5: Test of repeatability of riscosity measurements for $30 \% R-22$ in a 150 $S U S$ naphthenic oil 


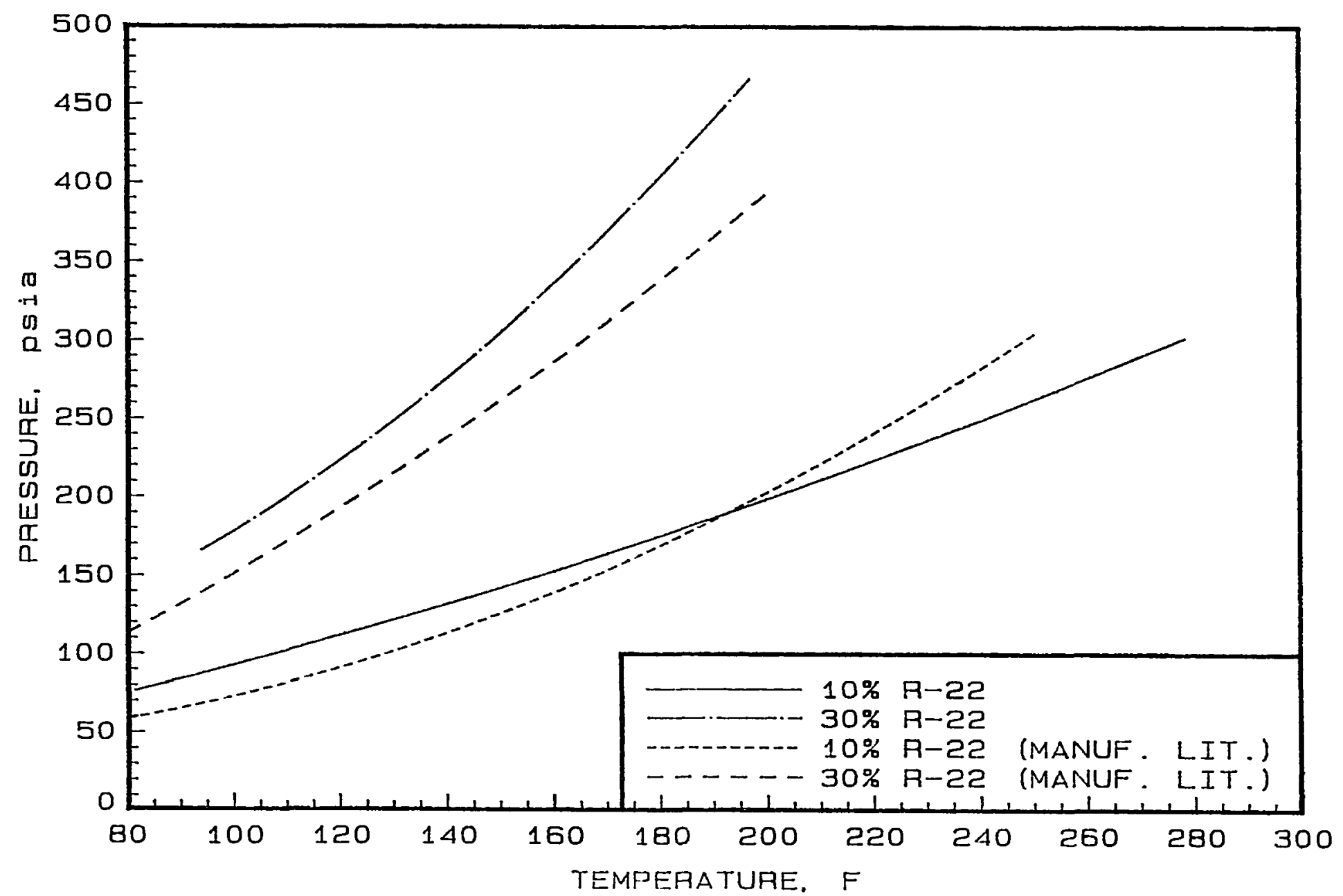

Figure 3.6: Solubility data for mixtures of R-22 and a $150 \mathrm{STS}$ naphthenic oil comparison with literature 


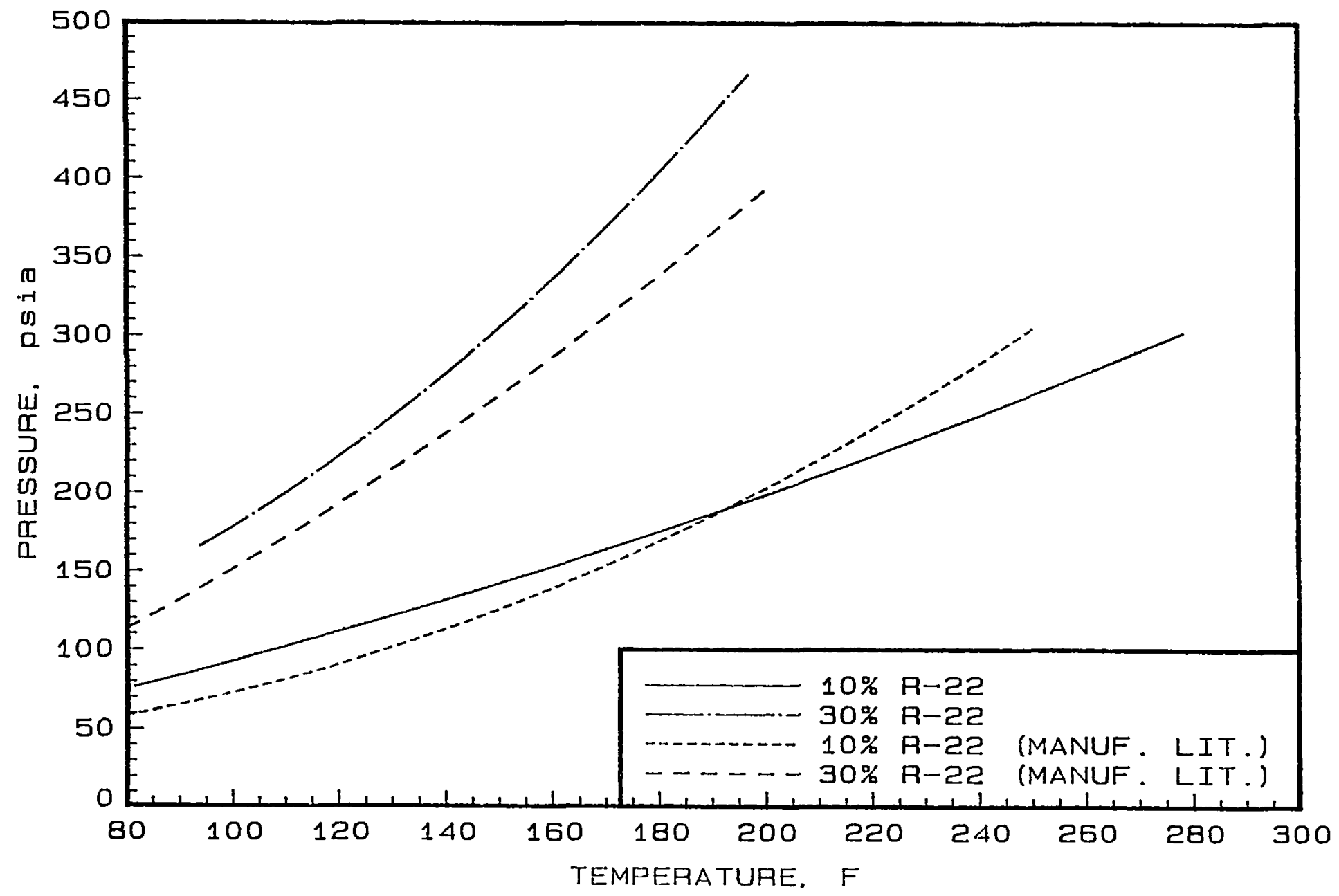

Figure 3.6: Solubility data for mixtures of R-22 and a $150 \mathrm{STS}$ naphthenic oil comparison with literature 


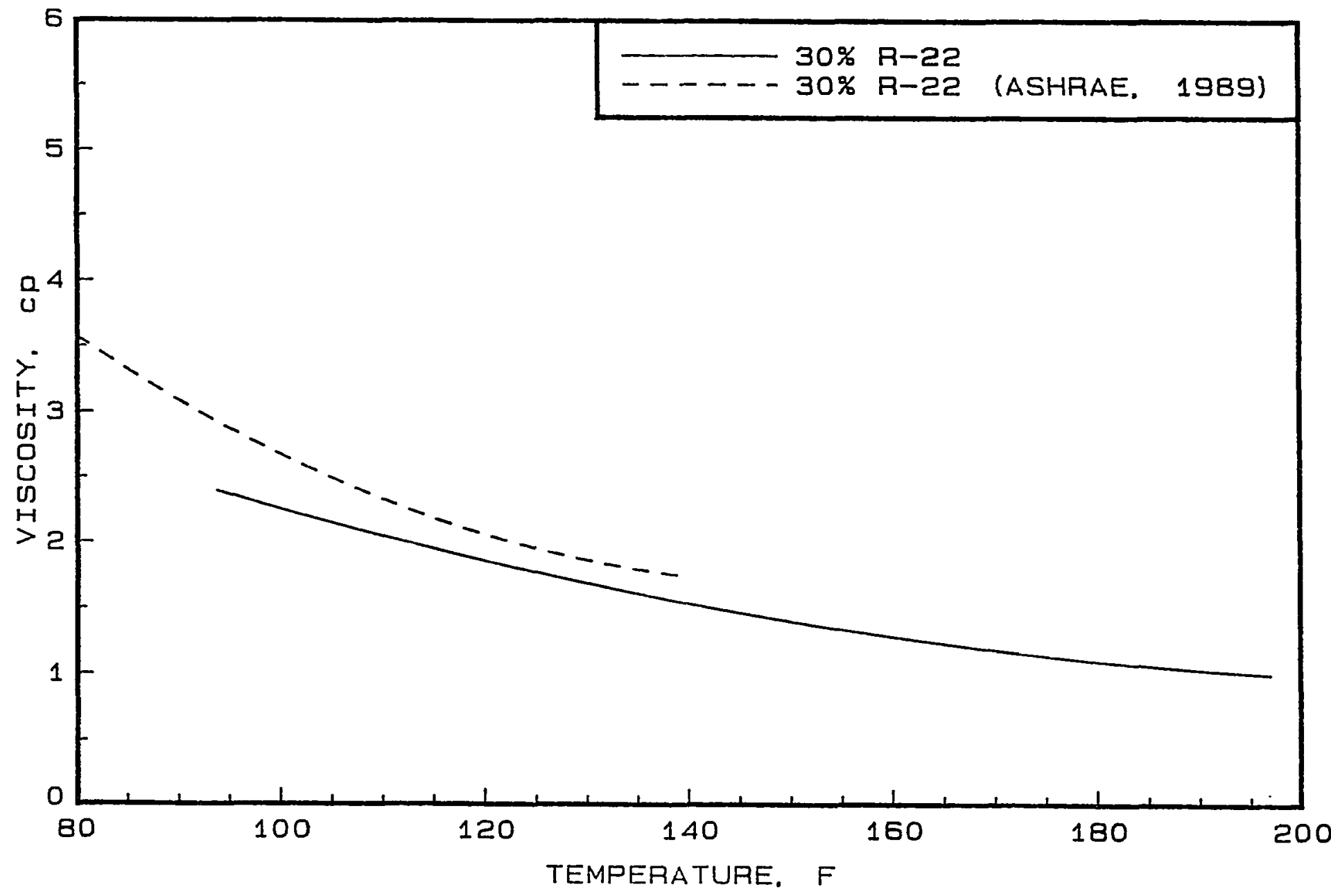

Figure 3.T: Viscosity data for mixtures of R-22 and a 150 SUS naphthenic oil comparison with literature 


\section{Data Reduction}

Calculations required to determine the liquid density and composition from observed data at each test condition have been discussed in general terms in a previous section which outlined experimental procedures. A more detailed discussion of these calculations and the associated uncertainties, illustrated by using an example test condition, is provided in Appendix B.

Once the basic components of temperature, composition, pressure, liquid viscosity and density are determined for each data point, a useful and convenient presentation of the results requires the development of correlating equations. The following section presents a discussion of the techniques which were used to derive coefficients for empirical correlating equations to represent the data. Also discussed here is the so-called "Daniel" plot which provides solution property information in a particularly useful format.

\section{Data correlation technique}

After all the data have been compiled into one file, a nonlinear regression analysis is performed to determine the best set of coefficients for the following empirical equations. These equations can be used to reproduce the data or to interpolate results at intermediate states for which data were not directly obtained. It should be noted that these equations are empirical fits of the data, and are not based on theoretical considerations.

$$
\begin{aligned}
\log _{10} \mu= & A_{0}+A_{1} C+A_{2} \theta+A_{3} C^{\prime} \theta+A_{4} C^{2} \\
& +A_{5} C^{2} \theta+A_{6} C^{\prime} \theta^{2}+A_{7} \theta^{2}+A_{8} C^{2} \theta^{2}
\end{aligned}
$$




$$
\begin{aligned}
P= & B_{0}+B_{1} C^{\prime}+B_{2} \theta+B_{3} C^{\prime} \theta+B_{4} C^{\prime 2} \\
& +B_{5} C^{2} \theta+B_{6} C^{\prime} \theta^{2}+B_{7} \theta^{2}+B_{8} C^{2} \theta^{2} \\
\rho_{L}= & D_{0}+D_{1} C^{\prime}+D_{2} \theta+D_{3} C^{\prime} \theta+D_{4} C^{2} \\
& +D_{5} C^{2} \theta+D_{6} C^{2} \theta^{2}+D_{7} \theta^{2}+D_{8} C^{2} \theta^{2}
\end{aligned}
$$

where

$$
\begin{aligned}
& \mu=\text { absolute viscosity, centipoise }(\mathrm{cp}), \\
& P=\text { the absolute pressure, } \mathrm{MPa}, \\
& \rho_{L}=\text { the density of the liquid, } \mathrm{g} / \mathrm{mL}, \\
& C=\text { the mass fraction of refrigerant in the liquid, and } \\
& \theta=\text { the temperature in } \mathrm{K} \text { divided by }
\end{aligned}
$$$$
\text { a reference temperature of } 293.15 \mathrm{~K} \text {. }
$$

Though the above equations are nonlinear, they are linearized using the following variable substitutions in order to make use of a general-purpose multivariate linear regression algorithm to determine the coefficients:

$$
\begin{array}{llll}
X_{1}=C^{\prime} ; & X_{2}=\theta ; & X_{3}=C^{\prime} \theta ; & X_{4}=C^{2} ; \\
X_{5}=C^{2} \theta ; & X_{6}=C^{2} \theta^{2} ; & X_{7}=\theta^{2} ; & X_{8}=C^{2} \theta^{2}
\end{array}
$$

The resulting equations are linear in the eight variables $X_{1}$ through $X_{8}$. For example,

$$
\begin{aligned}
\log _{10 \mu}= & A_{0}+A_{1} X_{1}+A_{2} X_{2}+A_{3} X_{3}+A_{4} X_{4} \\
& +A_{5} X_{5}+A_{6} X_{6}+A_{7} X_{7}+A_{8} X_{8}
\end{aligned}
$$


The regression algorithm is provided in the Fortran subroutine RGIVN available in a library of mathematical and statistical subroutines (INSL 1989). Another of these subroutines, RSTAT, is employed to provide statistical information about the significance of each of the coefficients in the above equations, and to calculate regression coefficients as an indication of the overall goodness of fit of each equation.

\section{"Daniel" plot}

One form of the oil/refrigerant solution property data that is convenient for compressor designers is the "Daniel" plot. In a manner similar to that of Daniel et al. (1982), the figure has two parts. On the upper portion of this figure, kinematic viscosity of the oil/refrigerant solution is plotted vs. temperature for a range of refrigerant concentrations. This upper grid is identical in form to the ASTM viscositytemperature charts, which have nonlinear scales for both kinematic viscosity and temperature. For many oils, the kinematic viscosity-temeprature relationship plots as a nearly straight line on this type of chart. The equation of a straight line on this nonlinear grid is given by

$$
\log (\log (\nu+0.7))=A+B \cdot \log T
$$

where

$$
\begin{aligned}
& \nu=\text { kinematic viscosity, in centistokes, } \\
& T=\text { thermodynamic temperature, in } \mathrm{K} \text { or }{ }^{\circ} \mathrm{R}, \\
& \text { and } A \text { and } B \text { are constants specific to the fluid. }
\end{aligned}
$$

In the lower part of the figure, solubility information is presented in the form of pressure vs. temperature for a range of refrigerant concentrations. Using the upper and lower parts of this figure together, the viscosity-temperature relationship can be 
graphically determined for any desired pressure. This type of plot is employed several times in later chapters.

\section{Summary}

Experimental procedures for operation of the oil/refrigerant test facility have been described in detail. Data reduction techniques, including the correlation equations and the "Daniel" plot, were outlined. Data presented in this chapter show that the instrumentation is accurate and that the test results are repeatable. Thus, some confidence in the results presented in the next chapters is warranted. 


\section{CHAPTER 4. R-22 AND OIL SOLUTION PROPERTY RESULTS}

This chapter presents results of solubility, viscosity, and density measurements for $\mathrm{R}-22$ in a naphthenic oil and in an alkylbenzene. Ciraphical representations of the data and the results of the regression analysis are given. Tabulations of the actual experimental data are contained in Appendix C.

\section{Results and Discussion}

Results of the measurements with R-22 in both a 150 SL'S napthenic oil and a 150 SUS alkylbenzene oil are presented below. The naphthenic oil used for these measurements is characterized by carbon-type composition as $C_{A} 14 \%, C_{N} 43 \%$, $C_{P} 43 \%$, and has a molecular weight of approximately 300 . The other lubricant was a branched alkylbenzene with an approximate molecular weight of 330 . For each oil/refrigerant pair, the data set at a nominal liquid composition consists of the temperature, pressure, actual composition, absolute viscosity, and density values for a series of test points. The results are provided graphically as well as in the form of empirical correlations derived from the original test data. Results for the two oil/refrigerant pairs are compared with existing data where available. Finally, the pressure (solubility) and viscosity results for the two oil/refrigerant pairs are compared with each other. 
As described in the previous chapter, the correlating equations are empirical fits of the data, and are not based on theoretical considerations. The coefficients for these correlating equations, as derived for both oil/refrigerant pairs, are given in Table 4.1. Figures 4.1 through 4.4 show that the correlations for solubility and viscosity of the $\mathrm{R}-22$ /oil solutions are well fit to the test data, generally within $\pm 5 \%$. Plots showing goodness-of-fit for the density correlations are not given because the fits were well within $\pm 1 \%$. It should be noted that. when using the correlations in lieu of the graphs, care must be taken to avoid extrapolation beyond the limits of applicability given along with the coefficients in Table 4.1 .

\section{R-22/Naphthenic Oil Solutions}

Results for the solubility of R-22 in a 150 SUS naphthenic oil for solutions of 0 to 40 weight percent R-22 are given in Figure 4.5. This figure, which is a plot of pressure vs. refrigerant concentration for a range of temperatures, shows that the pressure increases with increasing refrigerant concentration and temperature.

Figure 4.6 provides the results of the correlation equation for absolute viscosity as a function of temperature and refrigerant mass fraction. Note that this semilogarithmic graph is different from an ASTM chart where kinematic viscosity is plotted vs. temperature on non-linear axes, according to Equation 3.5. The temperature range is from $104^{\circ} \mathrm{F}\left(40^{\circ} \mathrm{C}\right)$ to $302^{\circ} \mathrm{F}\left(150^{\circ} \mathrm{C}\right)$, well beyond the temperature range of viscosity data reported in the existing literature. Similarly, the results for the mixture density are given in Figure 4.T. In this figure, the curves for the specified compositions are truncated at various temperatures. These endpoints are approximately the 
Table 4.1: Ciofficients for Empirical Correlations of Viscosity, Pressure, and Density Data for R-22/oil Solutions

R-22/150 SUS Naphthenic Oil C'orrelations

\begin{tabular}{||clll||}
\hline Term & Viscosity (Eq. 3.1) & Pressure (Eq. 3.2) & Density (Eq. 3.3) \\
\hline Intercept & $A_{0}=12.064$ & $B_{0}=0.0000$ & $D_{0}=0.9680$ \\
$C^{\prime}$ & $A_{1}=-23.115$ & $B_{1}=-40.624$ & $D_{1}=8.0012$ \\
$\theta$ & $A_{2}=-15.034$ & $B_{2}=0.0000$ & $D_{2}=0.0000$ \\
$C^{\prime} \theta$ & $A_{3}=29.756$ & $B_{3}=44.437$ & $D_{3}=-12.329$ \\
$C^{2}$ & $A_{4}=0.0000$ & $B_{4}=336.20$ & $D_{4}=-37.574$ \\
$C^{2} \theta$ & $A_{5}=0.0000$ & $B_{5}=-572.75$ & $D_{5}=63.512$ \\
$C^{\prime} \theta^{2}$ & $A_{6}=-10.937$ & $B_{6}=0.0000$ & $D_{6}=5.1303$ \\
$\theta^{2}$ & $A_{7}=4.7125$ & $B_{7}=0.0000$ & $D_{7}=-0.07068$ \\
$C^{2} \theta^{2}$ & $A_{8}=1.8135$ & $B_{8}=233.87$ & $D_{8}=-27.448$ \\
\hline
\end{tabular}

R-22/150 SUS Alkylbenzene Correlations

\begin{tabular}{||clll|}
\hline Term & Viscosity (Eq. 3.1) & Pressure (Eq. 3.2) & Density (Eq. 3.3) \\
\hline Intercept & $A_{0}=11.838$ & $B_{0}=0.0000$ & $D_{0}=0.9425$ \\
$C$ & $A_{1}=-25.046$ & $B_{1}=-39.913$ & $D_{1}=4.8540$ \\
$\theta$ & $A_{2}=-14.821$ & $B_{2}=0.0000$ & $D_{2}=0.0000$ \\
$C^{\prime} \theta$ & $A_{3}=30.781$ & $B_{3}=40.523$ & $D_{3}=-7.7083$ \\
$C^{2}$ & $A_{4}=7.5077$ & $B_{4}=254.81$ & $D_{4}=-18.812$ \\
$C^{2} \theta$ & $A_{5}=-5.2574$ & $B_{5}=-425.86$ & $D_{5}=33.075$ \\
$C^{\prime} \theta^{2}$ & $A_{6}=-10.232$ & $B_{6}=0.0000$ & $D_{6}=3.2031$ \\
$\theta^{2}$ & $A_{7}=4.6660$ & $B_{7}=0.0000$ & $D_{7}=-0.07654$ \\
$C^{2} \theta^{2}$ & $A_{8}=0.0000$ & $B_{8}=172.55$ & $D_{8}=-14.431$ \\
\hline
\end{tabular}

Note: The limits of applicability of the correlations are:

Composition - 0 to 40 weight percent Refrigerant-22

Temperature $-40^{\circ} \mathrm{C}$ to $150^{\circ} \mathrm{C}\left(100^{\circ} \mathrm{F}\right.$ to $\left.300^{\circ} \mathrm{F}\right)$

$(\theta: 1.07$ to 1.44$)$

Pressure - 0 to $3.5 \mathrm{MPa}(0$ to $500 \mathrm{psia})$ 


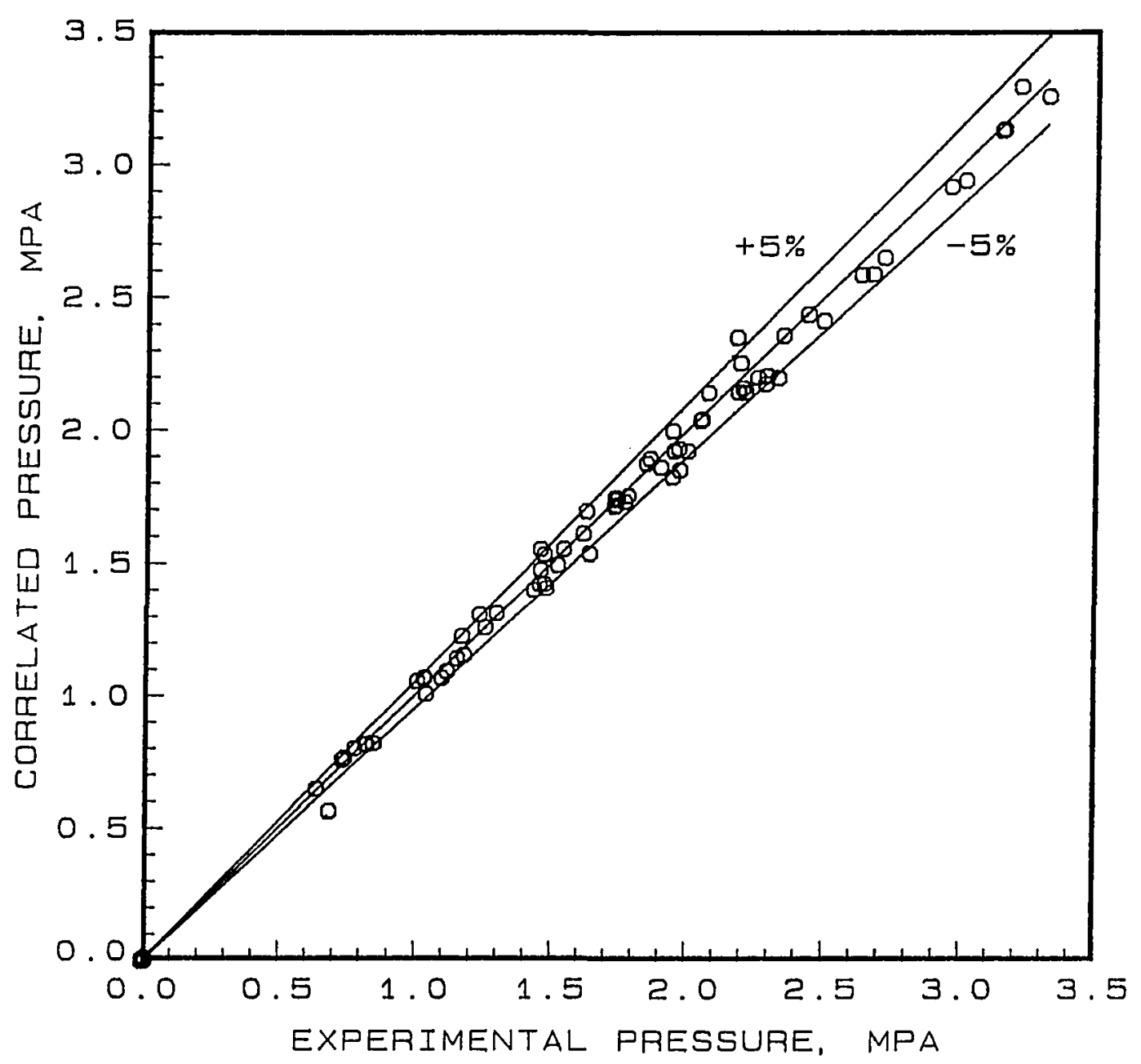

Figure 4.1: Goodness-of-fit of pressure correlation with experimental data for solutions of R-22 in a 150 SUS naphthenic oil 


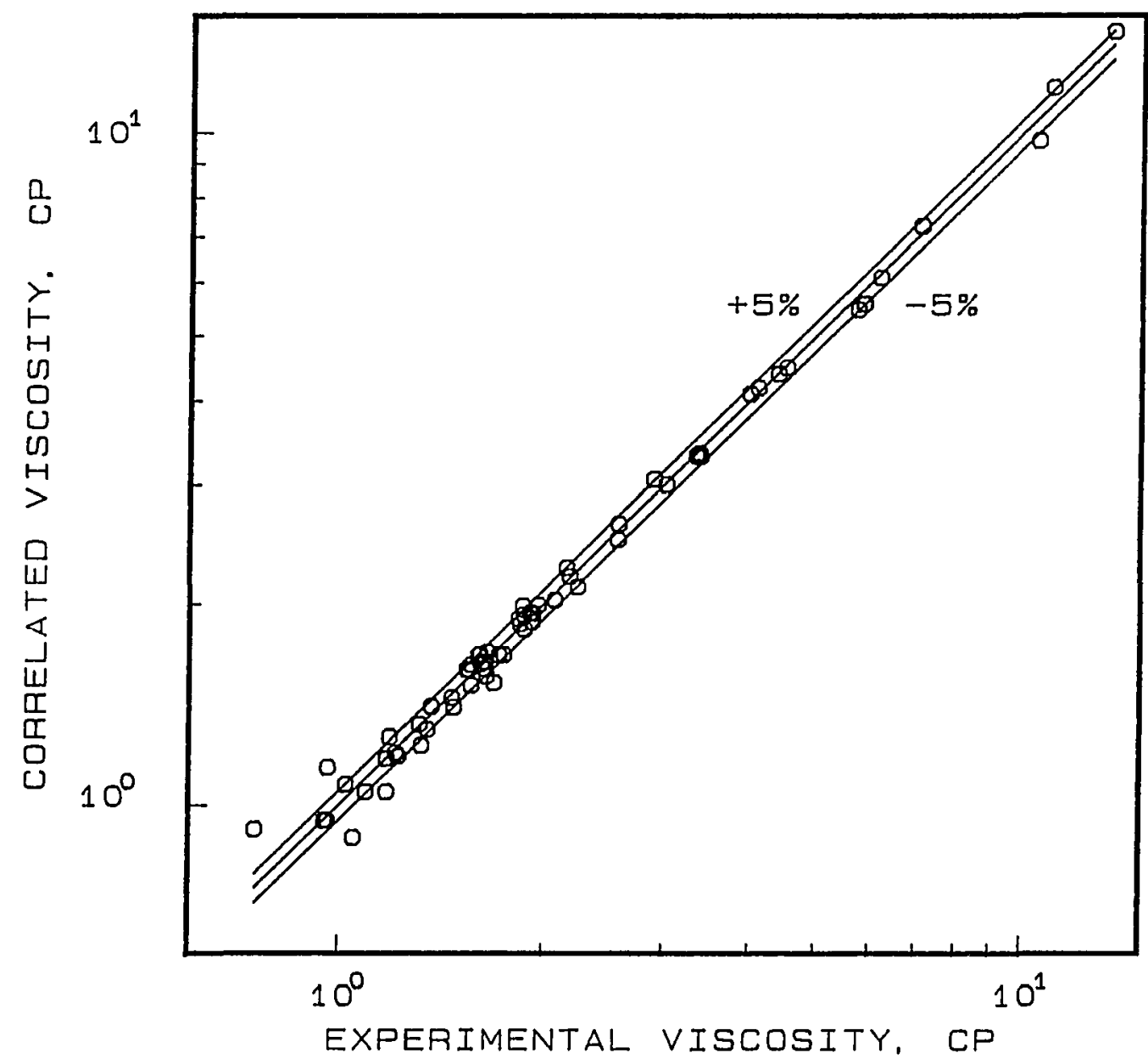

Figure 4.2: Goodness-of-fit of viscosity correlation with experimental data for solutions of R-22 in a 150 SUS naphthenic oil 


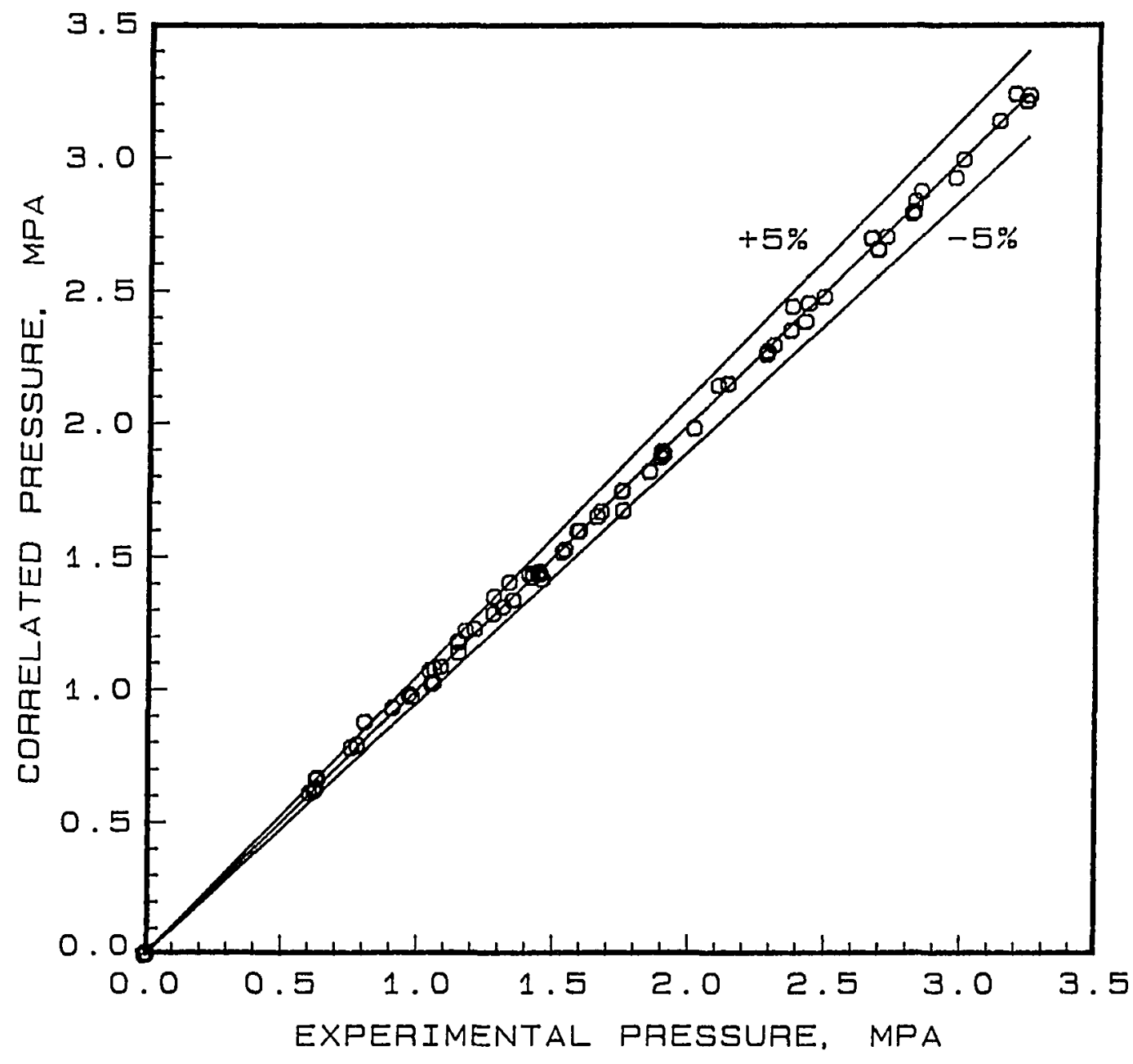

Figure 4.3: Goodness-of-fit of pressure correlation with experimental data for solutions of R-22 in a 150 SUS alkylbenzene 


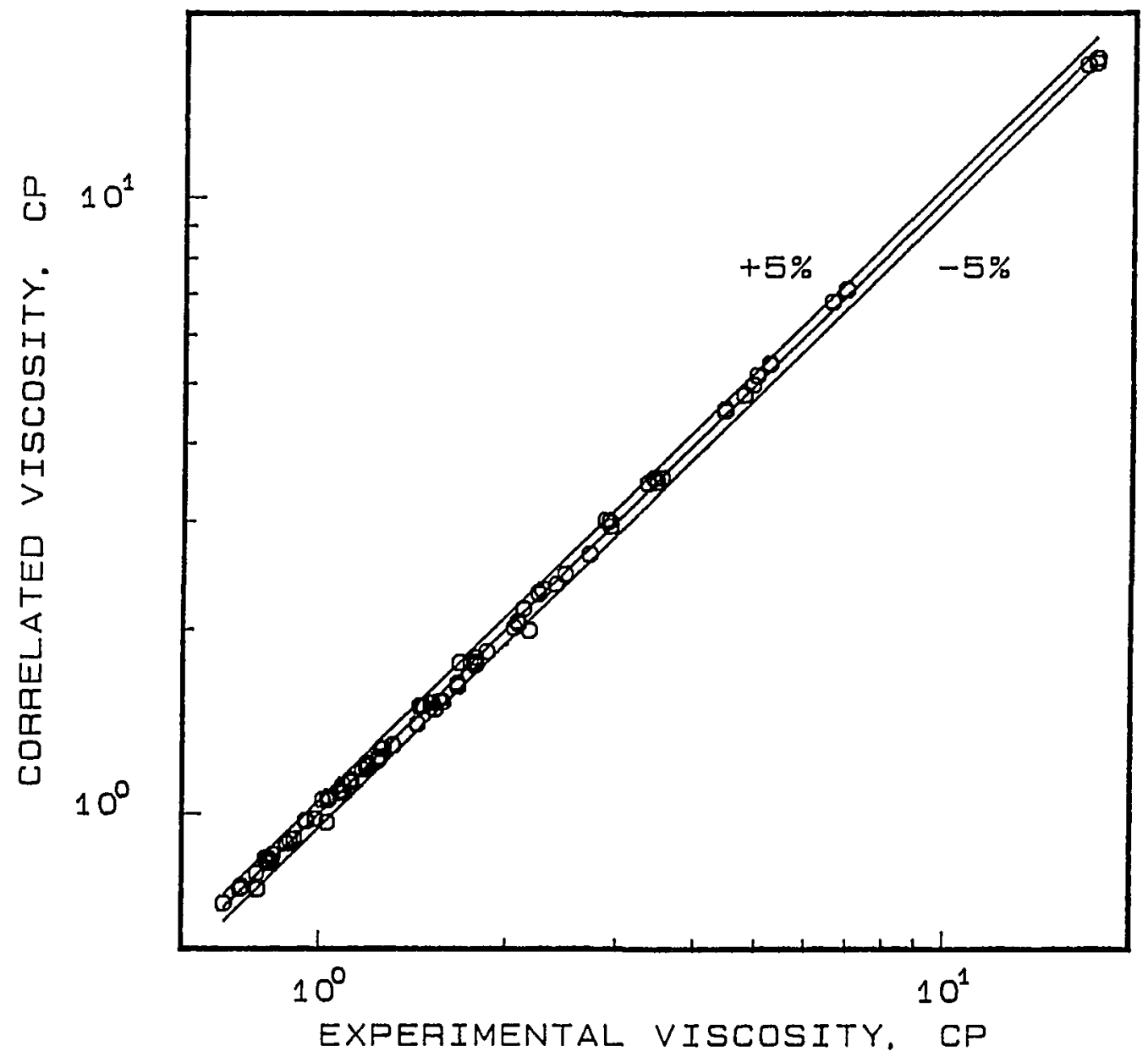

Figure 4.4: Goodness-of-fit of viscosity correlation with experimental data for solutions of R-22 in a 150 SUS alkylbenzene 


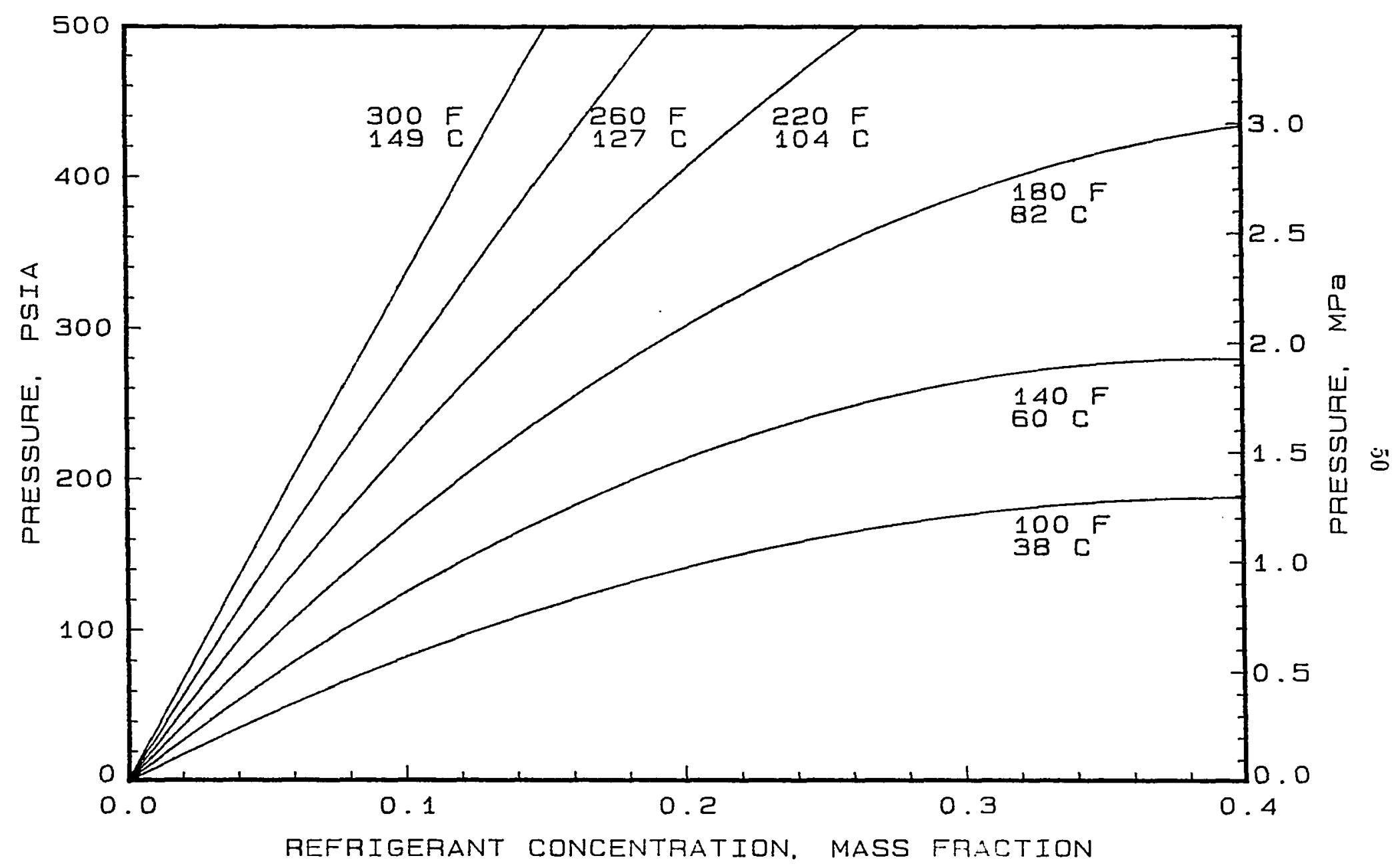

Figure 4.5: Solubility of R-22 in a 150 SUS naphthenic oil 


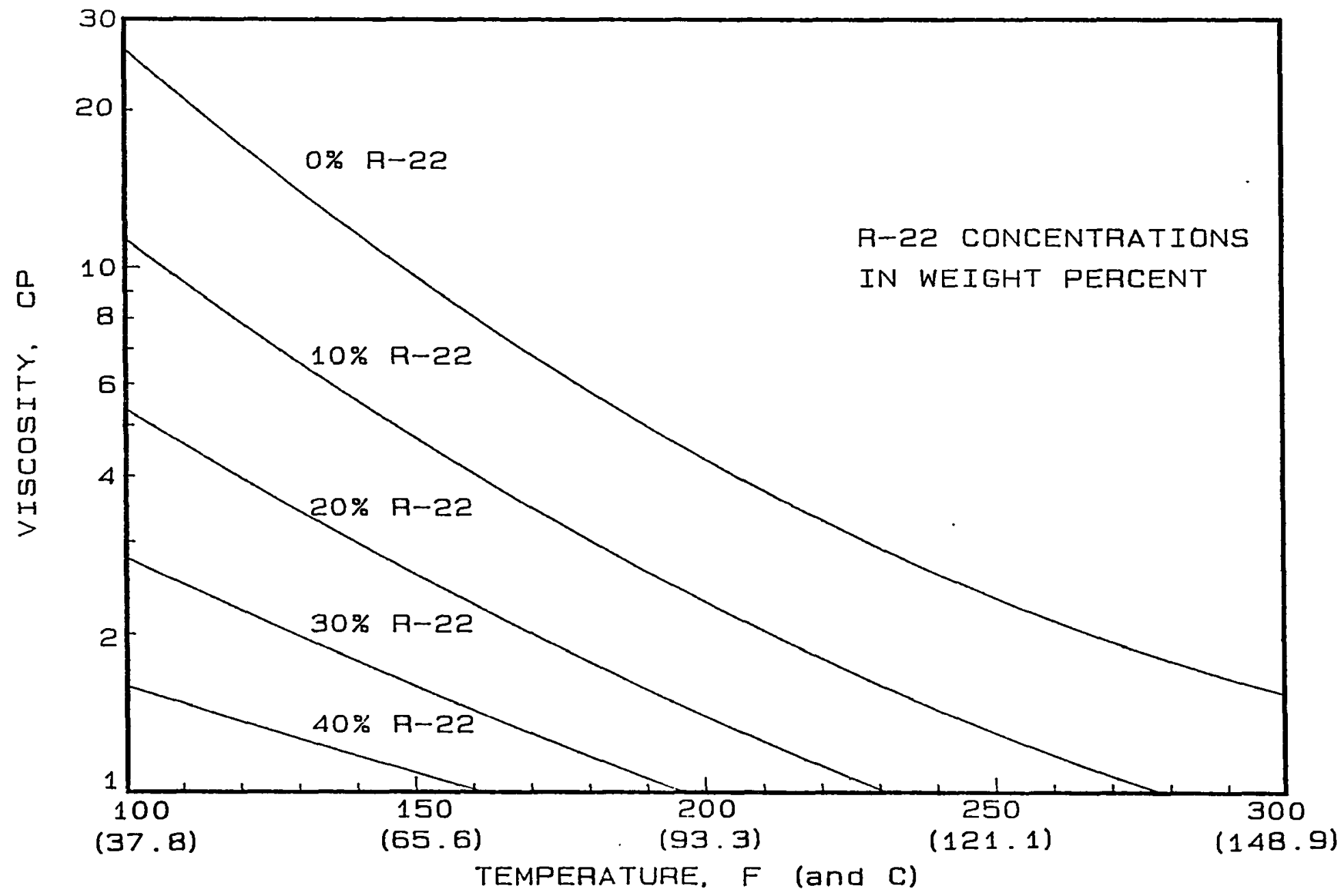

Figure 4.6: Absolute viscosity of R-22 in a $150 \mathrm{SUS}$ naphthenic oil 


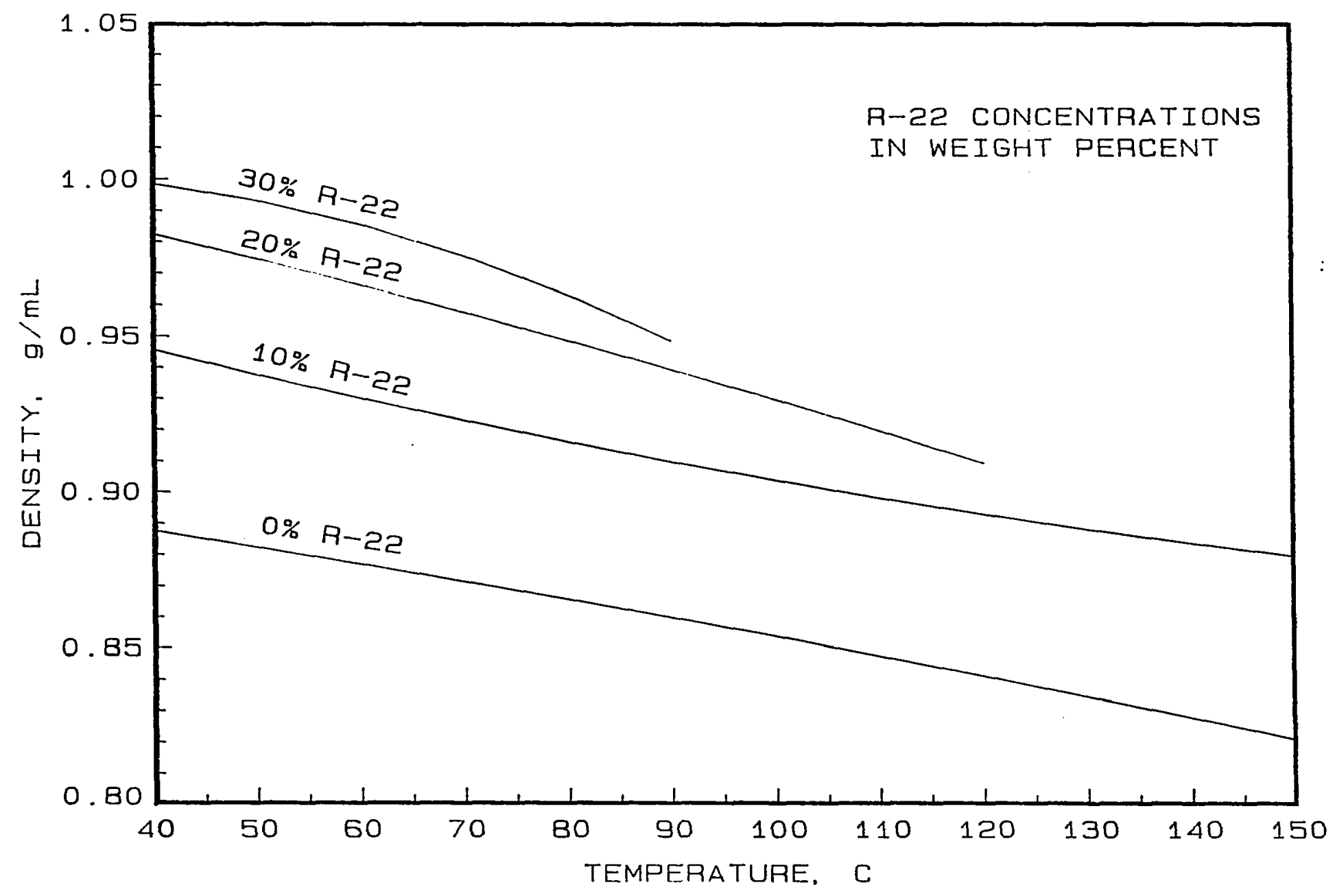

Figure 4.T: Density of R.2.2 in a 150 SUS naphthenic oil 
points beyond which the correlation is no longer expected to be applicable, and correspond roughly to test conditions at which the pressure approached the maximum limit.

Figure 4.8 is a "Daniel" plot which provides kinematic viscosity information for these solutions in a form convenient for designers. As explained in Chapter 3, the figure has two parts. On the upper portion of this figure, kinematic viscosity of the oil/refrigerant solution is plotted vs. temperature for a range of refrigerant concentrations. Since kinematic viscosity is equal to the absolute viscosity divided by the density, this upper graph is actually a derivation from the basic information in Figures 4.6 and 4.7. In the lower part of Figure 4.8, the solubility information of Figure 4.5 is recast in the form of pressure vs. temperature for a range of refrigerant concentrations. Several constant-pressure curves of viscosity vs. temperature are provided in this figure. (The curves shown have been computed from the correlations. rather than by graphical derivation.)

The upper part of Figure 4.8 shows that as temperature and refrigerant concentration increase, the viscosity of the solution decreases. The constant concentration lines have some curvature, especially at the higher temperatures. By comparison, similar curves on ASTM viscosity plots at lower temperatures are somewhat more linear. For a given pressure, viscosity initially increases and then decreases as temperature increases. The cause of this behavior is the decrease in the concentration of refrigerant in the oil as temperature increases, thus lessening the viscosity reduction caused by the refrigerant. However, the viscosity of the oil also decreases as temperature increases, and this effect eventually overcomes the earlier effect that had caused the viscosity to increase. 


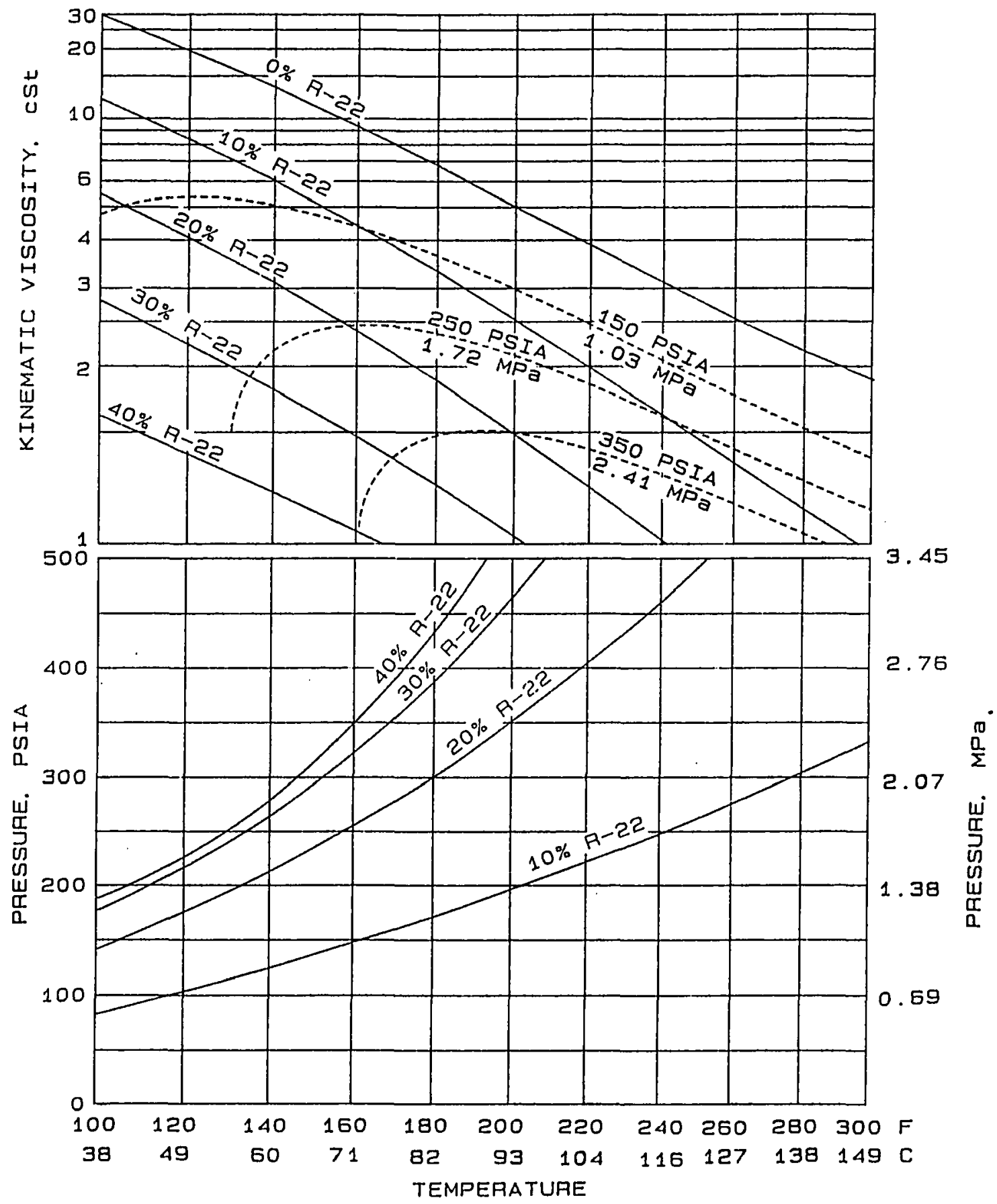

Figure 4.8: Viscosity-temperature-pressure chart for solutions of R-22 in a $150 \mathrm{SL}$ S naphthenic oil 
C'omparison with solubility data in the manufacturer's literature shows that the current experimental data and the associated correlation give pressures that are somewhat higher than those reported by the manufacturer (see Figure 4.9). Discussions with experienced users of these lubricants indicate that differences are to be expected due to the variability inherent in the oil due to processing changes that have been made over the years. No viscosity data for $\mathrm{R}-22$ solutions in this particular oil were readily available from the existing literature for comparison with the experimental data reported here.

\section{R-22/Alkylbenzene Solutions}

The presentation of the results for solutions of R-22 in a 150 SUS alkylbenzene is similar to that of the previous section for a naphthenic oil. Figures $4.10,4.11$, and 4.12 provide the solubility, absolute viscosity, and density data, respectively. Figure 4.13 provides the kinematic viscosity and solubility combined in a form convenient to designers. Again, especially for viscosity, the data presented here extend the temperature range well beyond that of any data previously available. As previously noted, the curvature seen in the curves compared to ASTM viscosity charts may be due to the fact that higher temperatures are being investigated.

Figure 4.14 gives a comparison of test results with solubility data reported by Glova (1984) for a similar alkylbenzene. It appears that the presently reported pressures are somewhat higher. Figure 31 of Chapter 8 in ASHRAE (1990) provides an estimate of the viscosity- temperature-pressure relationship for solutions of R-22 in a 150 SUS alkylbenzene for temperatures up to $60^{\circ} \mathrm{C}\left(140^{\circ} \mathrm{F}\right)$. Since the present test data begin at $100^{\circ} \mathrm{F}\left(38^{\circ} \mathrm{C}\right)$, a comparison with estimated values is possible over the 


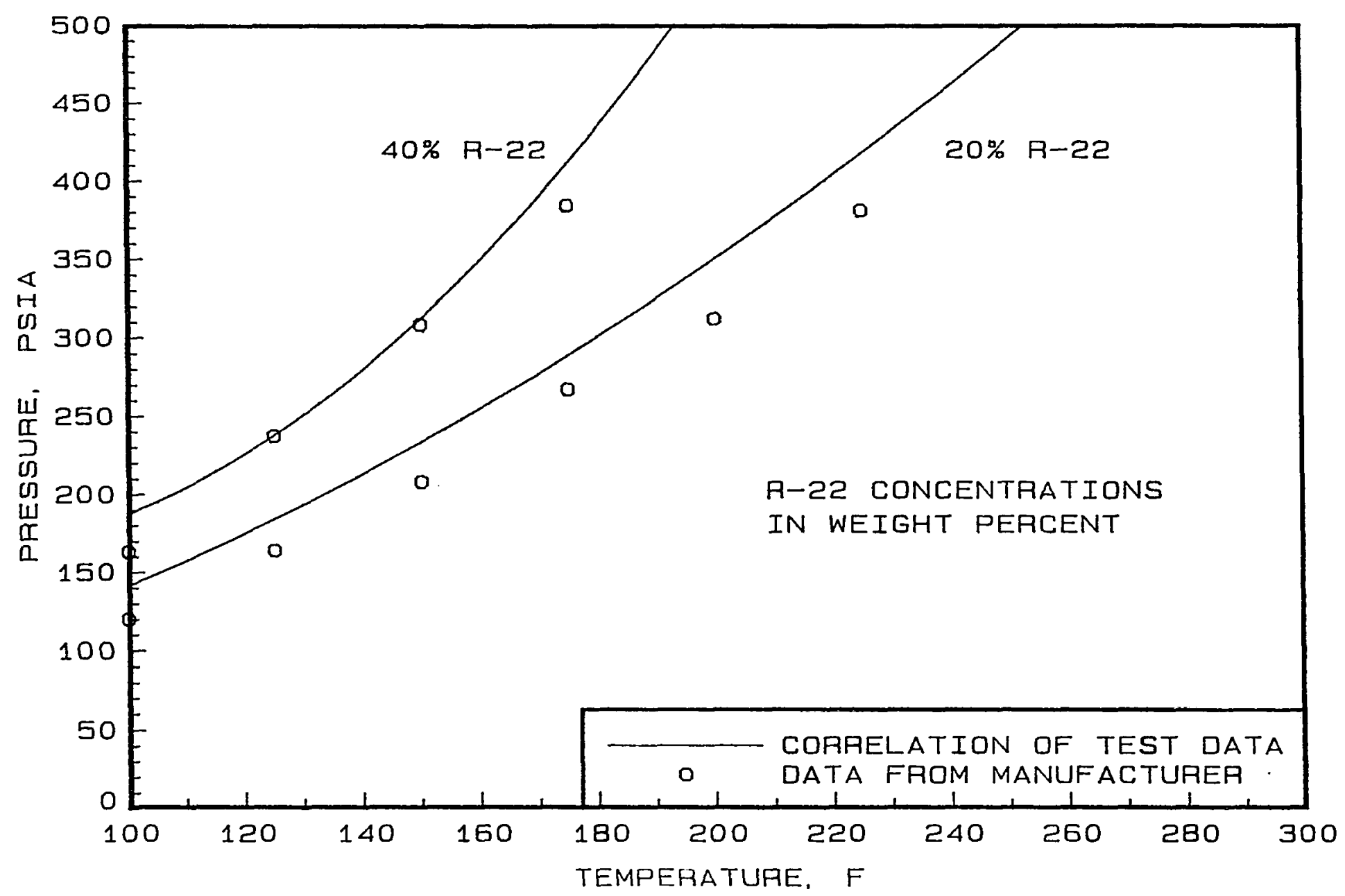

Figure 4.9: Correlation of test results compared with manufacturer's solubility data for solutions of R-22 in a 150 SLS naphthenic oil 


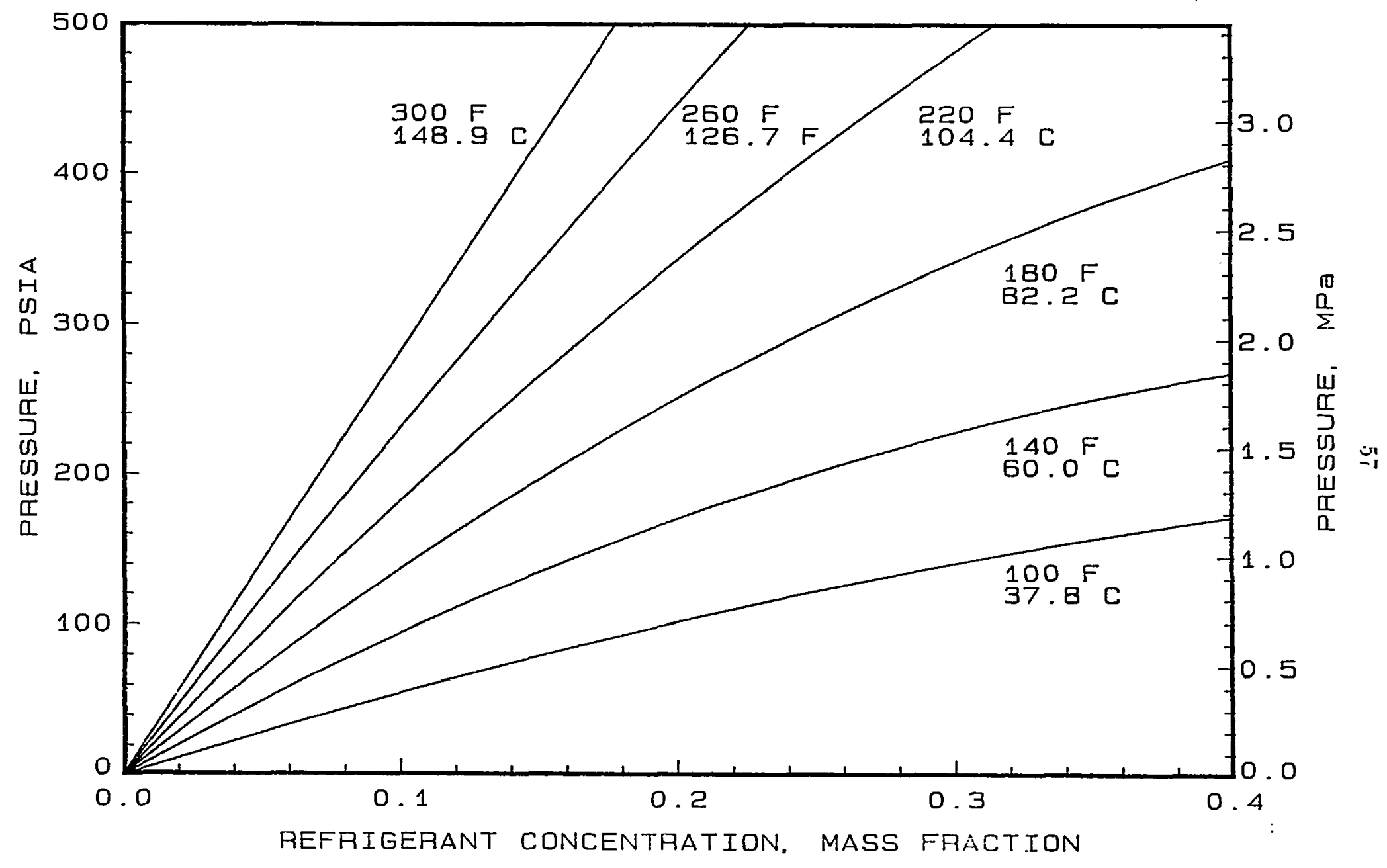

Figure 4.10: Solubility of R-22 in a 150 SUS alkylbenzene 


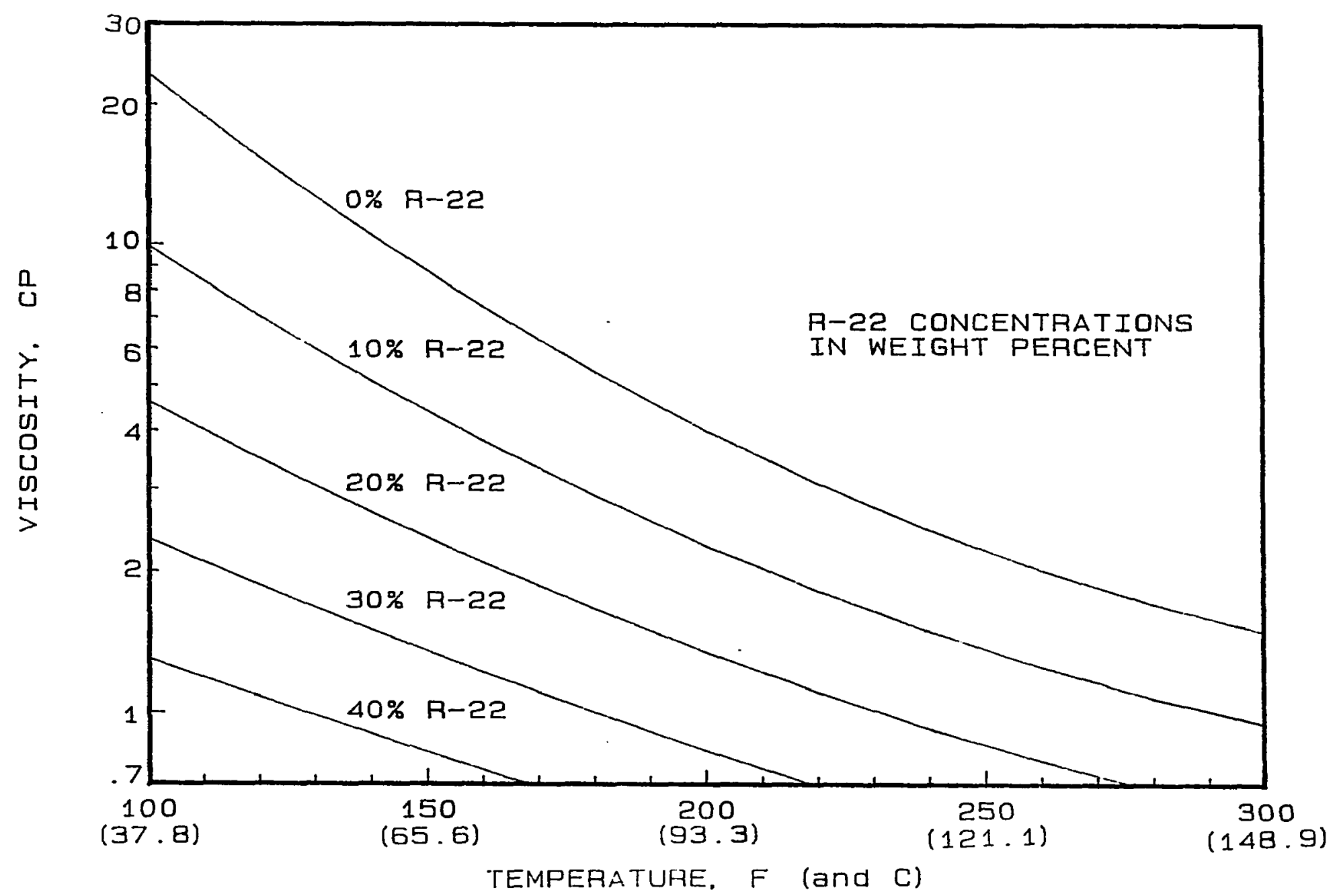

Figure 4.11: Absolute viscosity of R-22 in a $150 \mathrm{SL}$ S alkylbenzene 


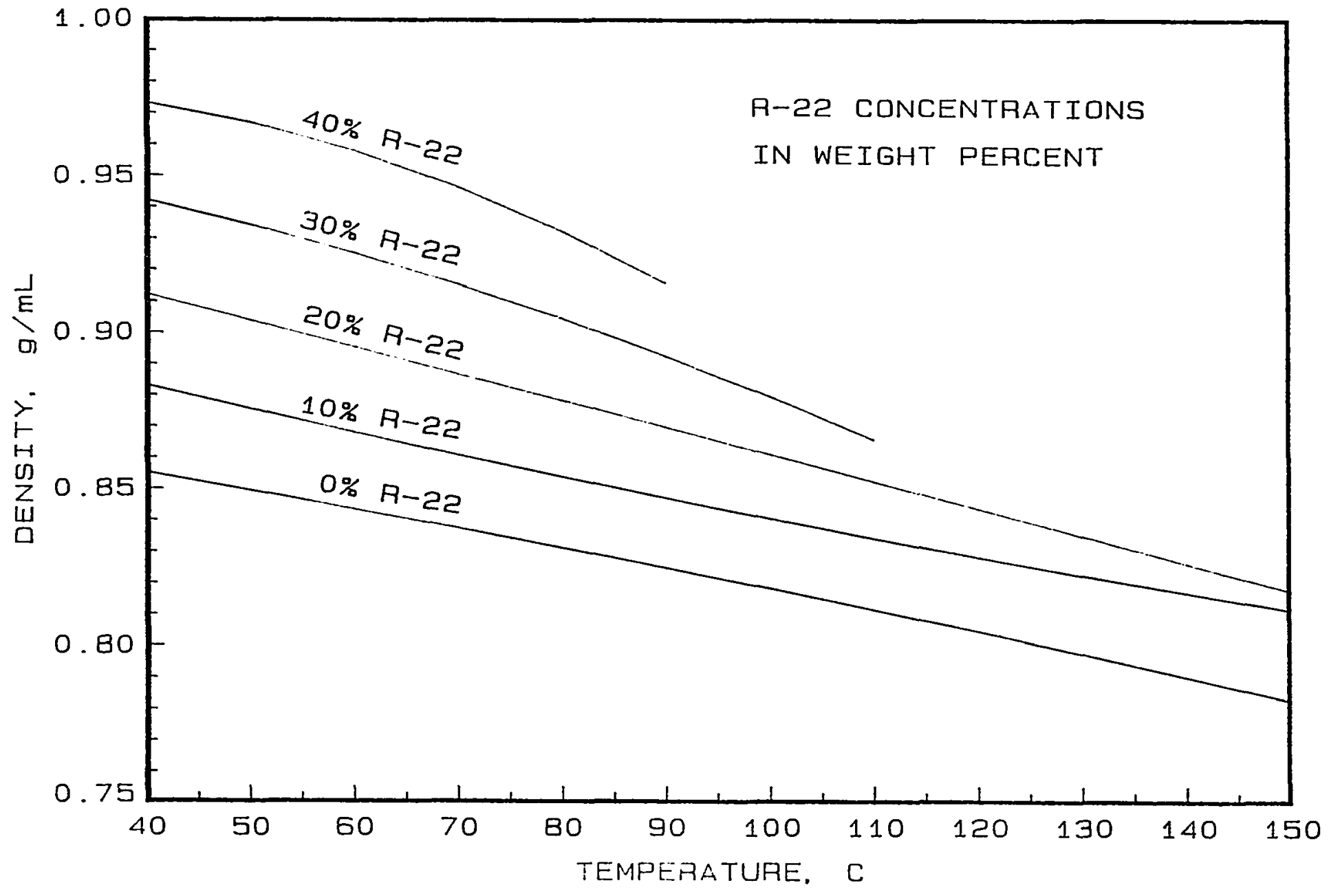

Figure 4.12: Density of R-22 in a 150 SUS alkylbenzene 


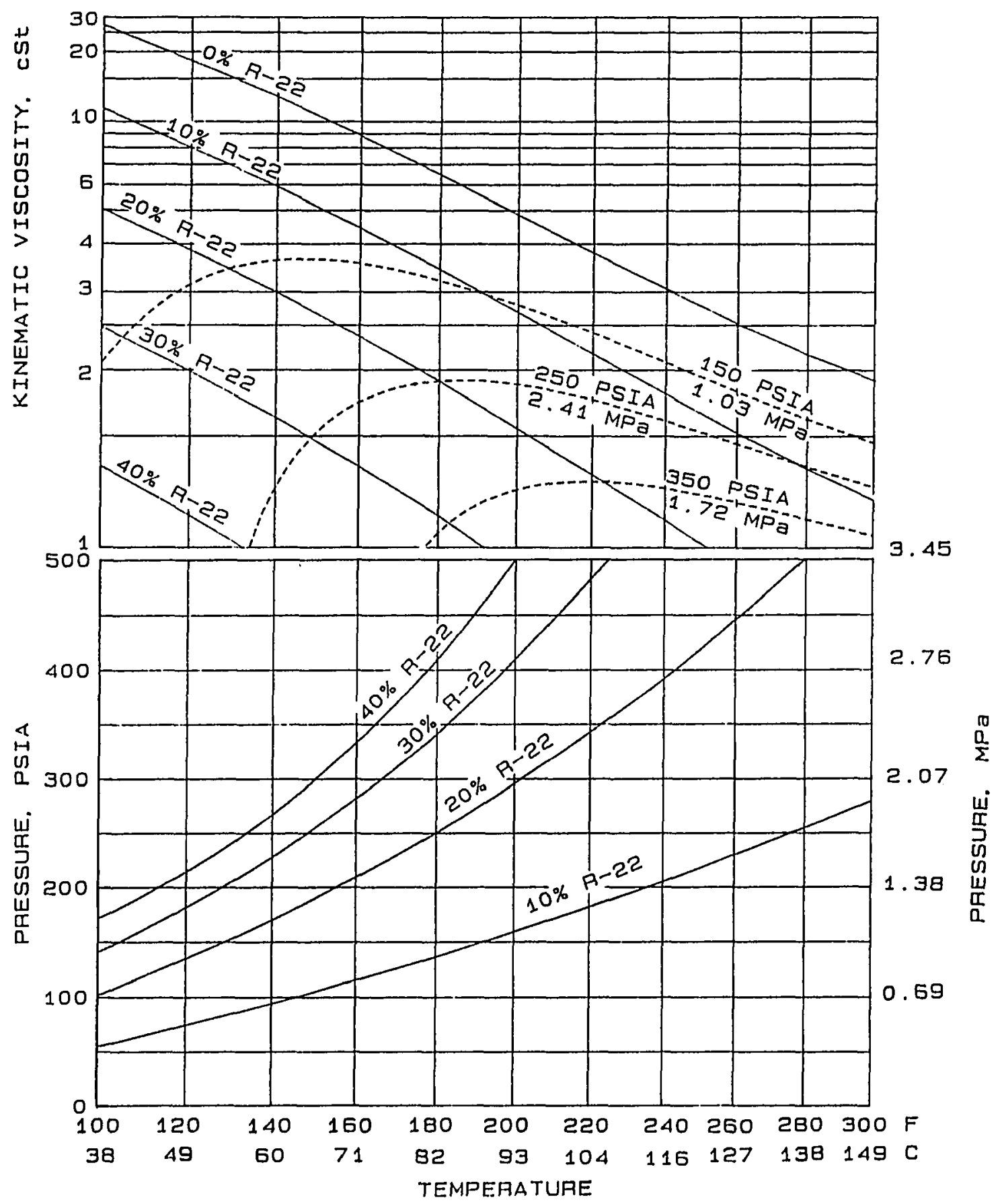

Figure 4.13: Viscosity-temperature-pressure chart for solutions of R-2.2 in a $1.50 \mathrm{SLS}$ alkylbenzene 


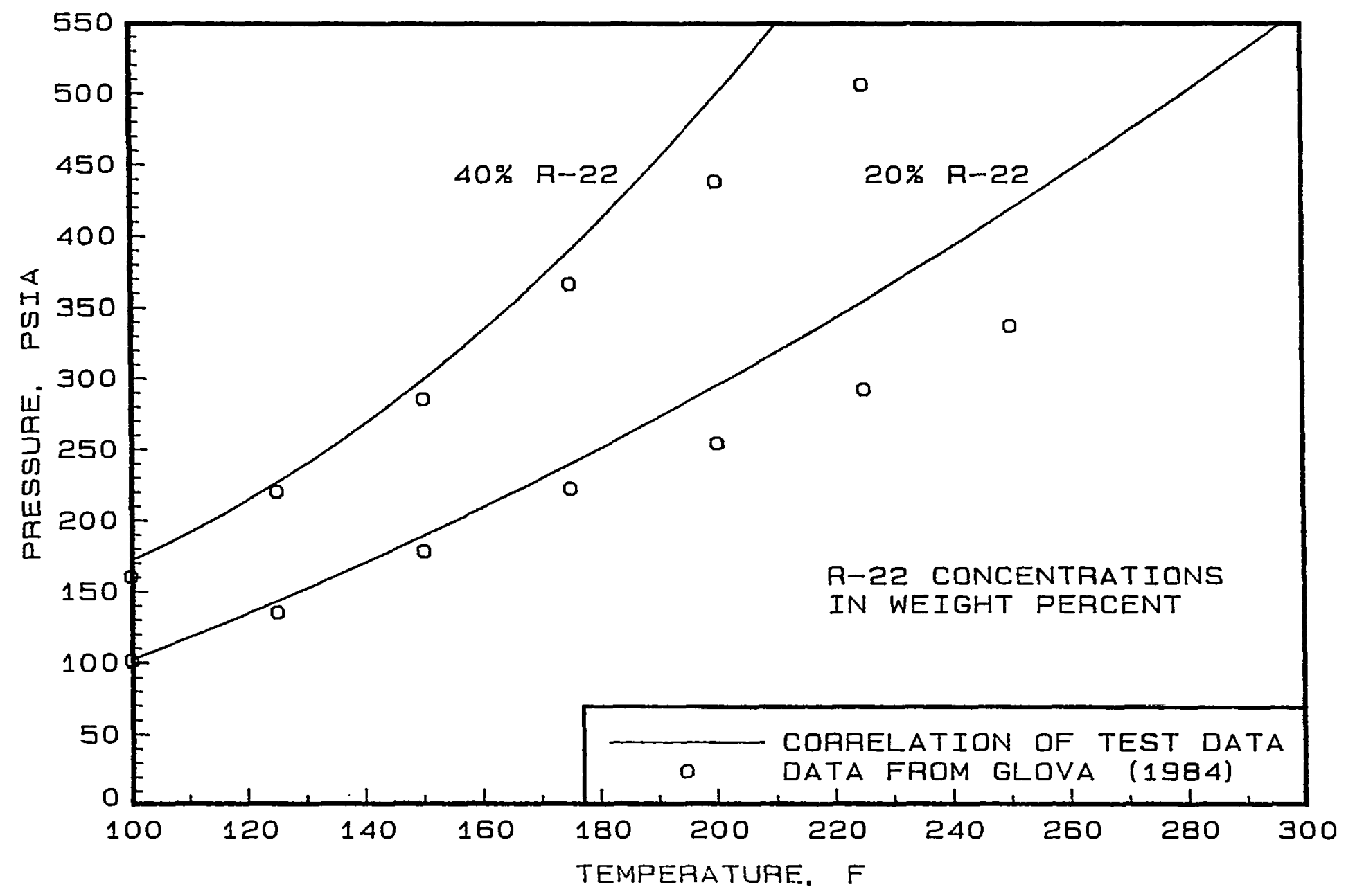

Figure 4.14: Correlation of test results compared with previously reported solubility data for solutions of R-22 in a 150 SUS alkylbenzene 
limited range of $38^{\circ} \mathrm{C}$ to $60^{\circ} \mathrm{C}\left(100^{\circ} \mathrm{F}\right.$ to $\left.140^{\circ} \mathrm{F}\right)$. Figure 4.15 shows that very good agreement is indicated.

\section{Comparison of R-22/Naphthenic Oil and R-22/Alkylbenzene Results}

With the above data, it is possible to compare the solubility and viscosity of $R$ 22 in solutions with naphthenic oil and with alkylbenzene. Figure 4.16 is an overlay of selected solubility data from Figures 4.5 and 4.10. Figure 4.17 compares absolute viscosities as correlated for two representative concentrations. They show that the R-22/150 SUS alkylbenzene solutions have lower pressures and generally lower absolute viscosities than do the R-22/150 SUS naphthenic oil solutions at a specified temperature and composition.

\section{Summary}

Data for solutions of R-22 in both a 150 SUS naphthenic oil and a 150 SUS alkylbenzene oil have been collected. These tests greatly extend the temperature range of previously available data for these two oil/refrigerant pairs, providing solubility and viscosity information for temperatures as high as $300^{\circ} \mathrm{F}\left(149^{\circ} \mathrm{C}\right)$. The results are presented as solubility, viscosity, and density charts that give pressure, liquid viscosity, and liquid density, respectively, as functions of temperature and refrigerant concentration. Empirical correlating equations (applicable only over the range of data collected) that allow convenient interpolation of the data are also provided. 


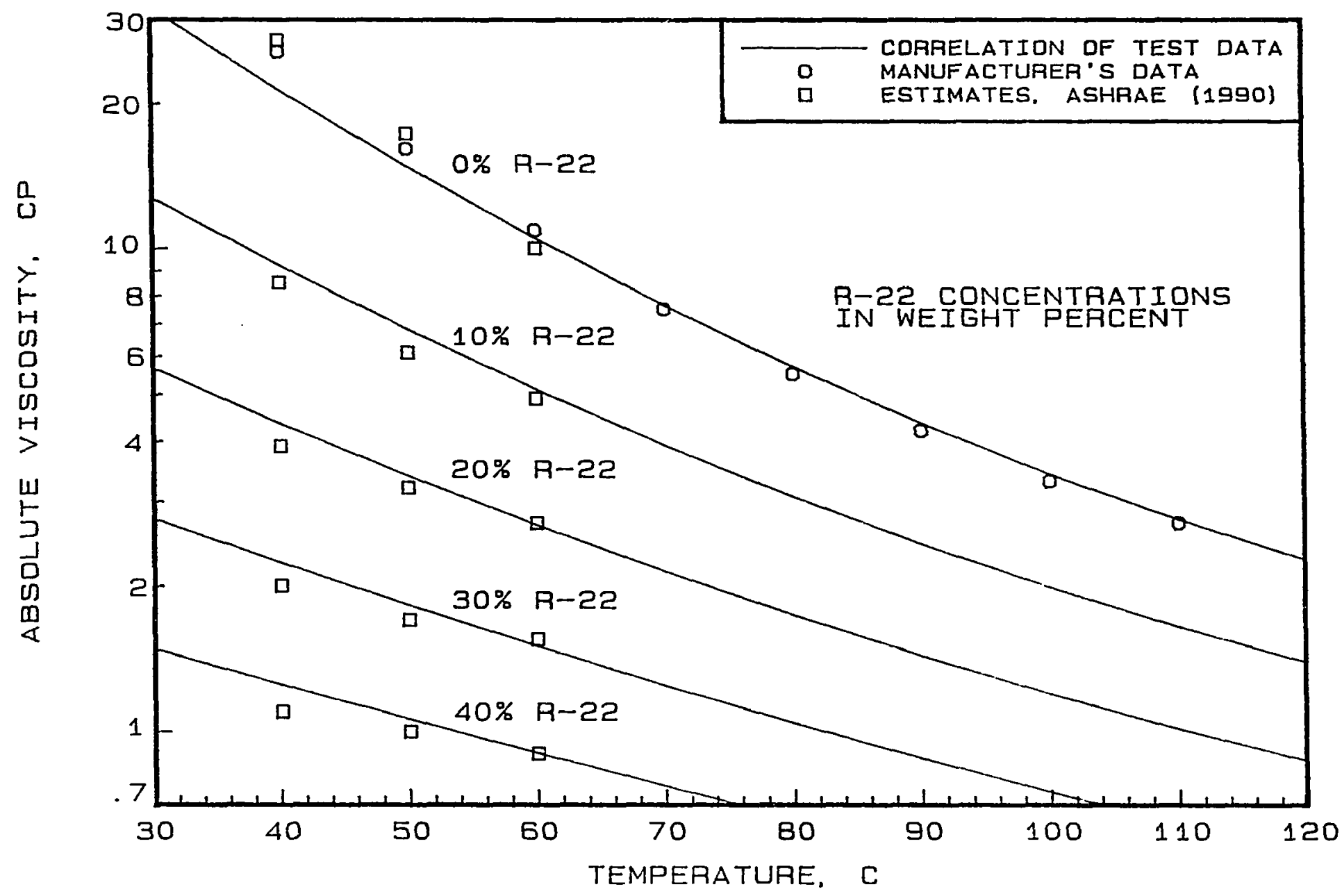

Figure 4.15: Correlation of test. results compared with estimates of viscosity data for solutions of R-22 in a 150 SUS alkylbenzene 


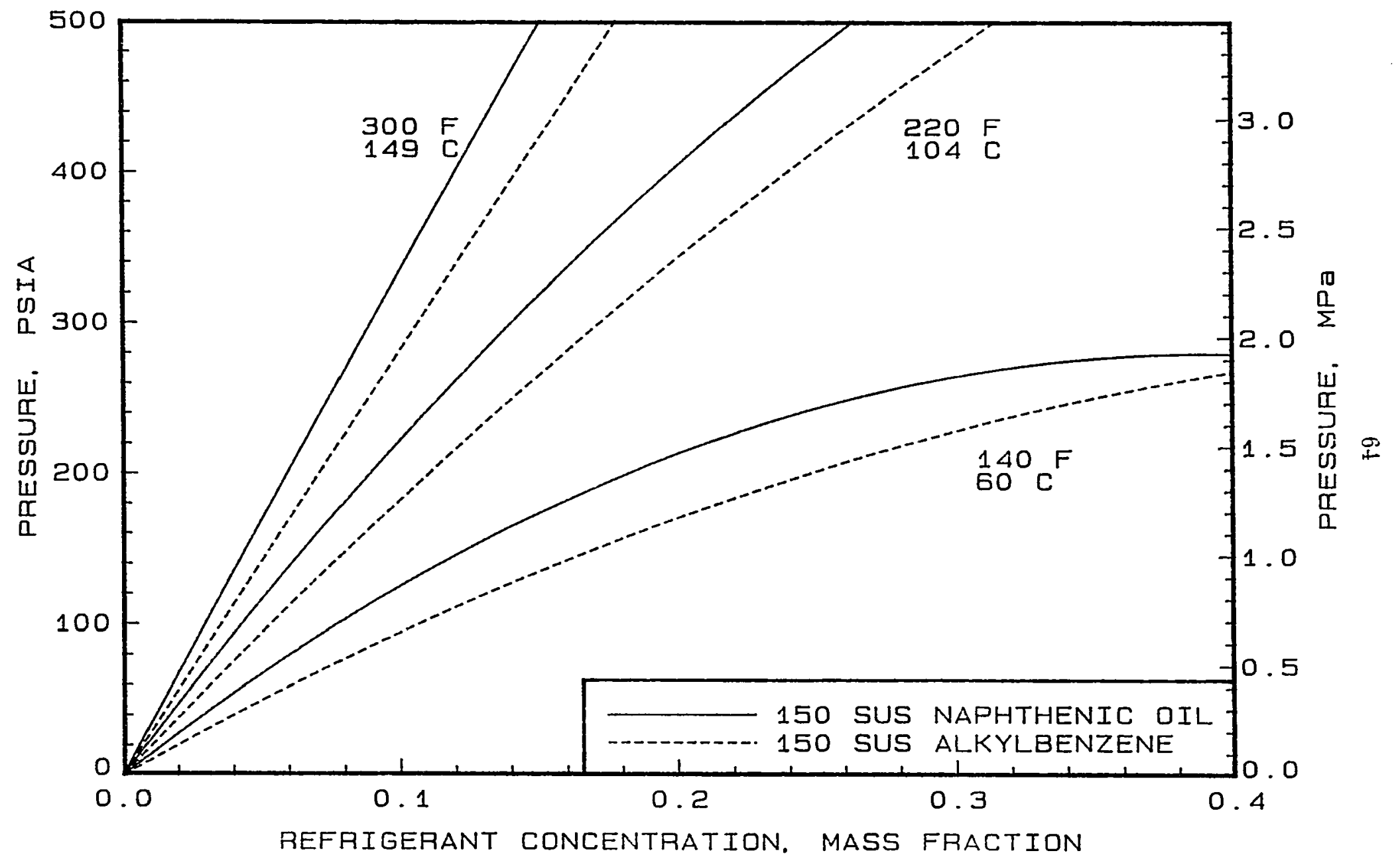

Figure 4.16: Comparison of the solubility of R-22 in a $150 \mathrm{SIS}$ naphthenic oil and in a 150 SLiS alkylbenzene 


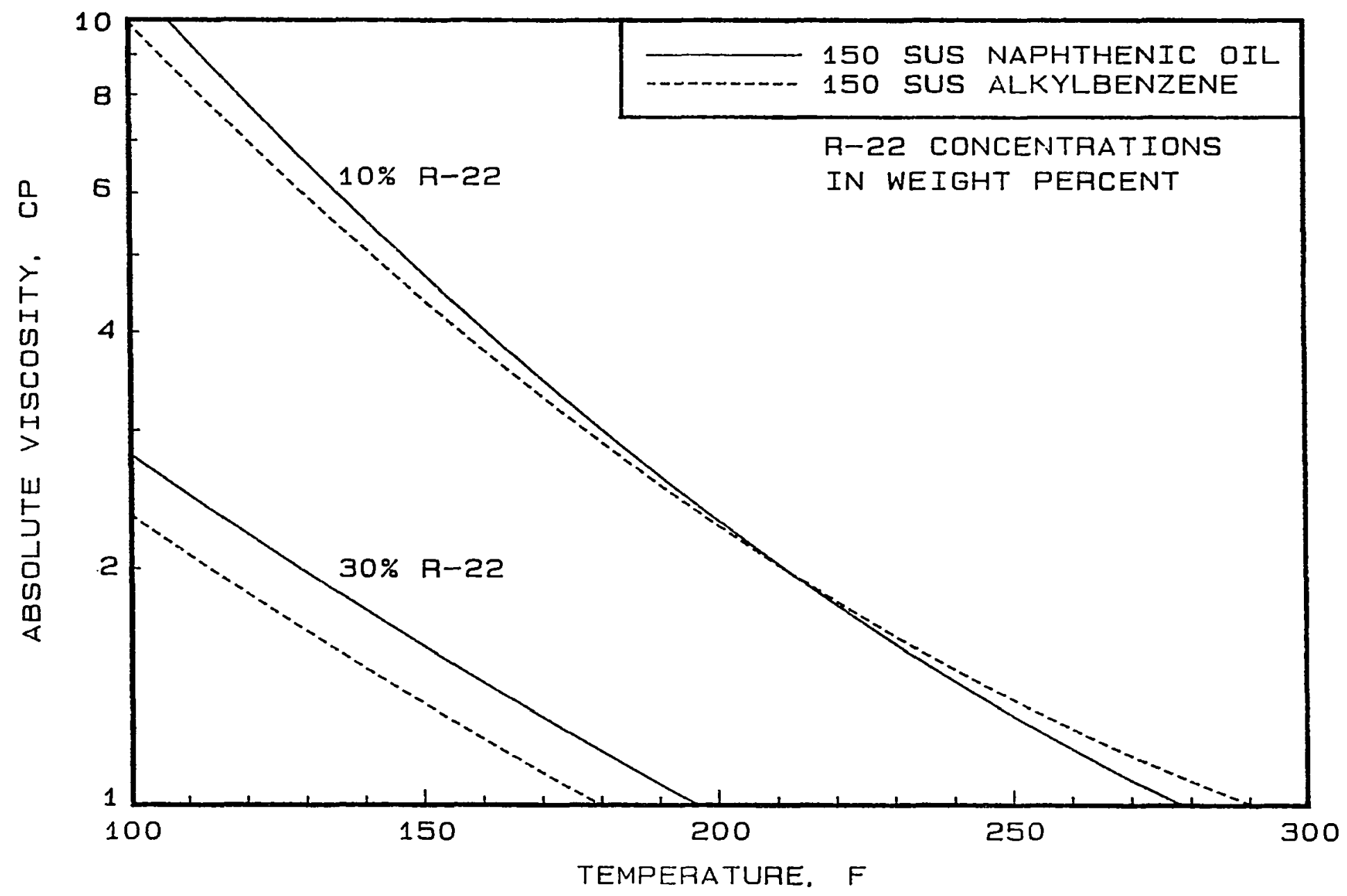

Figure 4.17: Comparison of the viscosity of R-22 in a $150 \mathrm{SLS}$ naphthenic oil and in a $150 \mathrm{SUS}$ alkylbenzene 


\section{CHAPTER 5. R-502 AND OIL SOLUTION PROPERTY RESULTS}

Solubility and viscosity data for solutions of R-502 with the same two lubricants used with the R-22 were also collected. This data is significant for design, and also for proving the methodology developed in this research project. Specifically, R-502 and the two lubricant combinations have miscibility characteristics similar to those expected of some alternative refrigerant/oil pairs that are of current interest because of the CFC issue.

This chapter presents results of measurements for $\mathrm{R}-502$ in a naphthenic oil and in an alkylbenzene using the equipment described in C'hapter 2. Results for the two oil-refrigerant pairs are compared with existing data where available. The pressure (solubility) and viscosity results for the two oil-refrigerant pairs are compared with each other. In a manner similar to that done for the R-22/oil mixtures, the coefficients of correlating equations were determined by the nonlinear regression analysis described in Chapter 3 for the solubility (pressure), viscosity, and density of these solutions. These coefficients, as well as graphical representations of the data. are given here. Tabulations of the actual experimental data are provided in Appendix C!. 


\section{Results and Discussion}

Results of the measurements with R-502 in both a 150 SL'S naphthenic oil and a $150 \mathrm{SUS}$ alkylbenzene oil are presented below. The lubricants used in these tests were samples drawn from the same lots that were used in the R-22/oil studies discussed in Chapter 4. The reader will recall that the naphthenic oil is characterized by carbon-type composition as $C_{A}{ }_{A} 14 \%, C^{\prime} . V 43 \%, C_{P}^{\prime} 43 \%$, and has a molecular weight of approximately 300. The other lubricant was a branched alkylbenzene with an approximate molecular weight of 330 .

The data set for each oil-refrigerant pair includes temperature, pressure, actual composition, absolute viscosity, and density for a range of conditions. The results are provided graphically as well as in the form of empirical correlations derived from the original test data. These equations are empirical fits of the data. as pointed out in ('hapter 3, and are not based on theoretical considerations. The coefficients for these correlating equations, as derived for both R-502/oil pairs, are given in Table 5.1 .

Figures 5.1 through 5.4 show that these correlations for solubility and viscosity of both R-502/oil solutions are well fit to the test data, generally within $\pm 5 \%$. Since the density correlations fit the data to well within $\pm 1 \%$, goodness-of-fit plots for density are not given. Again, it should be noted that, when using the correlations in lieu of the graphs, care must be taken to avoid extrapolation beyond the limits of applicability given along with the coefficients in Table 5.1. 
Table 5.1: Coefficients for empirical correlations of viscosity, pressure, and density data for R-502/oil solutions

R-502/150 SUS Naphthenic Oil Correlations

\begin{tabular}{||clll||}
\hline Term & Viscosity (Eq. 3.1) & Pressure (Eq. 3.2) & Density (Eq. 3.3) \\
\hline Intercept & $A_{0}=10.001$ & $B_{0}=0.0000$ & $D_{0}=1.0625$ \\
$C^{\prime}$ & $A_{1}=-2.7139$ & $B_{1}=0.0000$ & $D_{1}=0.0000$ \\
$\theta$ & $A_{2}=-11.948$ & $B_{2}=0.0000$ & $D_{2}=-0.1666$ \\
$C^{\prime} \theta$ & $A_{3}=0.0000$ & $B_{3}=-19.941$ & $D_{3}=1.2755$ \\
$C^{\prime 2}$ & $A_{4}=73.854$ & $B_{4}=115.36$ & $D_{4}=0.0000$ \\
$C^{2} \theta$ & $A_{5}=-138.60$ & $B_{5}=-229.38$ & $D_{5}=-1.0761$ \\
$C^{\prime} \theta^{2}$ & $A_{6}=0.0000$ & $B_{6}=26.173$ & $D_{6}=-0.6283$ \\
$\theta^{2}$ & $A_{7}=3.5653$ & $B_{7}=0.0000$ & $D_{7}=0.0000$ \\
$C^{2} \theta^{2}$ & $A_{8}=65.139$ & $B_{8}=103.33$ & $D_{8}=0.0000$ \\
\hline
\end{tabular}

R-502/150 SUS Alkylbenzene Correlations

\begin{tabular}{||clll||}
\hline Term & Viscosity.(Eq. 3.1) & Pressure (Eq. 3.2) & Density (Eq. 3.3) \\
\hline Intercept & $A_{0}=11.450$ & $B_{0}=0.0000$ & $D_{0}=1.0640$ \\
$C^{\prime}$ & $A_{1}=-6.6680$ & $B_{1}=0.0000$ & $D_{1}=0.4026$ \\
$\theta$ & $A_{2}=-14.194$ & $B_{2}=0.0000$ & $D_{2}=-0.1957$ \\
$C^{\prime} \theta$ & $A_{3}=3.3853$ & $B_{3}=-20.904$ & $D_{3}=0.0000$ \\
$C^{2}$ & $A_{4}=0.0000$ & $B_{4}=0.0000$ & $D_{4}=0.0000$ \\
$C^{\prime 2} \theta$ & $A_{5}=0.0000$ & $B_{5}=0.0000$ & $D_{5}=0.0000$ \\
$C^{\prime} \theta^{2}$ & $A_{6}=0.0000$ & $B_{6}=25.006$ & $D_{6}=0.0000$ \\
$\theta^{2}$ & $A_{7}=4.4120$ & $B_{7}=0.0000$ & $D_{7}=0.0000$ \\
$C^{2} \theta^{2}$ & $A_{8}=0.9122$ & $B_{8}=-5.8174$ & $D_{8}=-0.1865$ \\
\hline
\end{tabular}

Note: The limits of applicability of the correlations are:

Composition - 0 to 30 weight percent R-502 in napthenic oil 0 to 40 weight percent $R-502$ in alkylbenzene

Temperature $-40^{\circ} \mathrm{C}$ to $150^{\circ} \mathrm{C}\left(100^{\circ} \mathrm{F}\right.$ to $\left.300^{\circ} \mathrm{F}\right)$ $(\theta: 1.07$ to 1.44$)$

Pressure $\quad-0$ to $3.5 \mathrm{MPa}(0$ to 500 psia) 


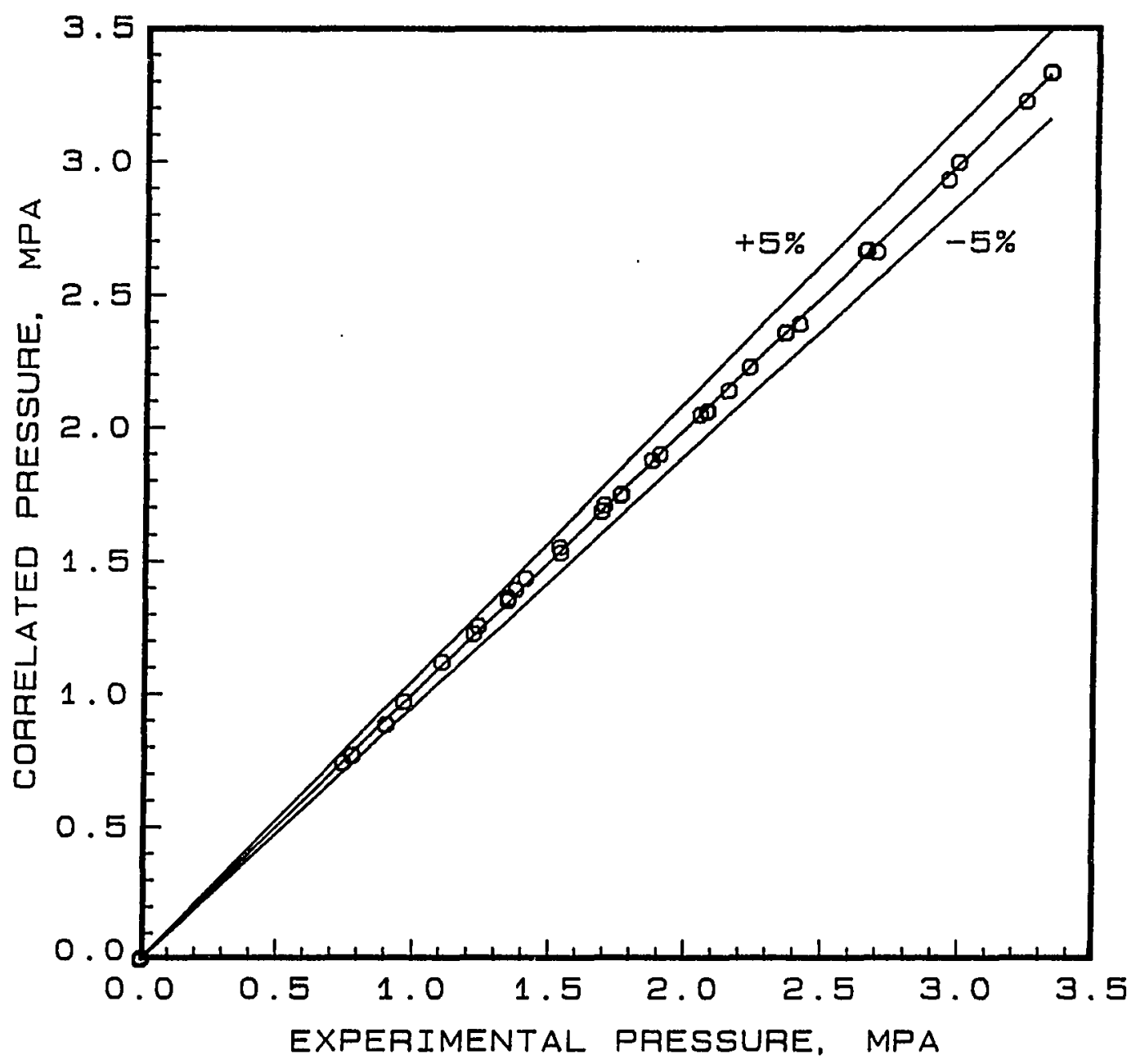

Figure 5.1: Goodness-of-fit of pressure correlation with experimental data for solutions of R-502 in a 1.50 SUS naphthenic oil 


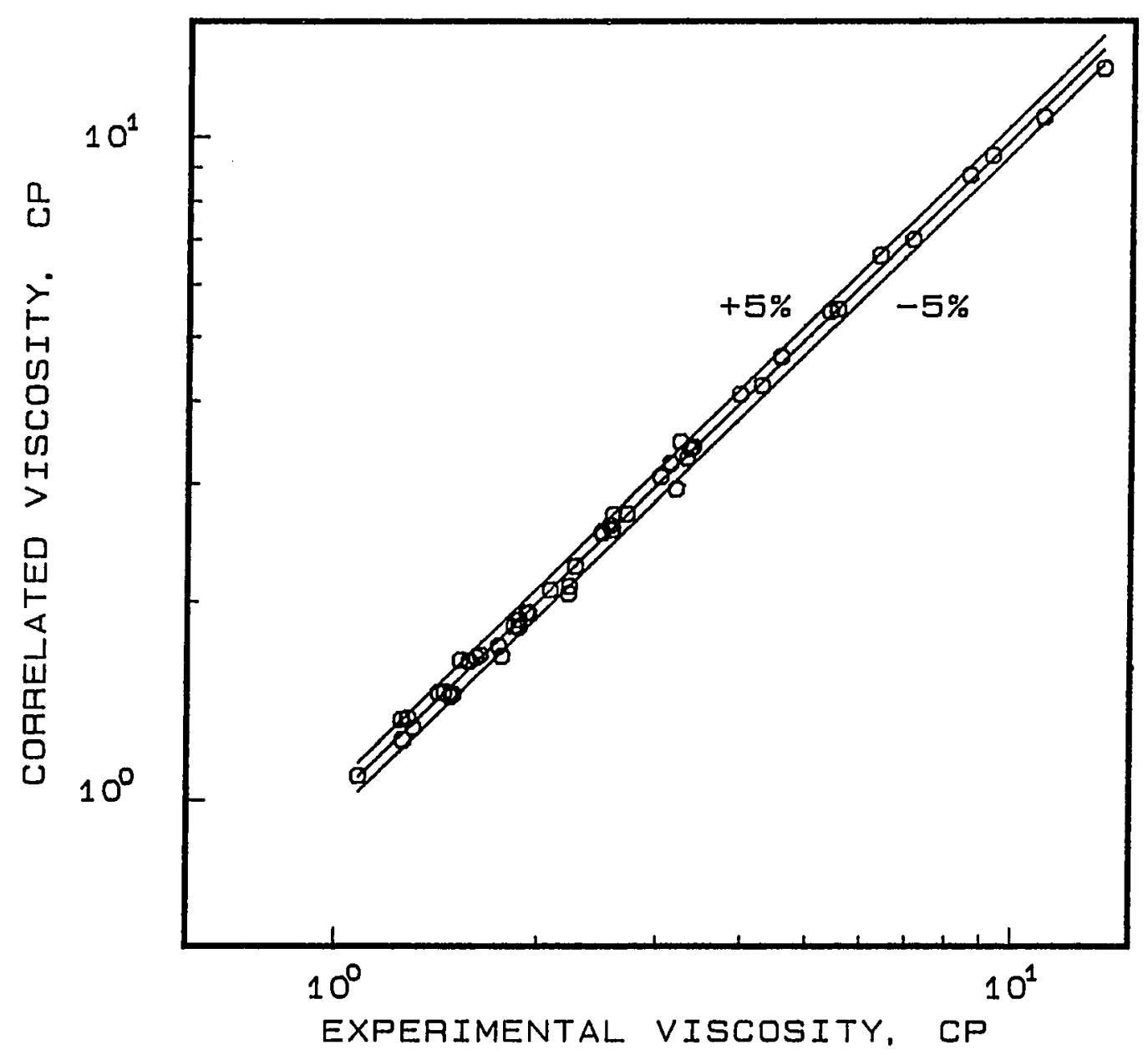

Figure 5.2: Cioodness-of-fit of viscosity correlation with experimental data for solutions of R-502 in a 150 SUS naphthenic oil 


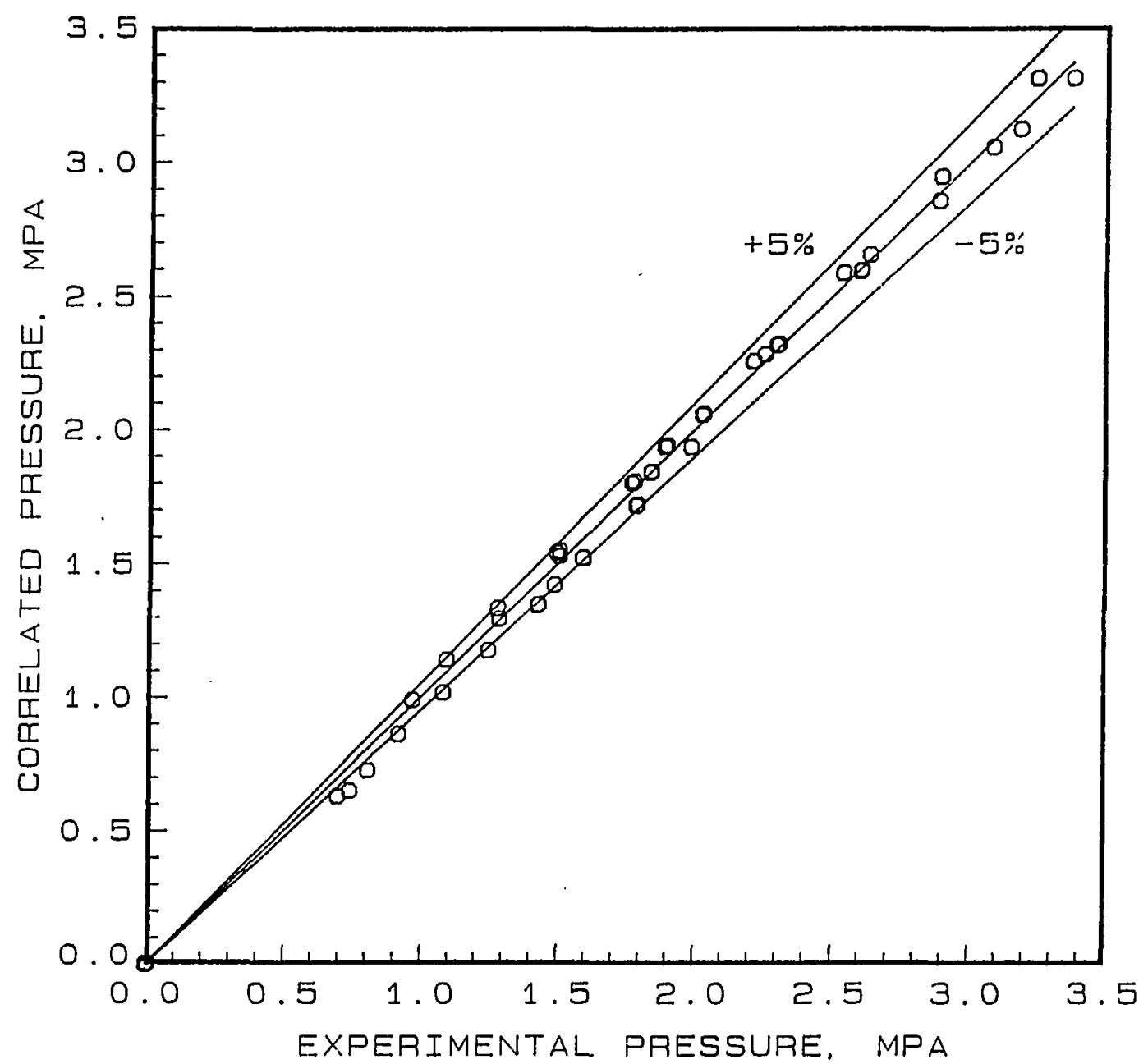

Figure 5.3: Goodness-of-fit of pressure correlation with experimental data for solutions of R-502 in a $150 \mathrm{SUS}$ alkylbenzene 
72

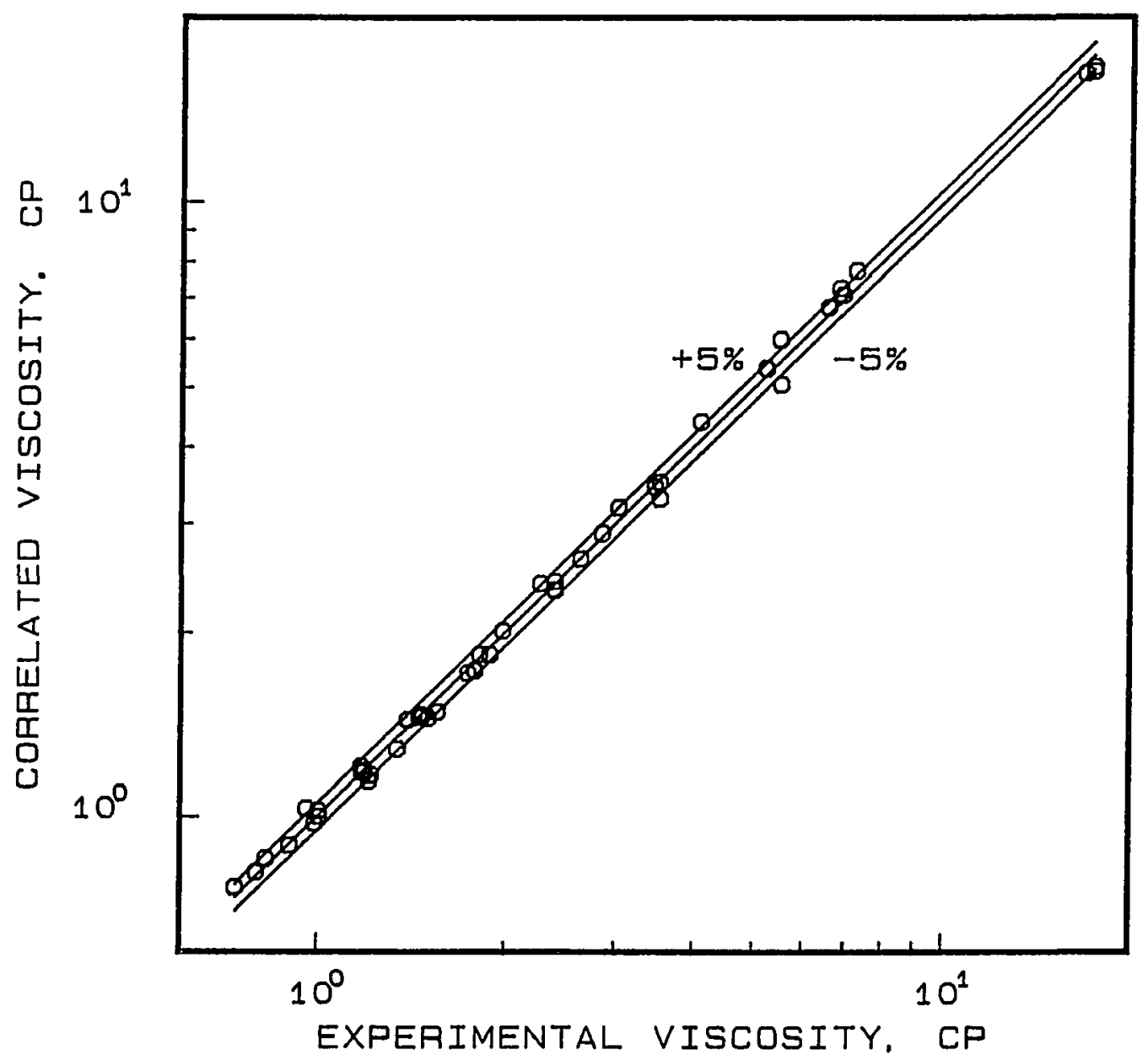

Figure 5.4: Goodness-of-fit of viscosity correlation with experimental data for solutions of R-502 in a 150 SUS alkylbenzene 


\section{R-502/Naphthenic Oil Solutions}

Results for the solubility of R-502 in a 150 SUS naphthenic oil for solutions of 0 to 30 weight percent R-502 are given in Figure 5.5. Absolute viscosity and density results are shown in Figures 5.6 and 5.7. The trends illustrated in these figures appear to be similar to those for the R-22/oil pairs previously discussed.

However, in contrast to the R-22 results, immiscibility was observed for higher concentrations of R-502 in solution with the naphthenic oil. This behavior is consistent with the critical solubility temperature data provided in Figure $T$, Chapter 8 of the Refrigeration Systems Handbook (ASHRAE, 1990). At a nominal overall composition of $45 \%$ of R-502, two clearly observable liquid phases were present at all temperatures in the test. One of these was an oil-rich, lower-density liquid. The other liquid phase was comparatively refrigerant-rich, less viscous, and of a higher density. The upper, less dense liquid phase was apparently quite viscous. since vigorous circulation of the lower, denser liquid phase by pumping had little observable effect on the motion of the inteface between the phases. It is possible that at higher temperatures a return to miscibility might occur; however, these conditions were not achievable without exceeding 500 psia $(3.45 \mathrm{MPa})$, the maximum pressure limitations of the test cell.

The detection of immiscibility, if present, is one of the tests required of the measurement methodology developed in this project. The current configuration of the test facility, with windows installed on each side of the test cell, makes visual observation of immiscibility very convenient. However, further modifications would have to be made to the test cell in order to be able to independently sample each of two liquid phases for determination of viscosity and density. For this reason, viscosity 


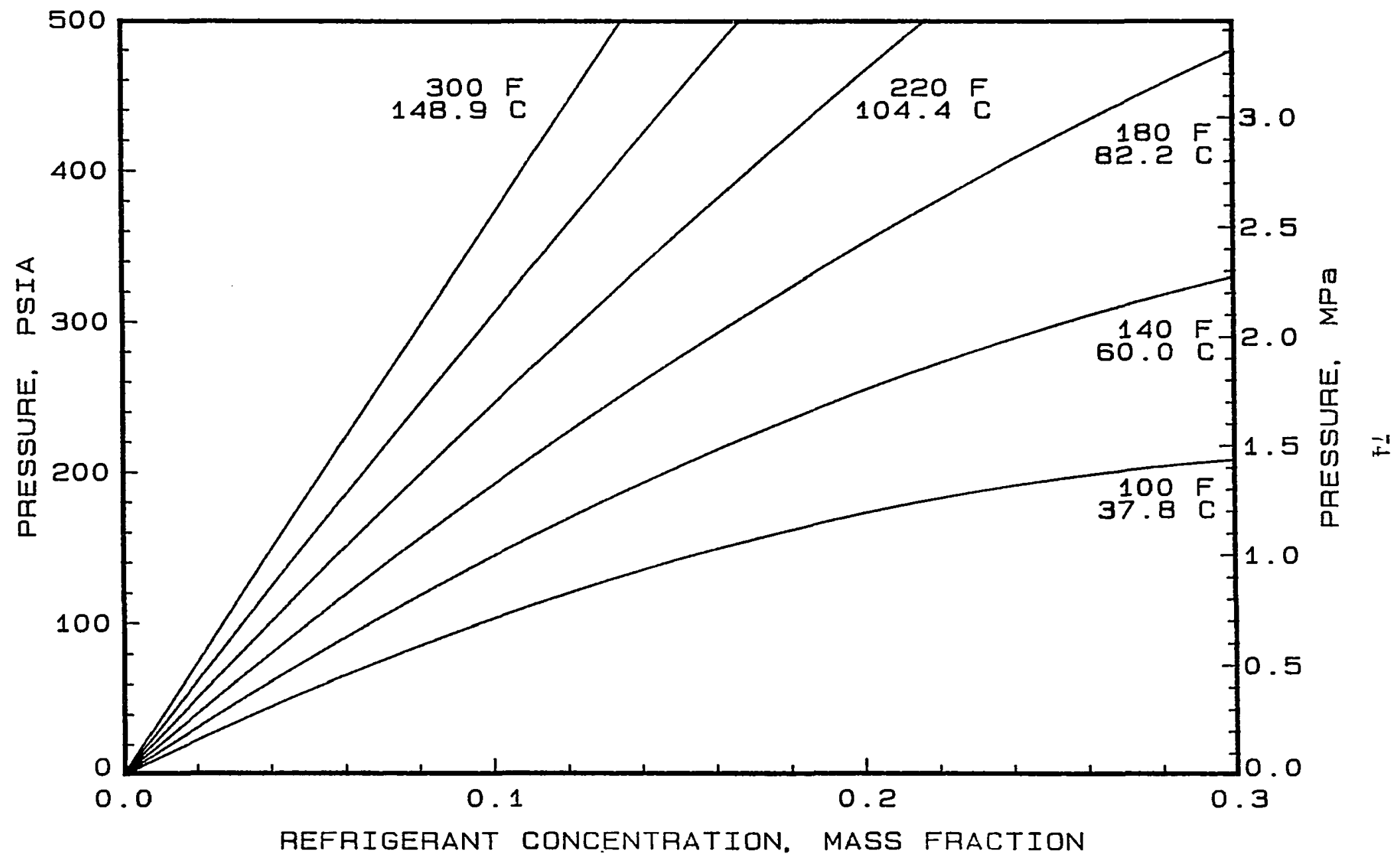

Figure 5.5: Solubility of R-502 in a $150 \mathrm{SLSS}$ naphthenic oil 


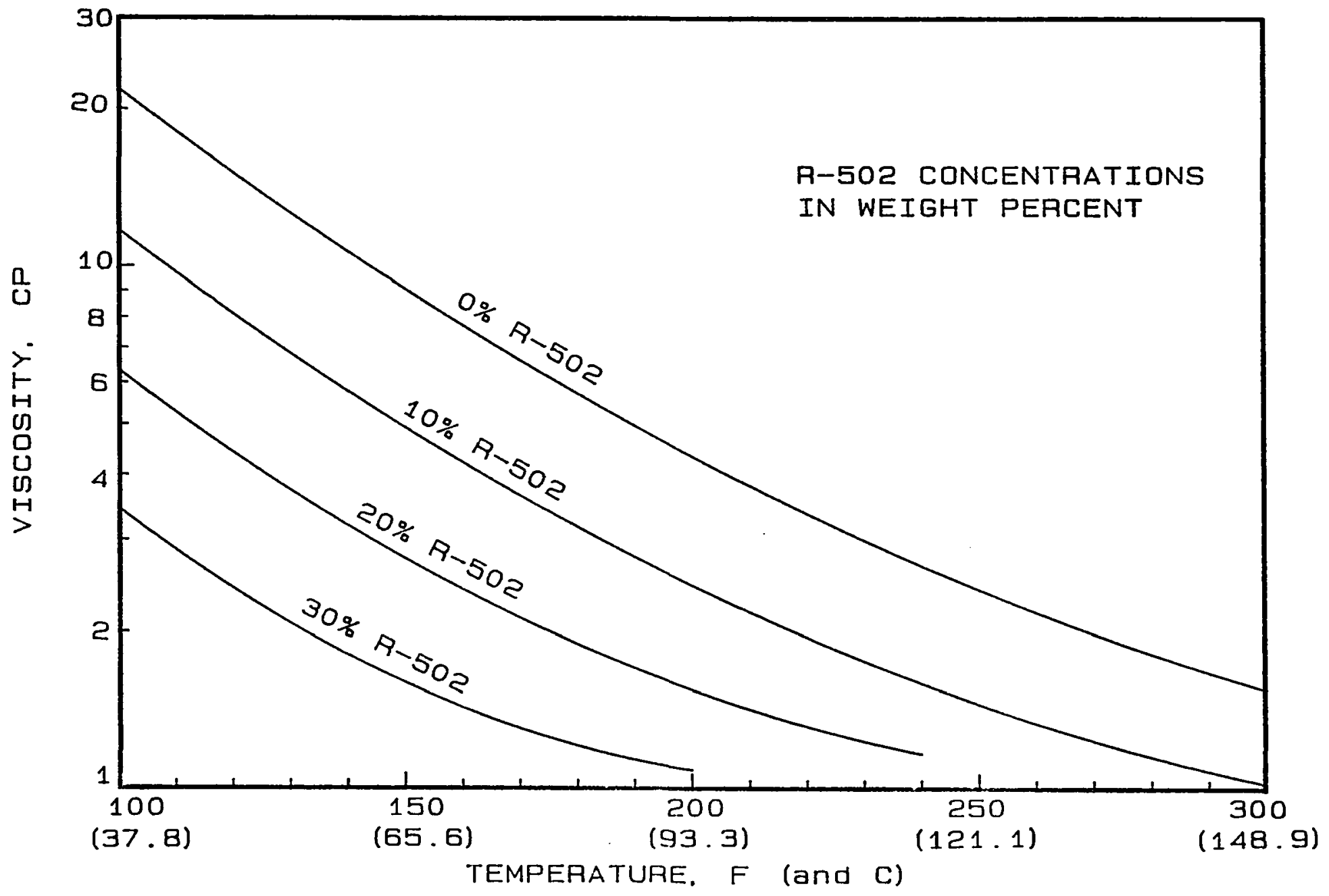

iㅣ

Figure 5.6: Absolute viscosity of R-502 in a 150 SUS naphthenic oil 


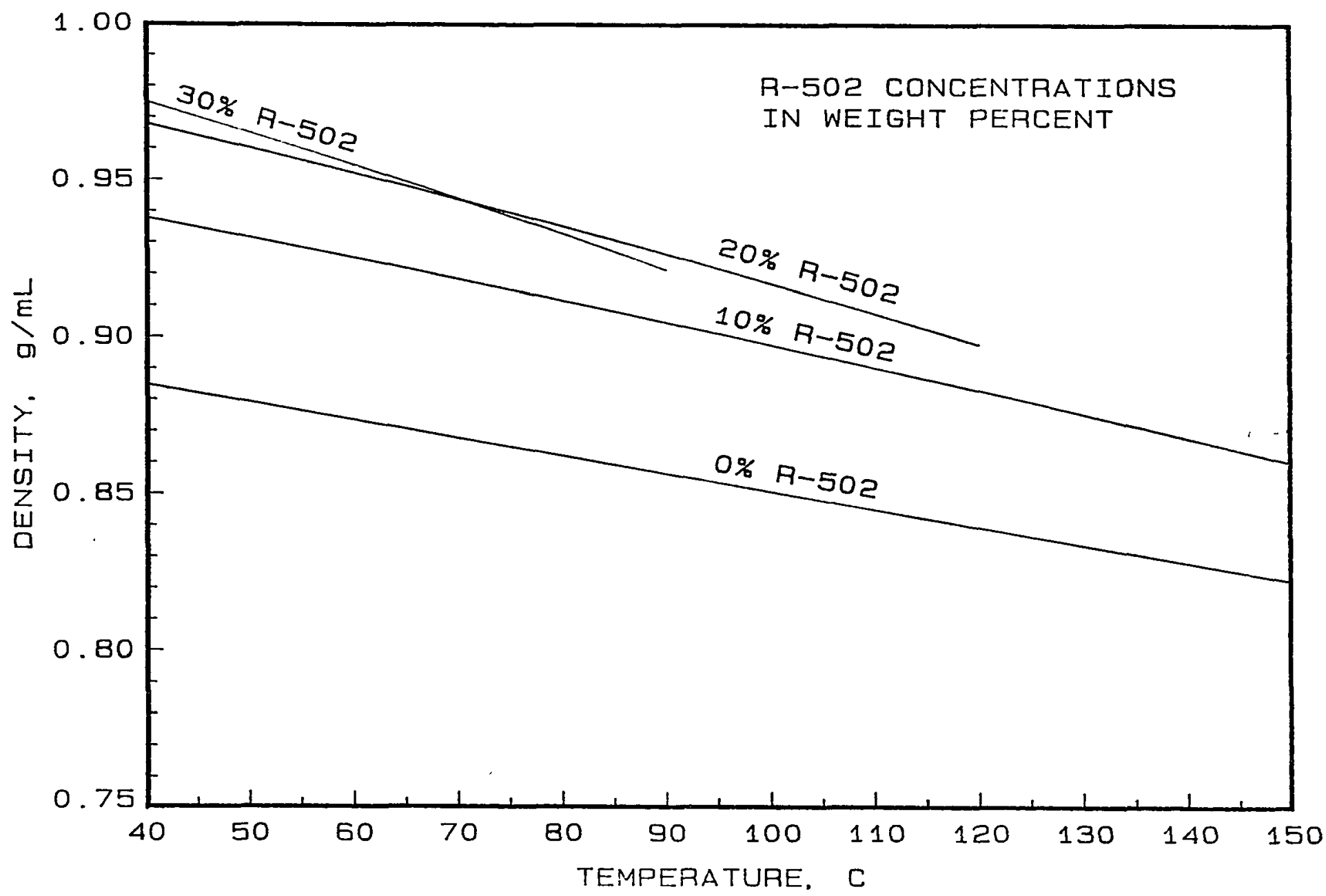

Figure 5.7: Density of R-502 in a 150 SUS naphthenic oil 
and density data recorded during tests with the two liquid phases present are not given here. The results presented here are for a range of test conditions in which only a single liquid phase exists in equilibrium with the vapor above it.

Figure 5.8 is the two-part "Daniel-type" plot for the same solutions from $100^{\circ} \mathrm{F}$ $\left(38^{\circ} \mathrm{C}\right)$ to $300^{\circ} \mathrm{F}\left(149^{\circ} \mathrm{C}\right)$. This plot is similar to those shown in Chapter 4 , and it provides a useful form of the kinematic viscosity and solubility information.

A comparison of test results with solubility data reported by the manufacturer is given in Figure 5.9. As with the R-22 results, some differences can be explained by variability in the oil as a result of processing changes over time. No comparable viscosity data for this oil/refrigerant pair were available.

\section{R-502/Alkylbenzene Solutions}

The presentation of the results for solutions of R-502 in a 150 SUS alkylbenzene is similar to that of the previous chapter in which the HCFC-22 results are discussed. The R-502 was miscible with the alkylbenzene at all four liquid compositions studied. Figures 5.10, 5.11, and 5.12 present the solubility, absolute viscosity, and density data. Again, a "Daniel" plot (Figure 5.13) provides the viscosity and solubility combined in a useful form. The data presented here extends the temperature range of the viscosity data well beyond that of any data previously available.

Figure 5.14 gives a comparison of test results with solubility data reported by Glova (1984) for a similar alkylbenzene. It appears that the presently reported pressures are somewhat higher. 


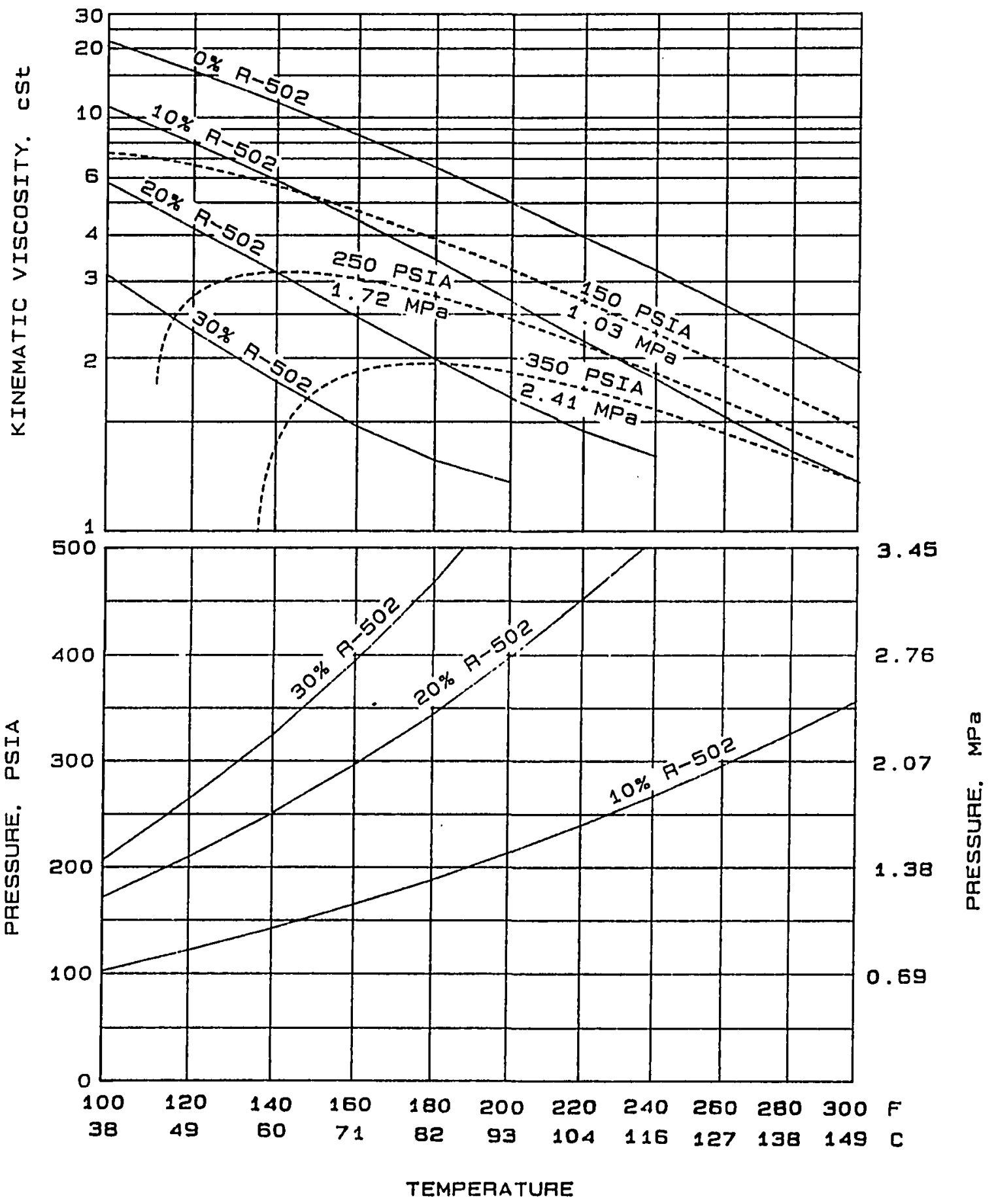

Figure 5.8: Viscosity-temperature-pressure chart for solutions of R-502 in a $1.50 \mathrm{SL}^{-} \mathrm{S}$ naphthenic oil 


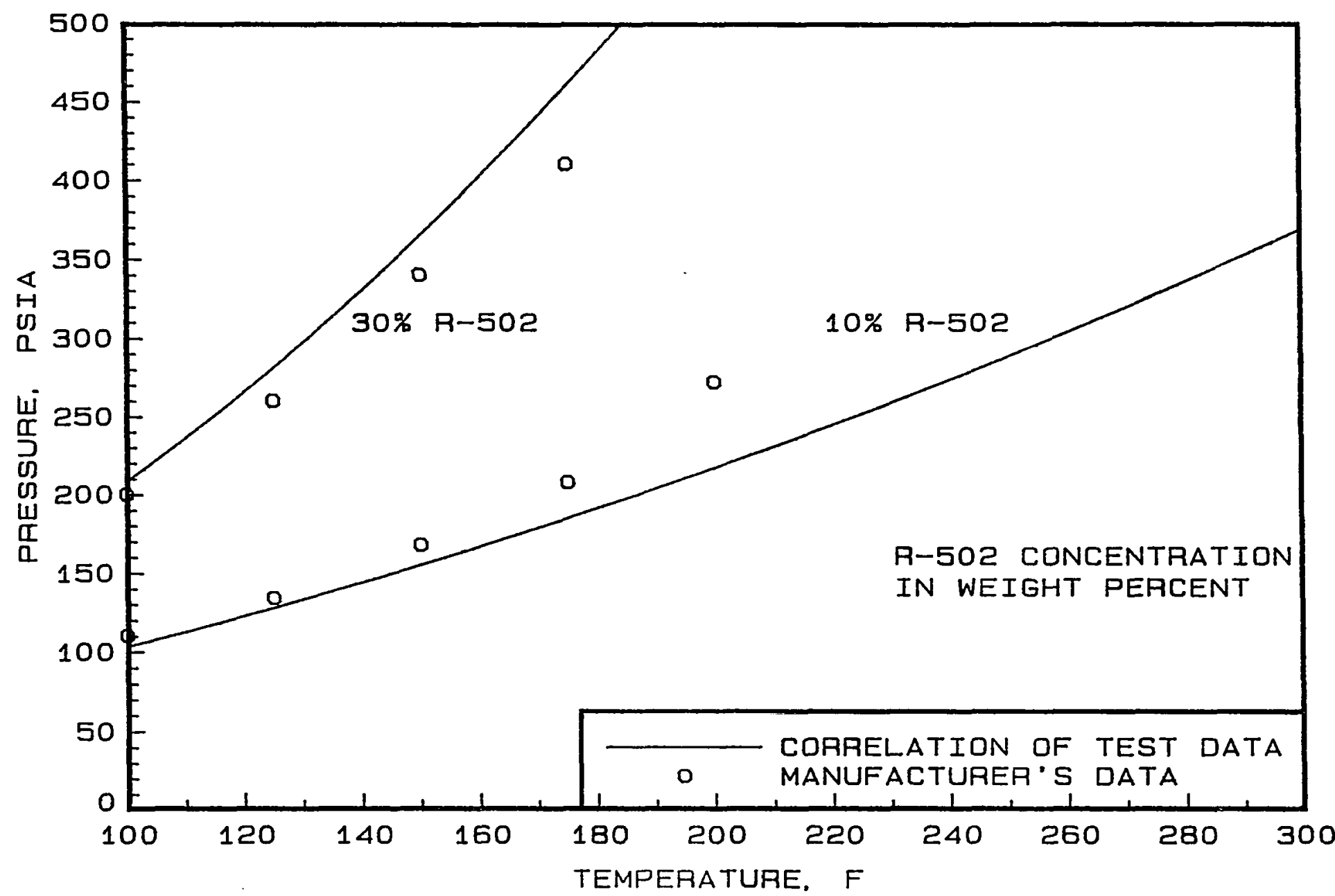

Figure 5.9: C'orrelation of test results compared with manufacturer's solubility data for solutions of R-502 in a 150 SUS naphthenic oil 


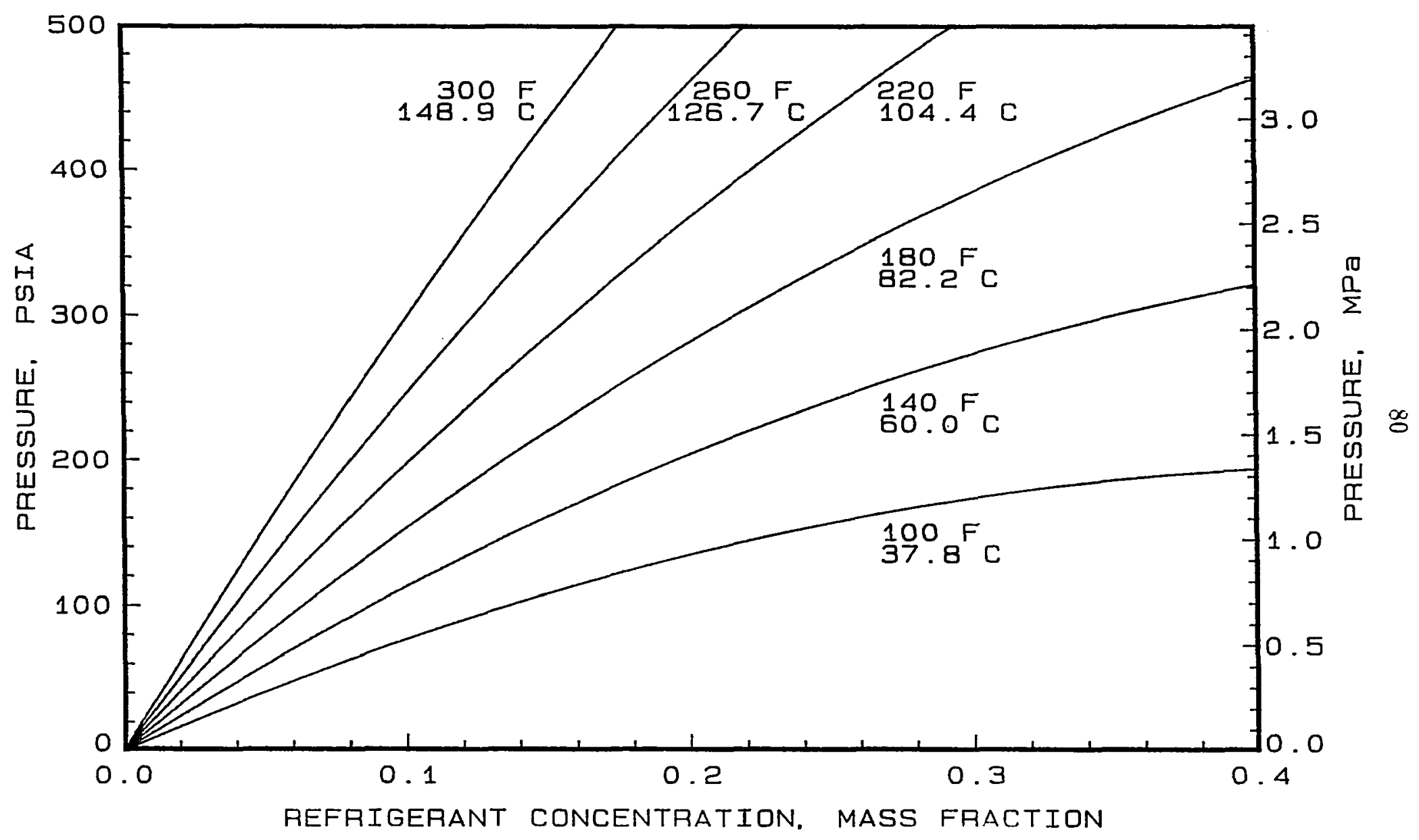

Figure 5.10: Solubility of R-502 in a $150 \mathrm{SI} \mathrm{S}^{\circ}$ alkylbenzene 


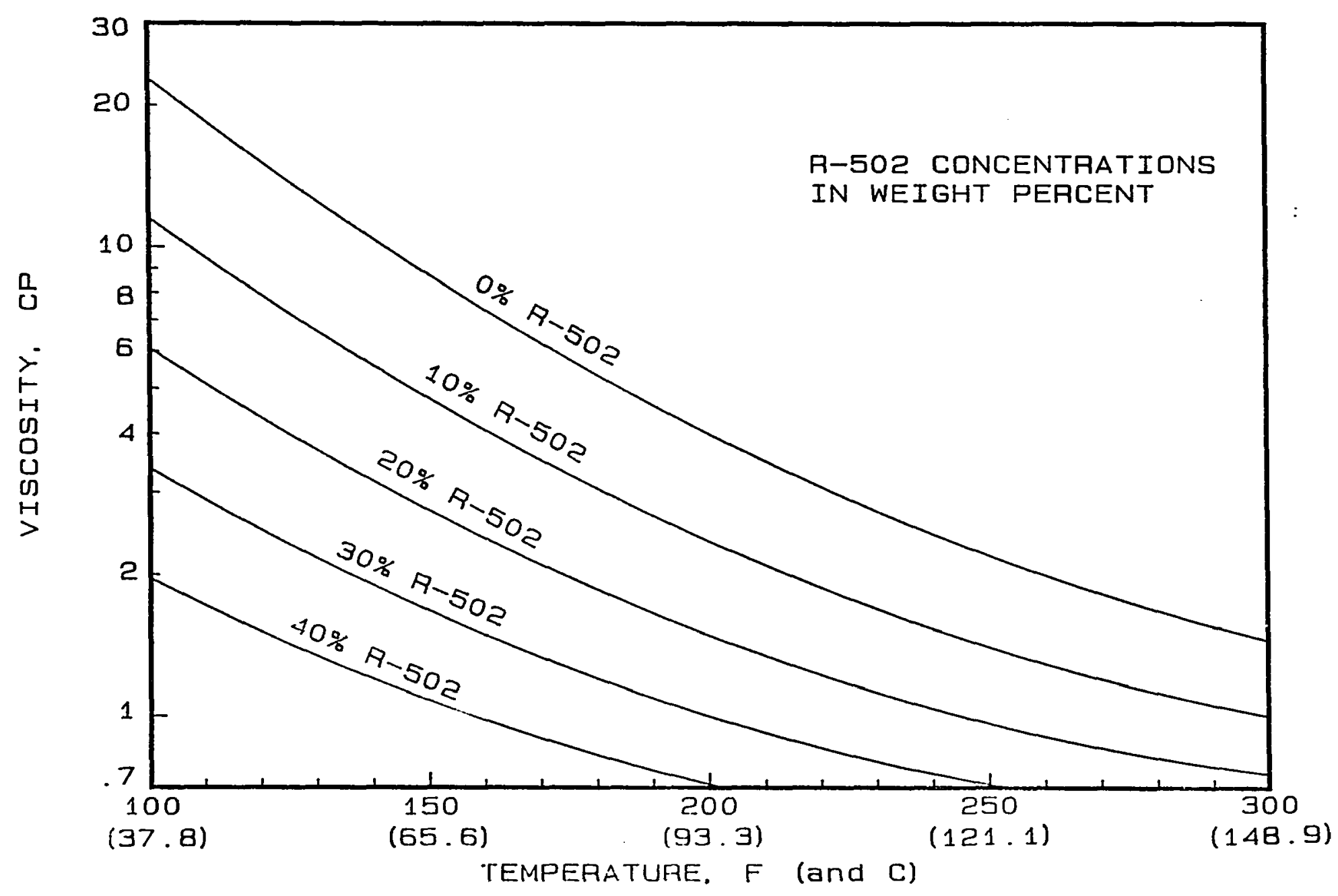

$\stackrel{\infty}{\rightleftharpoons}$

Figure 5.11: Absolute viscosity of R-502 in a $150 \mathrm{SUS}$ alkylbenzene 


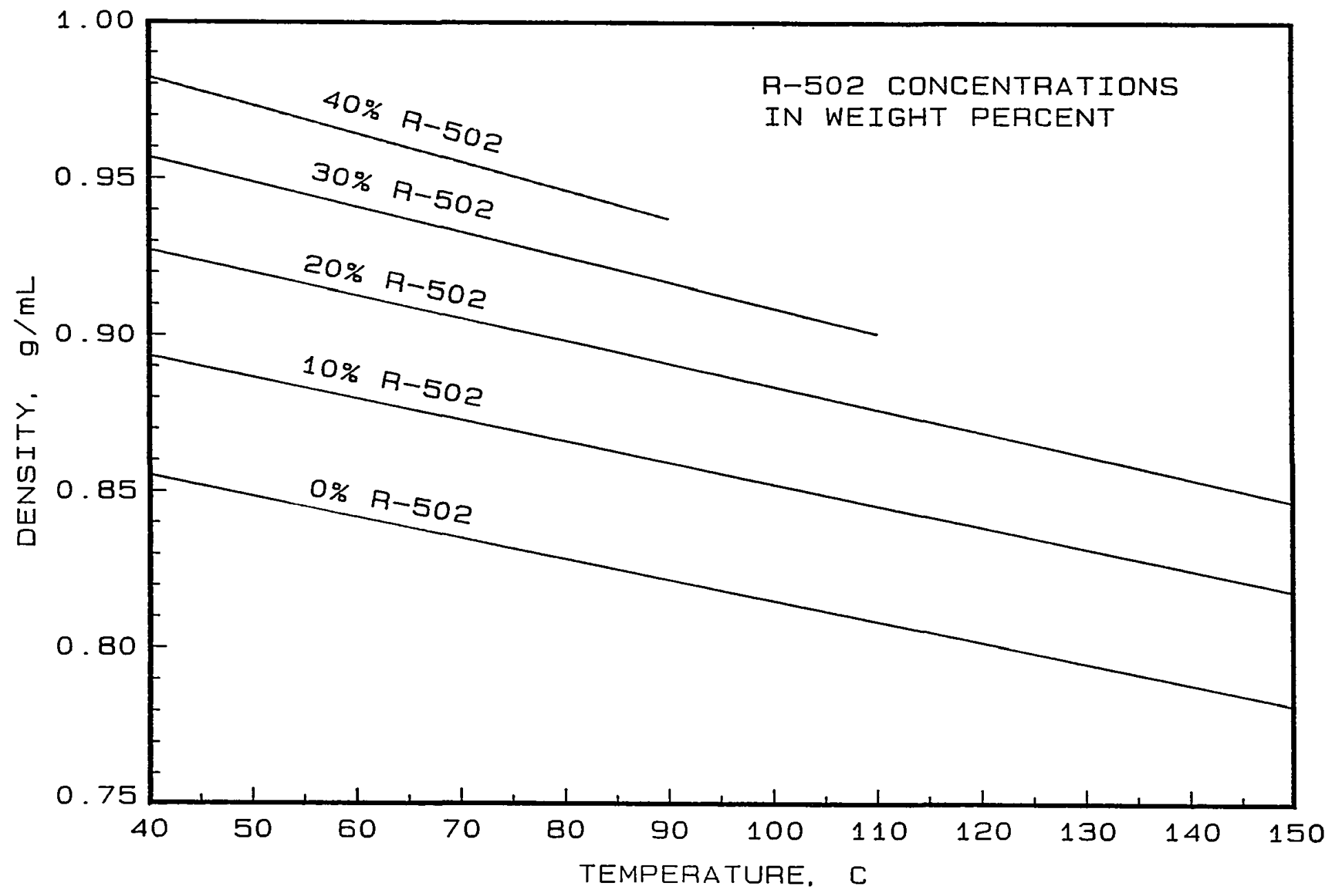

Figure 5.12: Density of R-502 in a $150 \mathrm{SL}$ S alkylbenzene 


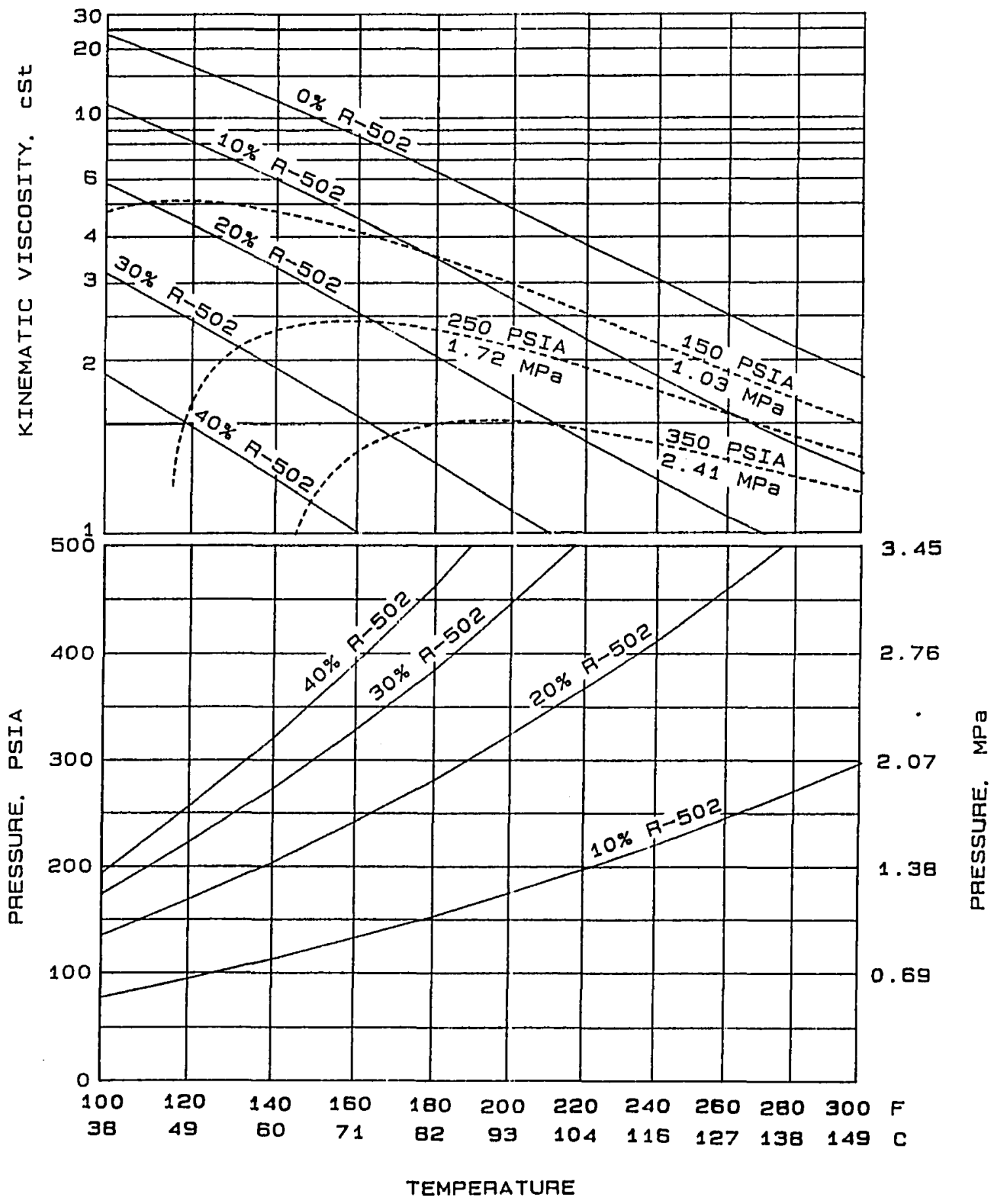

Figure 5.13: Viscosity-temperature-pressure chart for solutions of $R-502$ in a 1.50 SLiS alkylbenzene 


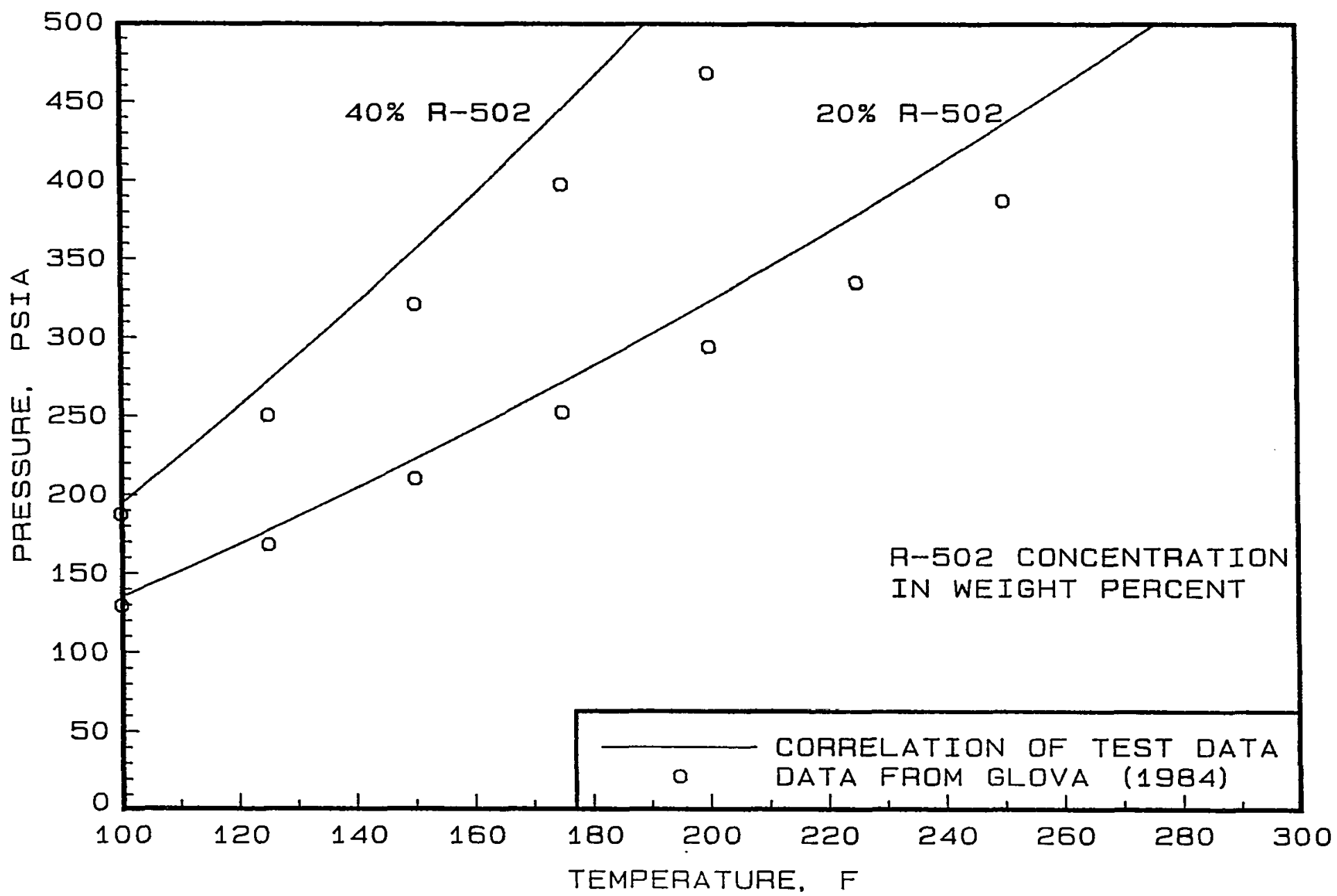

Figure 5.14: C'orrelation of test results compared with previously reported solubility data for solutions of R-502 in a 150 SUS alkylbenzene 


\section{Comparison of R-502/Naphthenic Oil and R-502/Alkylbenzene Results}

With the above data, it is possible to compare the behavior and properties of $R$ 502 in solutions with naphthenic oil and with alkylbenzene. Figure 5.15 is an overlay of selected data from Figures 5.5 and 5.10. Similarly, Figure 5.16 compares absolute viscosities as correlated for two representative concentrations. They show that the R-502/alkylbenzene solutions have lower pressures than do the R-502/naphthenic oil solutions at a specified temperature and composition. At a given concentration. the absolute viscosities of these mixtures appear to be quite similar.

However, as discussed previously, the major difference in the properties of the two solutions is the immiscibility evidenced by R-502/naphthenic oil solutions.

\section{Summary}

Data for solutions of R-502 in both a 150 SUS naphthenic oil and a 150 SUS alkylbenzene oil have been collected by using a newly developed test facility. These tests extend the temperature range of previously available data for these two oil/refrigerant pairs, providing solubility, viscosity, and density information for temperatures as high as $300^{\circ} \mathrm{F}\left(149^{\circ} \mathrm{C}\right)$. The immiscibility expected of $\mathrm{R}-502 /$ naphthenic oil solutions at higher refrigerant concentrations was successfully observed. 


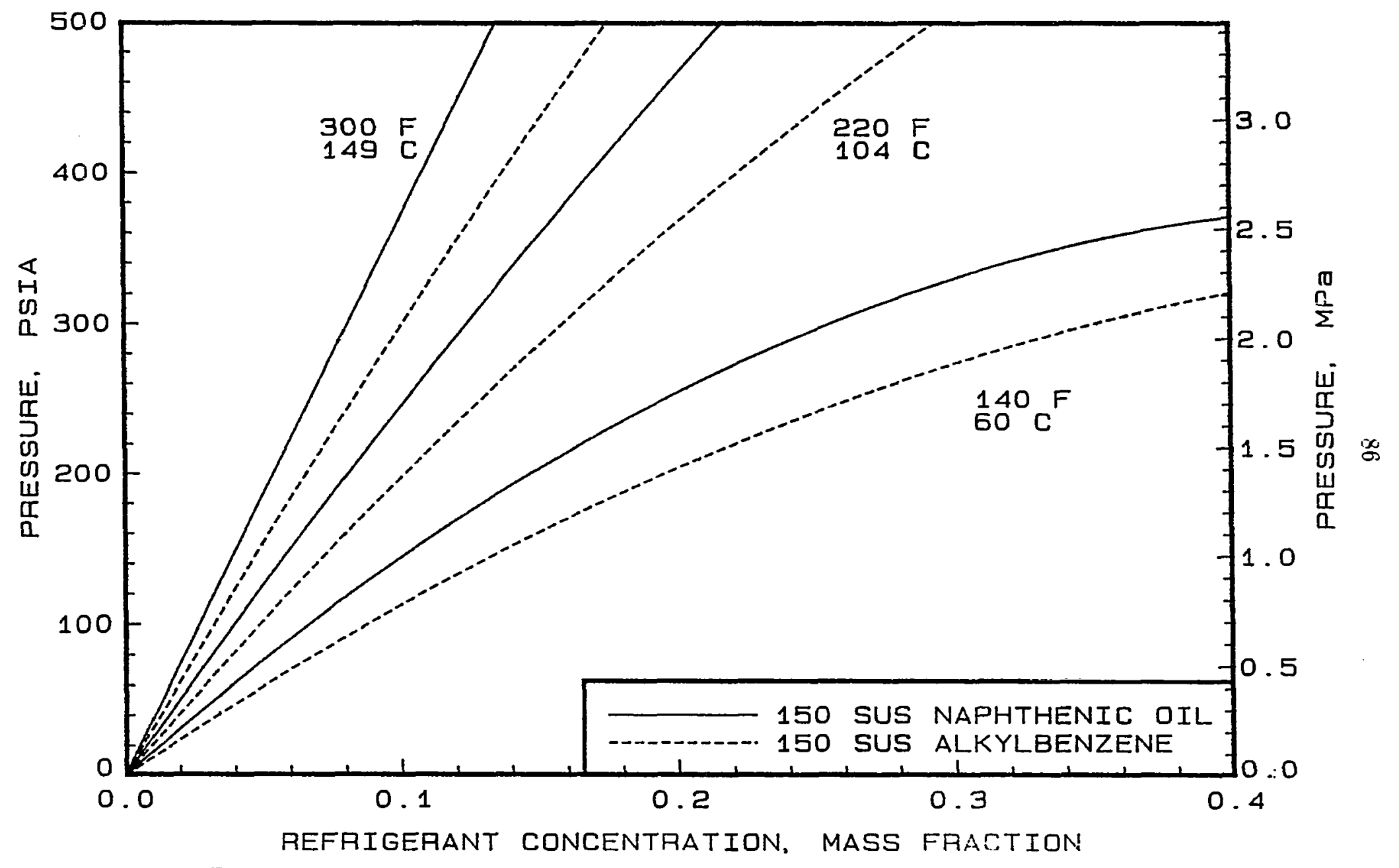

Figure 5.15: C'omparison of the solubility of R-502 in a 150 SUS naphthenic oil and in a 150 SUS alkylbenzene 


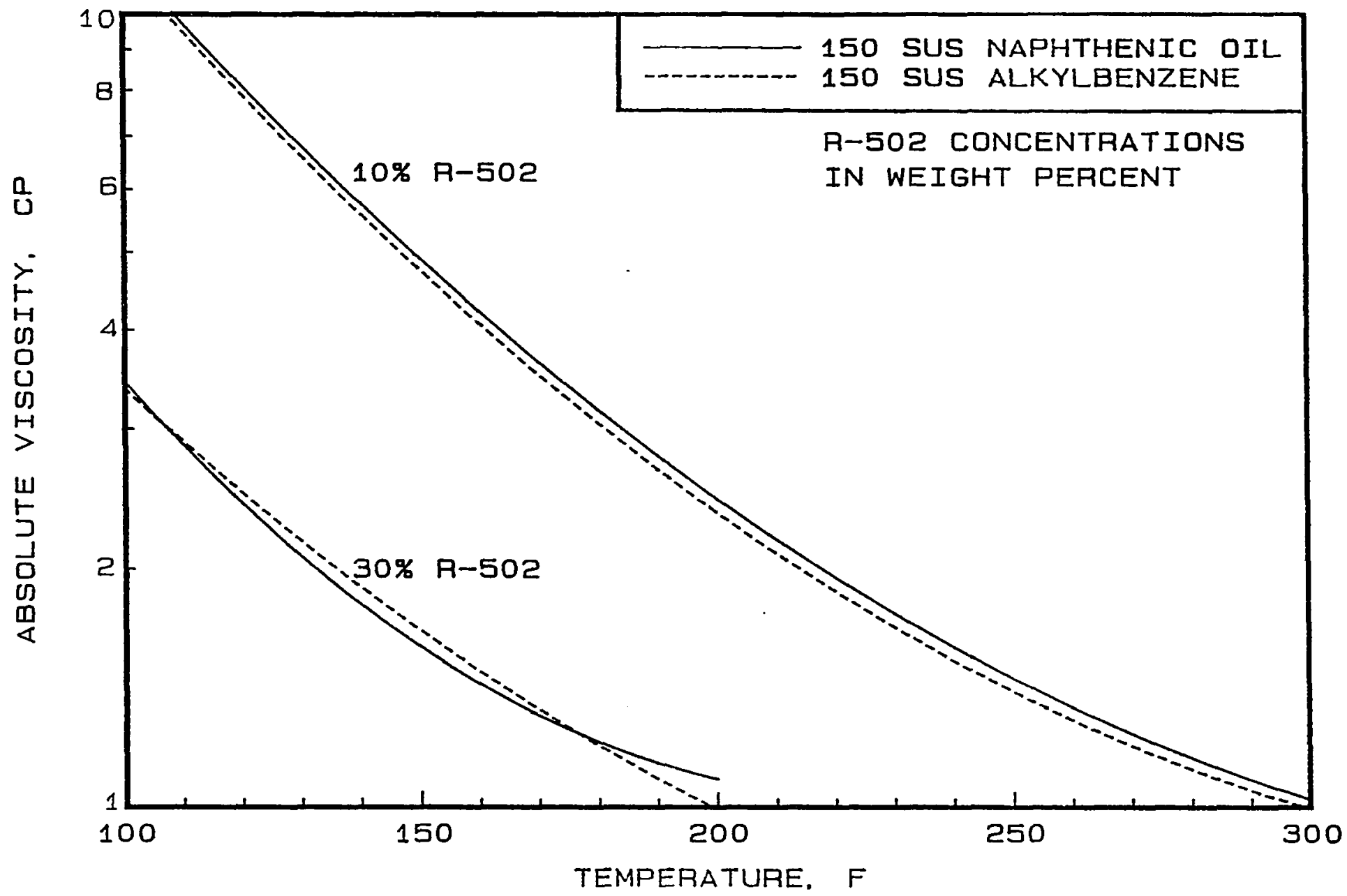

$\infty$

Figure 5.16: Comparison of the riscosity of R-502 in a $150 \mathrm{SUS}$ naphthenic oil and in a $1.50 \mathrm{SLiS}$ alkylbenzene 


\section{CHAPTER 6. CONCLUSIONS AND RECOMMENDATIONS}

A versatile oil/refrigerant test facility has been developed to provide critically needed property data, especially at high pressures and temperatures, for a wide variety of oil/refrigerant mixtures. Incorporating a commercially available viscometer, as well as windows for observation of the contents, it can be used for determination of the solubility, viscosity, density, and miscibility of these mixtures. Precise and convenient charging of mixtures with refrigerant compositions ranging from 0 to $100 \%$ is provided by a separate charging station. Operating temperature and pressure ranges for the test facility are $70^{\circ} \mathrm{F}\left(20^{\circ} \mathrm{C}\right)$ to $300^{\circ} \mathrm{F}\left(1.50^{\circ} \mathrm{C}\right)$, and 0 to .500 psia $(0$ to 3.5 $\mathrm{MPa}$ ), respectively. The viscosity measurement range is from $0.1 \mathrm{cp}$ to $200 \mathrm{cp}$, but this range may be readily extended, if necessary.

Experimental procedures for operation of the oil-refrigerant test facility have been described. Data reduction techniques, including the correlation equations and the "Daniel" plot, were outlined. Data have been presented which show that the instrumentation is accurate and that the test results are repeatable. The procedures have been successfully employed to obtain and present experimental results for mixtures of R-22 in a 150 SUS naphthenic oil and in a 150 SUS alkylbenzene lubricant as well as for mixtures of R-502 in both of these same oils.

Data for solutions of R-22 in both a 150 SUS naphthenic oil and a 150 SUS alkyl- 
benzene have been collected. These tests greatly extend the temperature range of previously available data for these two oil/refrigerant pairs, providing solubility and viscosity information for temperatures as high as $300^{\circ} \mathrm{F}\left(149^{\circ} \mathrm{C}\right)$ and for refrigerant mass fractions from 0 to $40 \%$, subject to a maximum pressure limitation of 500 psia (3.45 $\mathrm{MPa})$. The results are presented as solubility, viscosity, and density charts that give pressure, liquid viscosity, and liquid density, respectively, as functions of temperature and refrigerant concentration. Empirical correlating equations (applicable only over the range of data collected) that allow convenient interpolation of the data are also provided.

Data for solutions of R-502 in both a 150 SUS naphthenic oil and a 150 SUS alkylbenzene oil have been collected over an extended range of test conditions similar to those discussed above for R-22. The high temperature immiscibility expected of R-502/naphthenic oil solutions at refrigerant mass fractions greater than $30 \%$ was successfully observed. The solubility, viscosity, and density results for these solutions is presented in a manner similar to that of the $\mathrm{R}-22$ /oils results.

\section{Recommendations for Future Work}

As a result of the experience gained in the design and operation of the test facility, as well as in the data collection and correlation methods, several changes with the potential to improve and streamline the overall experimental operation have been envisioned. Recommendations for design modifications, procedural changes, and additional instrumentation are discussed below.

- Installation of an in-line densitometer in the auxiliary flow loop to eliminate the current need to use liquid volume and mass to calculate liquid density. 
Several manufacturers supply electronic mass flow meters that also provide an indication of density.

- Direct sampling of the liquid at each test condition may be desirable. As a review of the detailed calculations in Appendix B would show, this would eliminate the need to measure the height of the liquid-vapor interface which gives the vapor volume and, indirectly, the refrigerant concentration in the liquid. However, the sample mass should be small compared to the overall liquid mass, so that liquid compositions are not too greatly affected by the sampling process.

- Installation of a gas chromatograph would allow analysis of the vapor. Such an analysis would be useful in the study of solutions of azeotropes and/or blends in oils, especially if immiscibility is detected.

- Modifications in the design of the test cell to permit visibility of the lowest point in the volume of liquid, so that the presence of even a small amount of a second liquid phase indicating immiscibility does not go undetected. Extra wellplaced sampling ports would prove useful in determining the different refrigerant concentrations of each phase.

- Though earlier problems with seals have been solved with the current in-house design and manufacture of the windows and the proper choice of the necessary O-ring materials, others choosing to build a similar test facility may find commercially available pressure sight glasses to be more convenient to procure. In either case, the compatibility of any sealing materials with the intended test fluids must be investigated prior to purchase. 


\section{BIBLIOGRAPHY}

ASHRAE. 1986. ASHRAE handbook - 1986 Refrigeration Systems. Chap. 8. Atlanta: American Society of Heating, Refrigerating, and Air-Conditioning Engineers, Inc.

ASHRAE. 1989. ASHRAE handbook - 1989 Fundamentals, Chap. 17. Atlanta: American Society of Heating, Refrigerating, and Air-Conditioning Engineers. Inc.

ASHRAE. 1990. ASHRAE handbook - 1990 Refrigeration Systems, Chap. 8. Atlanta: American Society of Heating, Refrigerating, and Air-C'onditioning Engineers, Inc.

Baustian, J. J., M. B. Pate, and A. E. Bergles. 1988. "Measuring the concentration of a flowing oil-refrigerant mixture with a bypass viscometer." ASHRAE Transactions, Vol. 94, Pt. 2, pp. 588-600.

CAS. 1989. Cambridge Applied Systems viscosity-temperature sensor operations manual. Cambridge, MA: Cambridge Applied Systems, Inc.

Daniel, G., M.J. Anderson, W. Schmid, and M. Tokumitsu. 1982. "Performance of selected synthetic lubricants in industrial heat pumps." International Symposium on the Industrial Application of Heat Pumps, University of Warwick, U.K.

Glova, D.J. 1984. "High-temperature solubility of refrigerants in lubricating oil." ASHRAE Transactions, Vol. 90, Pt. 2B, pp. 806-825.

Holman, J.P. 1984. Experimental methods for engineers. Chap.3. New York: McGraw-Hill, Inc. 
IMSL. 1989. IMSL stat/library. Houston, TX: IMSL, Inc.

Kline, S.J., and F.A. McClintock. 1953. "Describing uncertainties in single sample experiments." Mechanical Engineering, Vol. 75, pp.3-8.

Reynolds, W.C. 1979. Thermodynamic properties in SI; graphs, tables, and computational equations for forty substances. Stanford, CA: Department of Mechanical Engineering, Stanford University.

Spauchus, H. O., and L. M. Speaker. 1987. "A review of viscosity data for oil-refrigerant solutions." ASHRAE Transactions, Vol. 93, Pt. 2. pp. 667-681.

Van Gaalen, N.A., M.B. Pate, and S.C. Zoz. 1990. "The measurement of solubility and viscosity of oil/refrigerant mixtures at high pressures and temperatures: Test facility and initial results for $\mathrm{R}-22$ /naphthenic oil mixtures." ASHRAE Transactions, Vol. 96, Pt. 2, pp. 183-190.

Van Gaalen, N.A., S.C. Zoz, and M.B. Pate. 1991. "The solubility and viscosity of solutions of HCFC-22 in a naphthenic oil and in an alkylbenzene at high pressures and temperatures." ASHRAE Transactions, Vol. 97, Pt. 1, pp. 100-108.

Van Gaalen, N.A., S.C. Zoz, and M.B. Pate. 1991. "The solubility and viscosity of solutions of R-502 in a naphthenic oil and in an alkylbenzene at high pressures and temperatures." ASHRAE Transactions, Vol. 97, Pt. 2, (to be published). 


\section{APPENDIX A. TEST FACILITY CONSTRUCTION DETAILS}

This appendix provides details of the construction of some elements of the test facility and lists the suppliers and approximate costs of the components which were procured. The schematic drawings given in Chapter 2, along with the drawings and lists of components given here, provide sufficient information for those who may wish to assemble a similar facility at another site. Additionally, C'hapter 6 discusses certain recommendations that, if adopted, would result in modifications to the test facility and, hence, to the information presented here and in C'hapter 2.

Detailed construction information for the test cell is presented in the Figures A.1 through A.3, which are working drawings of the cell and its components as manufactured "in-house" at the I.S.U. Engineering Research Institute Machine Shop. Figure A.1 is a drawing of the basic structure of the pressure vessel, providing design details sufficient to build the test cell except for the windows. Figures A.2 and A.3 together provide manufacturing details for the components of the windows and their assembly with the test cell.

DISCLAIMER: Because these drawings illustrate the details of manufacture for the test cell after several necessary design changes were implemented, some relaxation of traditional pressure vessel safety margins has occurred. It is highly recommended that a full review of the design details occur prior to construction of any new test cell 
based on these plans, and that the cell be hydrostatically tested. ASME code requires that unfired pressure vessels of this type be hydrostatically tested to at least $1.50 \%$ of the maximum working pressure. The current test cell has been hydrostatically tested to 650 psia and was never operated above 520 psia, and then only to test the pressure relief valve. Typically, the maximum pressure experienced in the tests reported here was 475 psia.

Suppliers and approximate costs for the components of the oil/refrigerant test facility and for the oil/refrigerant charging station are outlined in Tables A.I and A.2, respectively. These tables, along with diagrams and discussion provided in Chapter 2, provide the information needed to construct similar equipment, without constraining the arrangement of the components in unintended ways with detailed assembly drawings of all the fittings and supporting structures. The approximate total cost of the components listed is $\$ 36.000 .00$.

The overall project costs involve not only the component costs, but also the costs of labor to design, order, and construct the test facility. Since labor costs vary between institutions, they are not estimated here. Instead an estimate of labor time is provided so that labor costs may be determined from it by application of the appropriate wage and overhead rates. It is anticipated that given the information presented here, further design and the necessary construction to complete the facility would take six to eight person-months. Continued operation of the facility, including data reduction and analysis, on a daily basis would require the equivalent of a full time staff position. 


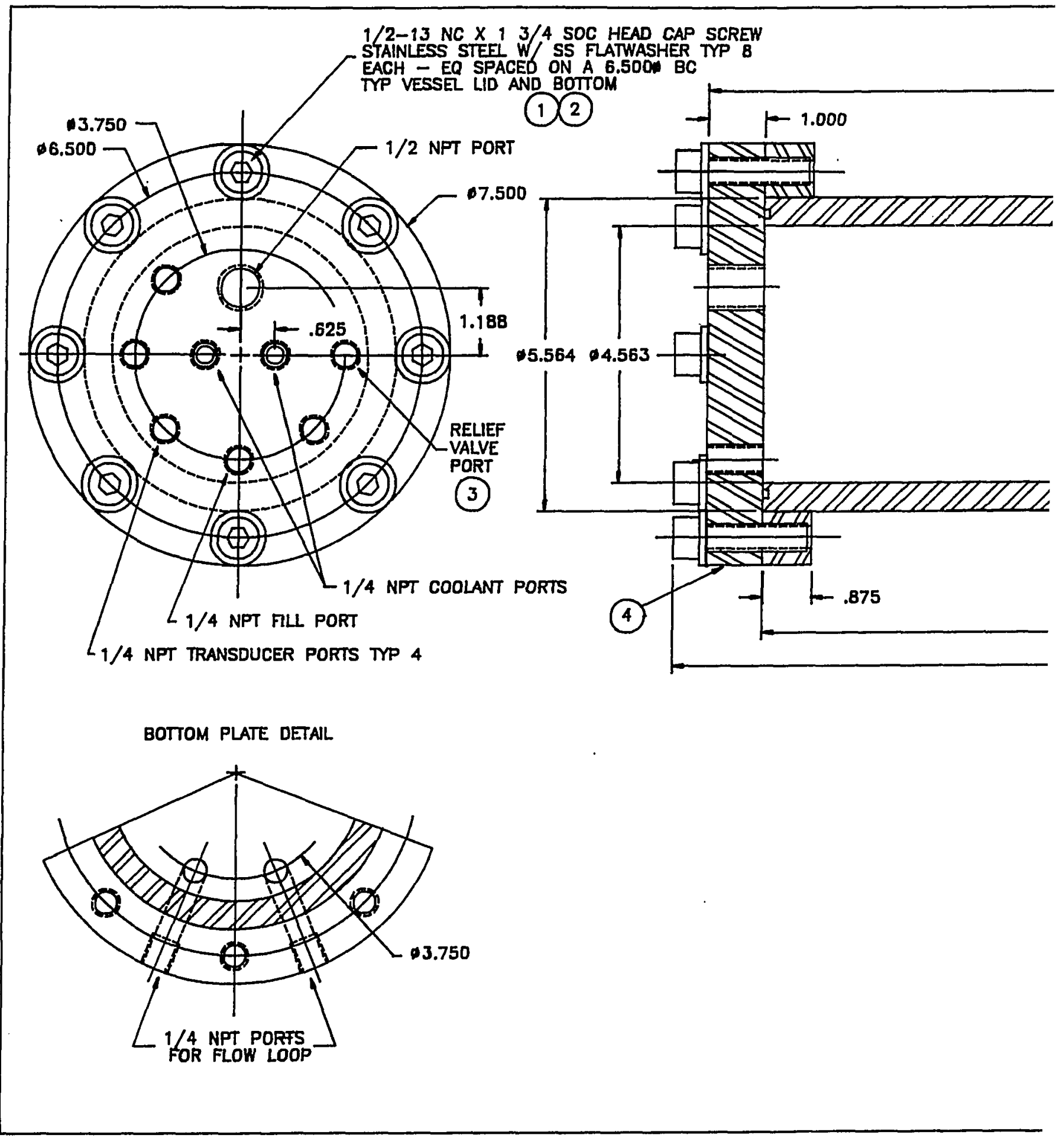

Figure A.1: Working drawing of pressure vessel 


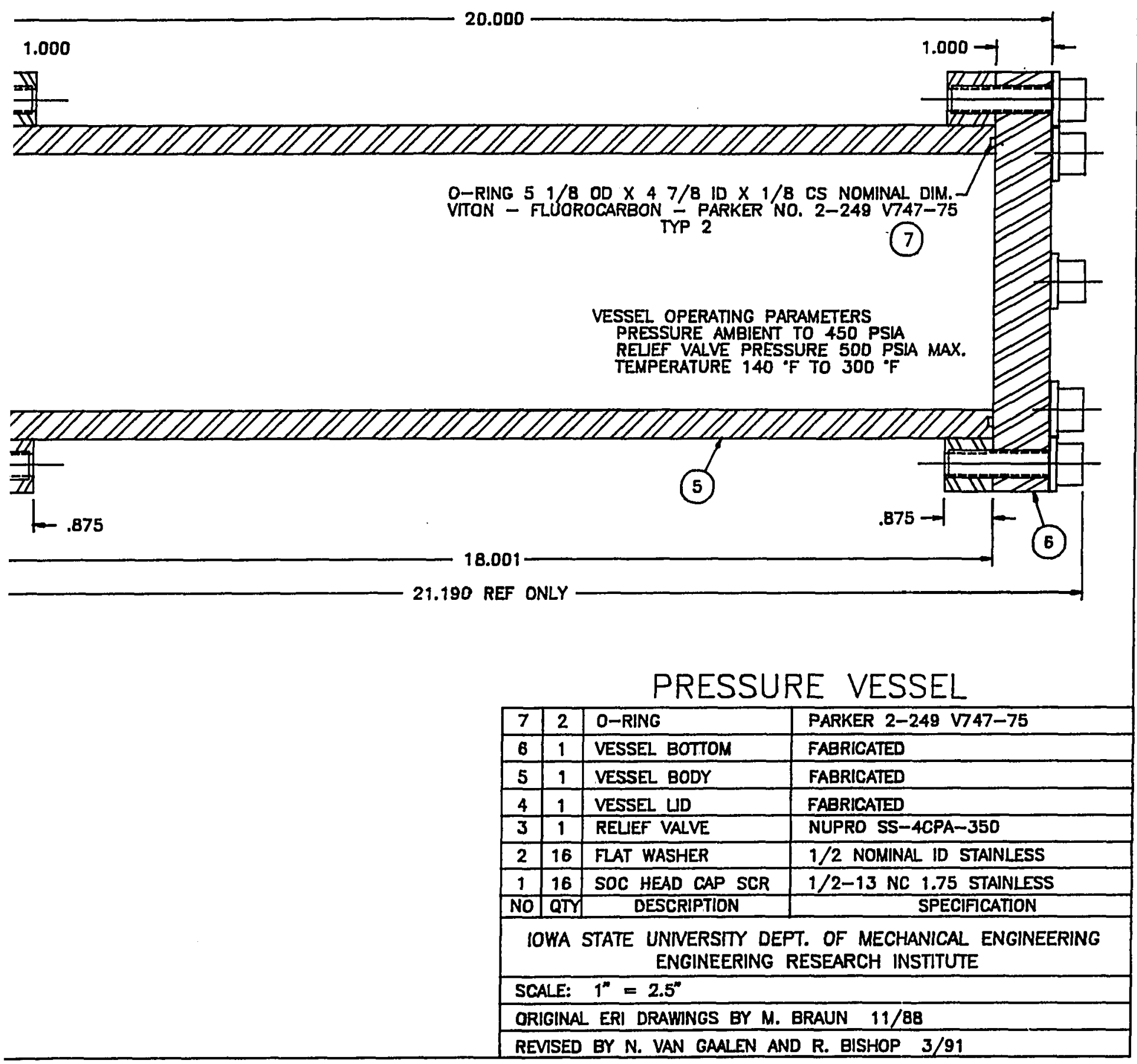


96

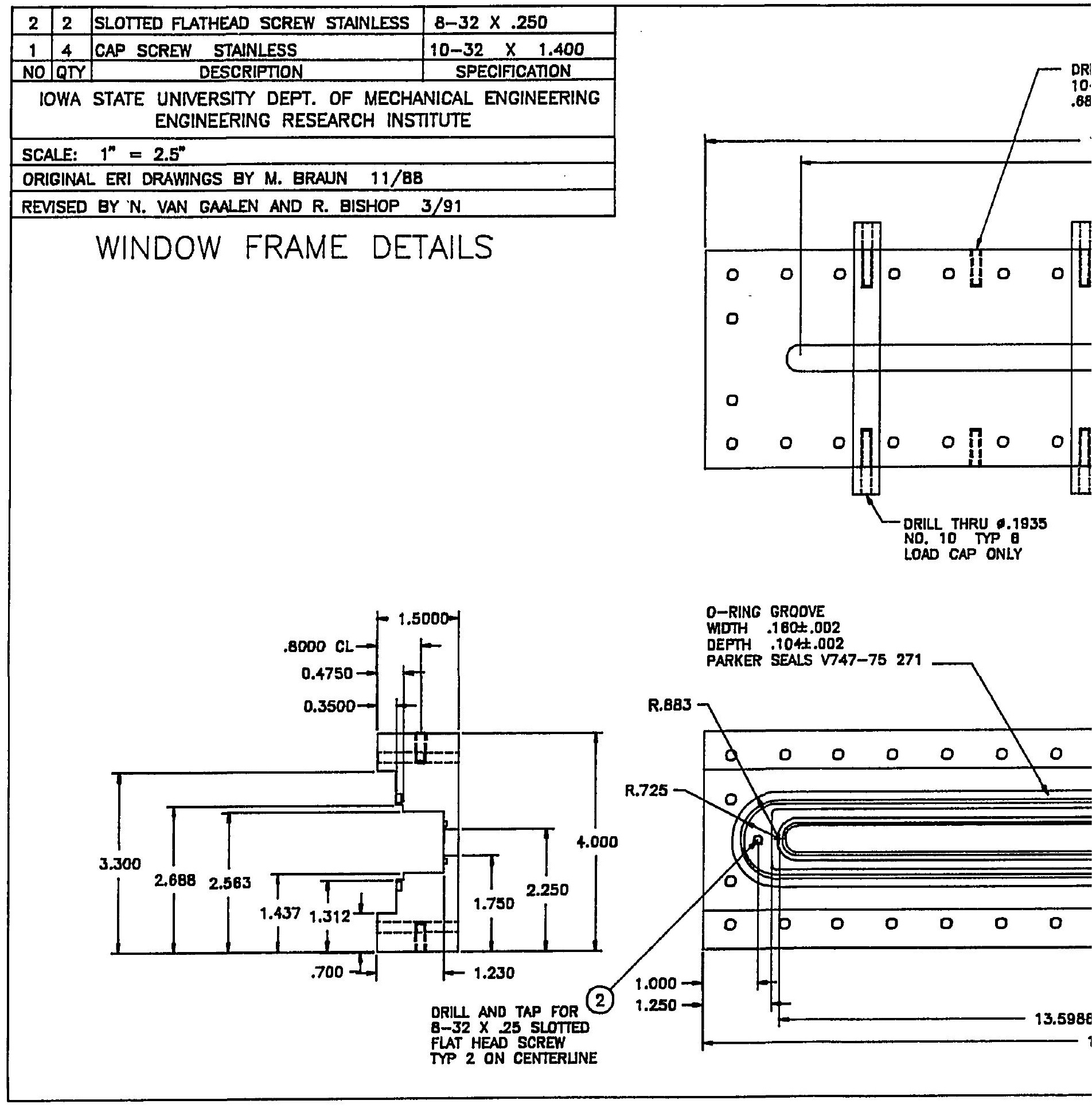

Figure A.2: Window frame details 
, 

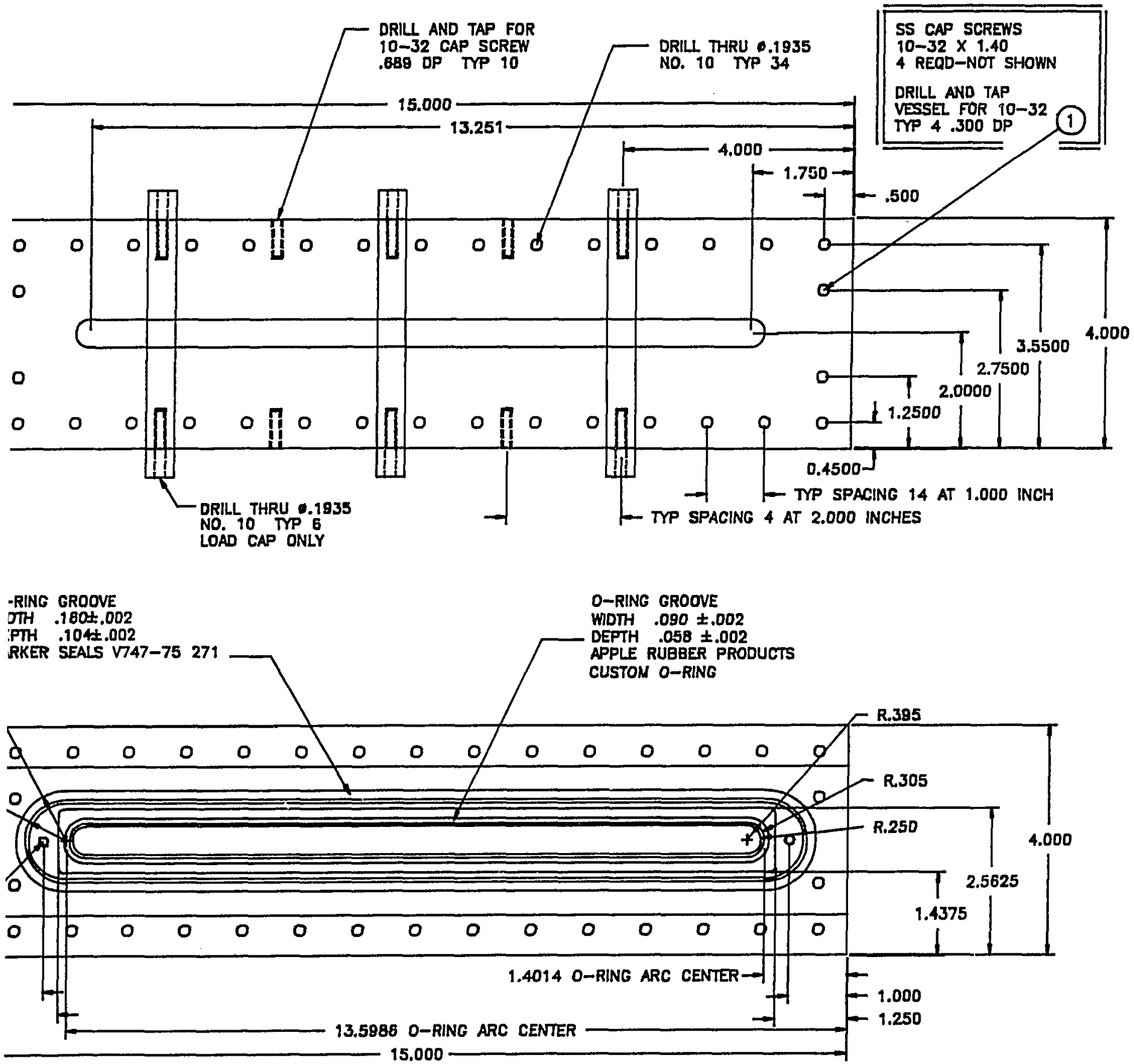



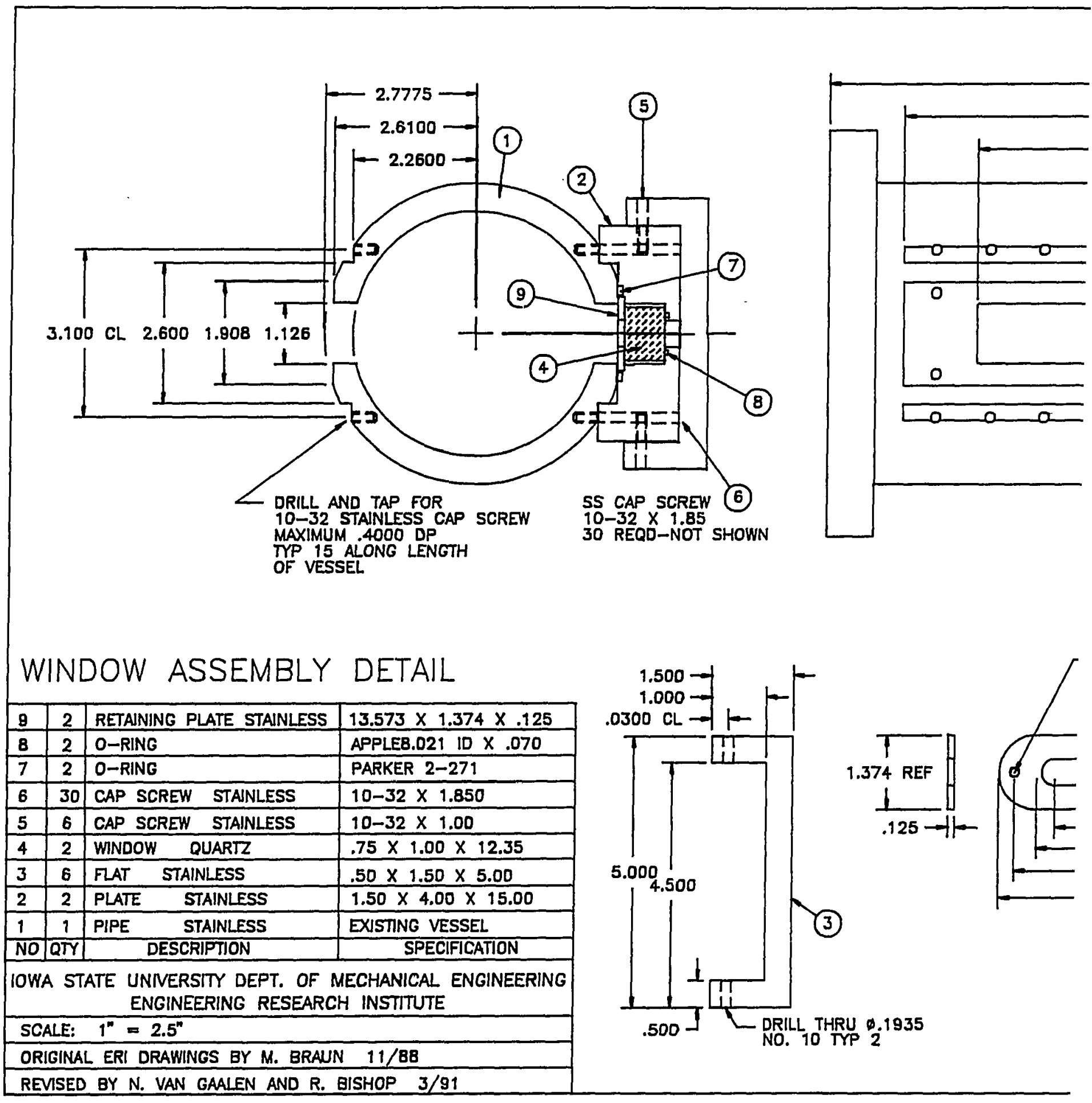

Figure A.3: Window assembly details 

Table A.1: List of test facility components

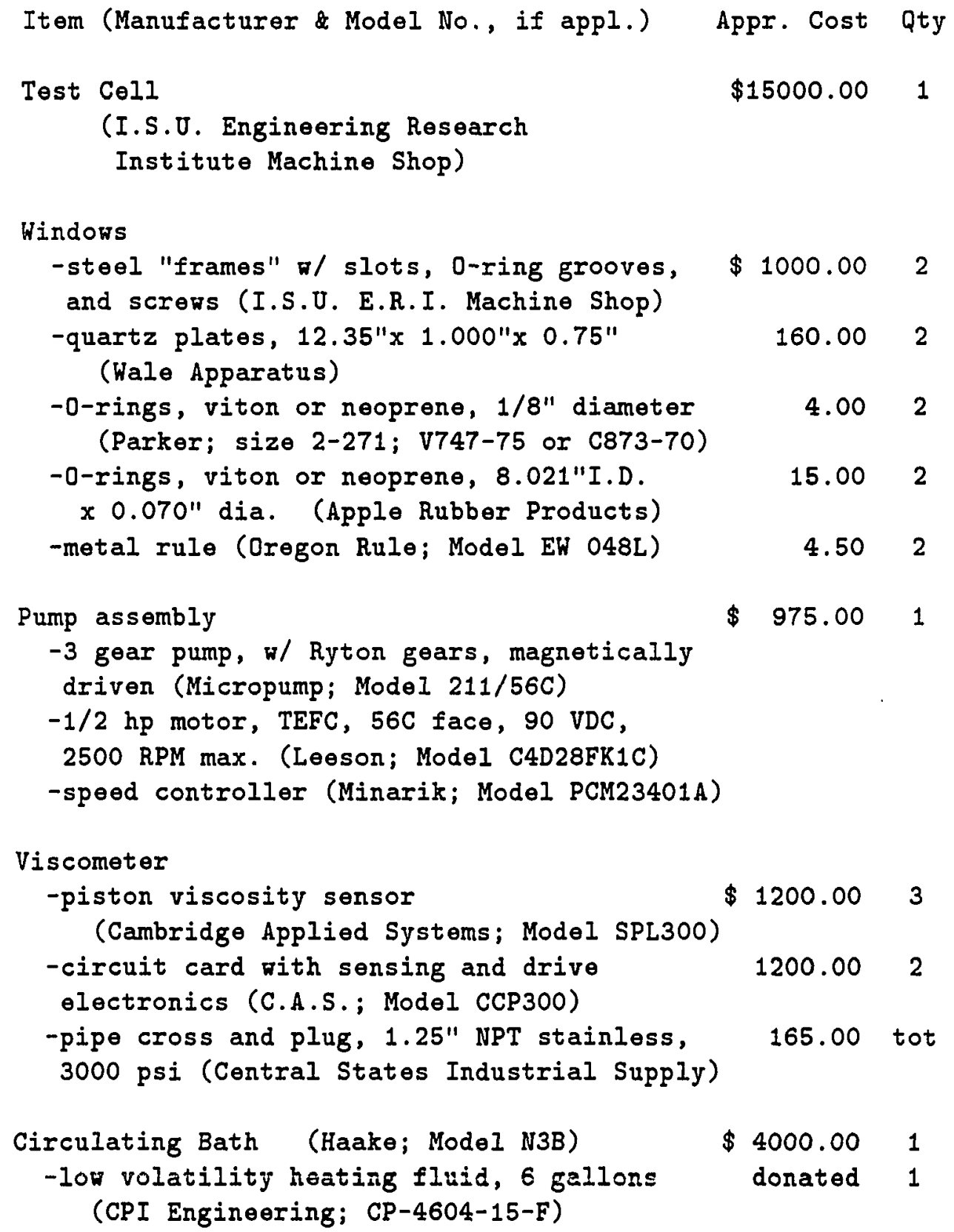


Table A.1 (Continued)

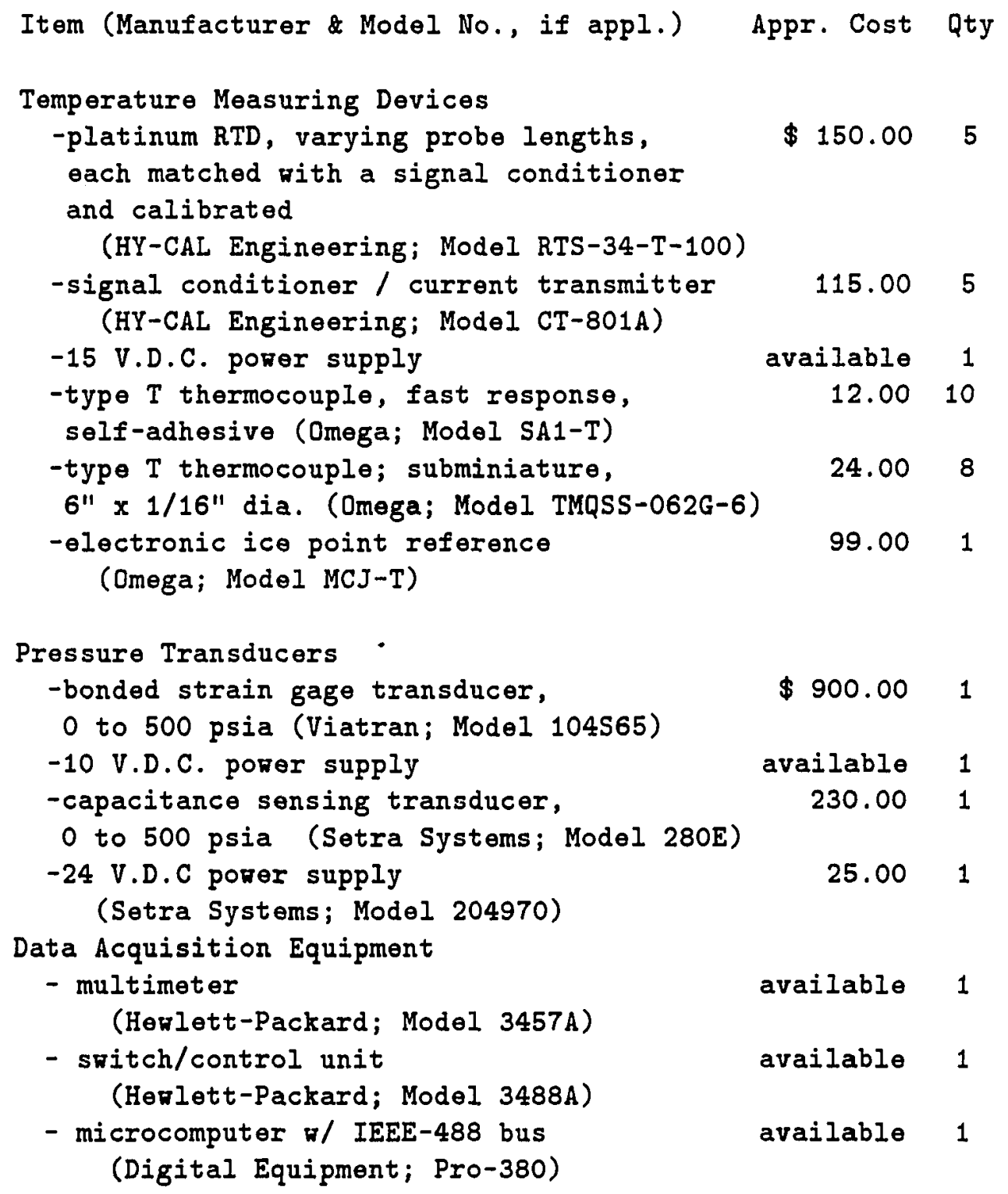


Table A.1 (Continued)

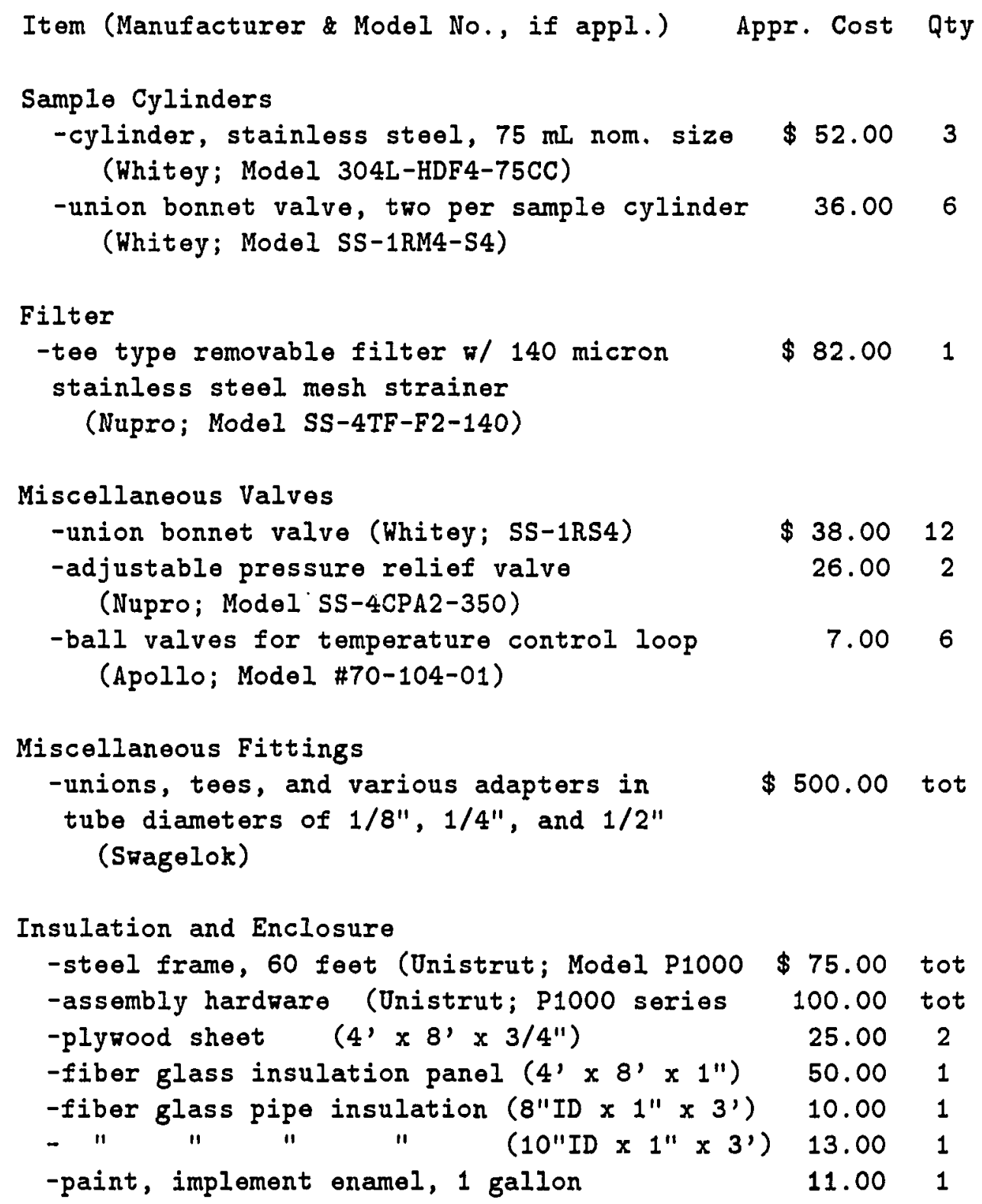


Table A.2: List of charging station components

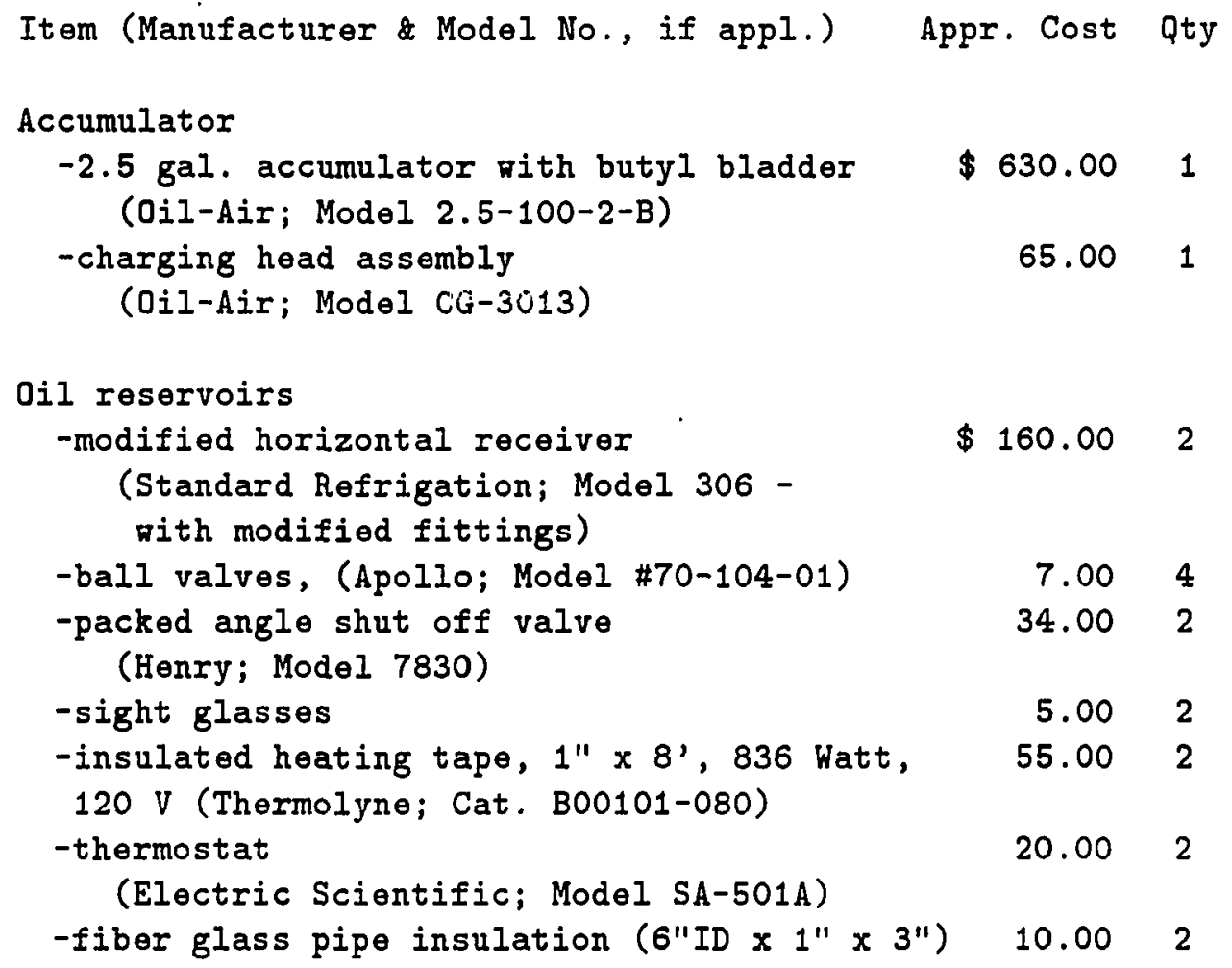

$\$ 70.002$

$25.00 \quad 2$

$\$ 173.001$

$\$ 12.50 \quad 4$

$15.50 \quad 1$ 
Table A.2 (Continued)

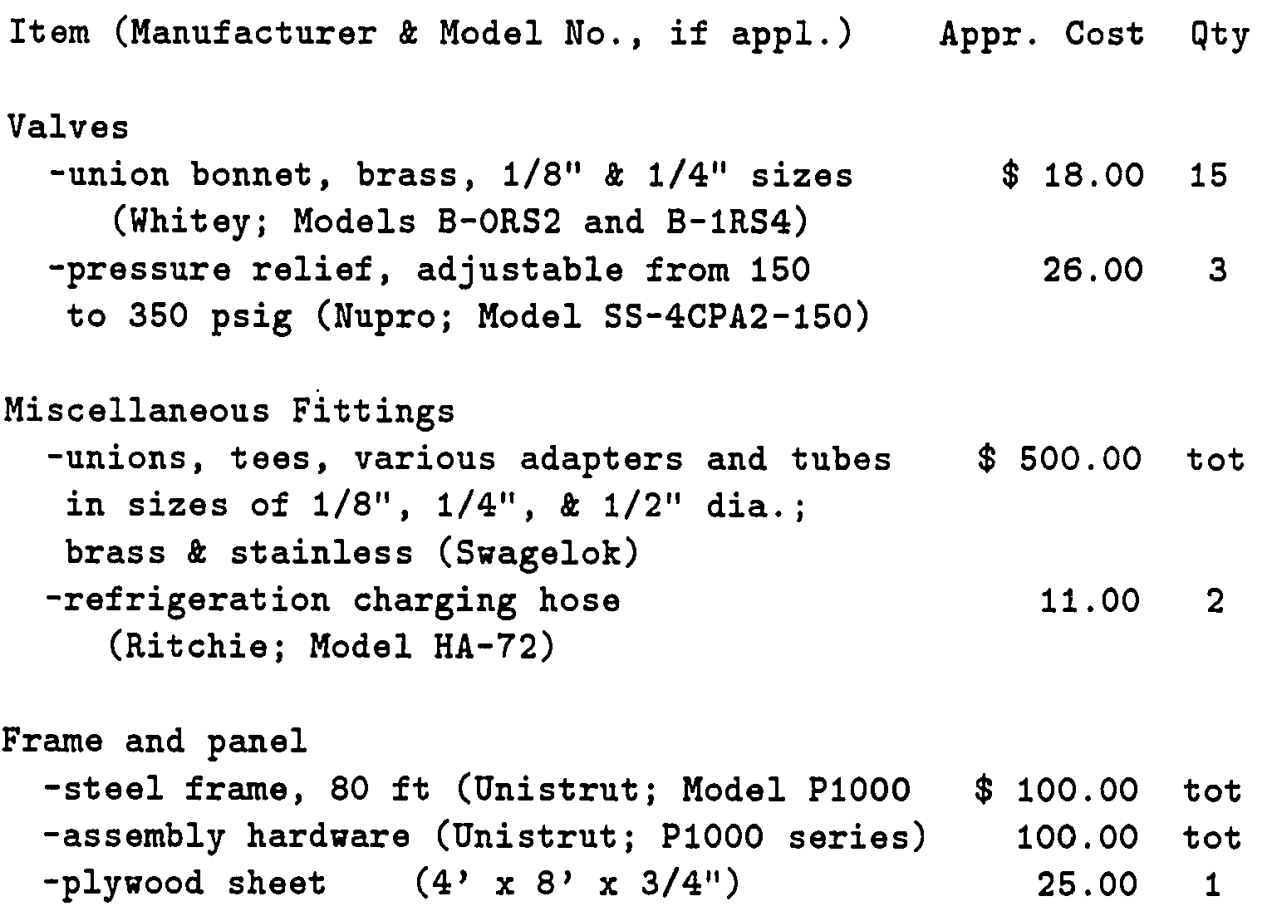




\section{APPENDIX B. UNCERTAINTY ANALYSIS}

The experimental uncertainties applicable to the data presented in this report are determined in several ways. The uncertainties of the measured values of pressure. temperature, and viscosity are determined from a consideration of the uncertainties of the output voltage measurements and the calibration equations for each device. The propagation of error method originally presented by Kline and McClintock (1953) and discussed by Holman (1984) is used to estimate the uncertainties of the liquid density and composition. Details of these determinations are provided in the following sections.

\section{Uncertainties of the Pressure, Temperature, and Viscosity Data}

The pressure, temperature, and viscosity sensors all produce output voltages which are channelled to a Hewlett-Packard $3457 \mathrm{~A}$ multimeter capable of d.c. voltage measurements to within 1 microvolt. If the transducers were all perfectly accurate, this voltage measurement uncertainty would translate to extremely low uncertainties of the pressure, temperature, and viscosity. However, non-linearities inherent in the transducers cause some uncertainty of these measurements. 


\section{Uncertainty of the pressure data}

The calibration equation for the bonded strain gage pressure transducer is

$$
P=20.067 \cdot V+0.1685
$$

where $P$ is the pressure in psia and $V$ is the output voltage in $\mathrm{mV}$. Thus, an output voltage uncertainty of 1 microvolt $(0.001 \mathrm{mV})$ would result in an uncertainty of the pressure of about 0.02 psia. This value, however, is much less than the uncertainty of the pressure due to the non-linearity (or inaccuracy) of the transducer itself as specified by the manufacturer. For this transducer, the manufacturer's specification on non-linearity is $0.15 \%$ of full scale output, or $0.0375 \mathrm{mV}$. This translates to an uncertainty of the pressure of 0.75 psia, which is far greater than the uncertainty arising from the voltage measurement system. Therefore, for this transducer, the uncertainty of the pressure is taken to be 0.75 psia.

By a similar argument, the uncertainty of the pressure data from the capacitance sensing pressure transducer is 0.55 psia. The reported pressure at each test condition is the average of the two pressure readings, with a resulting (root mean square) uncertainty of 0.47 psia.

\section{Uncertainty of the temperature data}

Temperature data are collected from platinum resistance thermometer devices (RTDs) matched with linearizing signal conditioners. Each signal conditioner produces a current output signal of 4 to $20 \mathrm{~mA}$ corresponding to the desired temperature span. This signal is read as a voltage drop of 1 to 5 volts across a load resistor. For these signal conditioners, the calibrated accuracy is $0.05 \%$ of the temperature span, 
which was specified to be $200^{\circ} \mathrm{C}$. or $360^{\circ} \mathrm{F}$ (from $-60^{\circ} \mathrm{F}$ to $300^{\circ} \mathrm{F}$ ), when ordered from the manufacturer. Since previous discussion has shown that the uncertainty of

the voltage measurement system is negligible, the uncertainty is taken as the $0.1^{\circ} \mathrm{C}$ $\left(0.2^{\circ} \mathrm{F}\right)$ due to the signal conditioner accuracy.

\section{Uncertainty of the viscosity data}

The uncertainty of the viscosity data is specified by the manufacturer to be $2 \%$ of the individual reading. For the most frequently used sensor, which outputs a voltage of 0.1 to 2 volts corresponding to the viscosity range of 1 to 20 centipoise, the resulting uncertainties of the individual readings vary from 0.02 to $0.4 \mathrm{cp}$. The reported viscosity at each test condition is the mean of 20 successive viscosity readings for which the minimum acceptable scatter, defined as the standard deviation divided by the mean, is $1 \%$. Again, the voltage measurement system uncertainty of 1 microvolt is negligible.

\section{Uncertainty of the Liquid Density}

As stated earlier, the uncertainty of the liquid density and composition is estimated using the propagation of error method proposed by Kline and McClintock for results derived from single-sample data. For a function $f=f(x, y, z, \ldots)$, the uncertainty of $f$ can be estimated by the following general propagation equation:

$$
W_{f}=\sqrt{\left(\frac{\partial f}{\partial x} W_{x}\right)^{2}+\left(\frac{\partial f}{\partial y} W_{y}\right)^{2}+\left(\frac{\partial f}{\partial z} W_{z}\right)^{2}+\ldots}
$$

where $W_{x}, W_{y}$, and $W_{z}$ are the uncertainties in the variables $x, y$, and $z$, all given with the same probability. In the special case where the function is a product or 
ratio of these terms, for example, $f=x \cdot y / z$, then the relative uncertainty may be expressed in a more convenient form:

$$
\frac{W_{f}}{f}=\sqrt{\left(\frac{W_{x}}{x}\right)^{2}+\left(\frac{W_{y}}{y}\right)^{2}+\left(\frac{W_{z}}{z}\right)^{2}}
$$

Both of the above forms of the propagation equation are employed in the following analysis.

The basic equation for the density of the liquid is

$$
\rho_{L}=\frac{m_{L}}{V_{L}}
$$

where $m_{L}$ is the mass of the liquid in the cell and $V_{L}$ is the volume that the liquid occupies. The relative uncertainty of $\rho_{L}$ is

$$
\frac{W_{\rho_{L}}}{\rho_{L}}=\sqrt{\left(\frac{W_{m_{L}}}{m_{L}}\right)^{2}+\left(\frac{W_{V_{L}}}{V_{L}}\right)^{2}}
$$

where $W_{m}$ and $W_{V_{L}}$ are the uncertainties of the mass of the liquid in the cell and of the liquid volume, respectively. These uncertainties are calculated in the following sections. Determination of $W_{V_{L}}$ is more straightforward and is discussed first. Following this, a propagation of error method is used to calculate $W_{m}$ for an example case.

\section{Uncertainty of the liquid volume}

The calibration equation for the liquid volume as a function of the liquid - vapor interface level, $h$, is

$$
V_{L}=274.66 \cdot h-4393.6
$$

where $V_{L}$ is in milliliters $(\mathrm{mL})$ and $h$ is the liquid level reading in inches, measured using a steel scale attached to the window of the cell. An arbitrary reference value 
of 20 " has been assigned to the very bottom of the 12 -inch long window slot. and. therefore, the scale reads 32 " at the top of the window. This scale is ruled in sixteenths of an inch. Thus, the uncertainty in the level reading, $W_{h}$, is approximately 0.031 inch, with a corresponding uncertainty of the liquid volume of $W_{L}=274.26 \cdot W_{h}$ $=8.6 \mathrm{~mL}$.

\section{Uncertainty of the liquid mass}

The determination of the uncertainty of the mass of liquid in the cell is complicated by the successive additions and sample withdrawals that are made as the refrigerant concentrations are changed during the course of a typical test run. Thus. the total mass of liquid in the test cell at any particular test condition is

$$
m_{L}=m_{O, i n j}+m_{R, i n j}-m_{S}-m_{R, V}
$$

where $m_{O, i n j}$ is the mass of oil injected at the start of testing, $m_{R, i n j}$ is the sum of the masses of initial and subsequent injections of refrigerant into the cell, $m_{S}$ is the total mass of liquid removed from the cell due to sampling since the initial injections of oil and/or refrigerant, and $m_{R, V}$ is the mass of the vapor (which is assumed to be pure refrigerant). The uncertainty of the mass of the liquid is then:

$$
W_{m_{L}}=\sqrt{\left(W_{m_{O, i n j}}\right)^{2}+\left(W_{m_{R, i n j}}\right)^{2}+\left(W_{m_{S}}\right)^{2}+\left(W_{m_{R, V}}\right)^{2}}
$$

The four terms contributing to $W_{m_{L}}$ are examined in turn for the following example test situation. 
History:

- Test run beginning with pure alkylbenzene

- Refrigerant-22 added in 4 separate injections to allow testing at liquid compositions of $10 \%, 20 \%, 30 \%$, and $40 \%$ refrigerant mass fraction

- One sample withdrawn at the end of testing of each composition including pure oil

Current conditions:

- Liquid composition: $x_{R}=41.4 \%$ (refrigerant mass fraction)

- Liquid level: $h=29.78^{\prime \prime}$ at $57.4^{\circ} \mathrm{C}$

- Liquid and vapor volumes: $V_{L}=3774 \mathrm{~mL} ; V_{V}=1413 \mathrm{~mL}$

- Vapor conditions: $P=1.846 \mathrm{MPa}$ at $59.3^{\circ} \mathrm{C}$

- Total oil injected: $m_{O, i n j}=2375 \mathrm{~g}$

- Total refrigerant injected: $m_{R, i n j}=1650 \mathrm{~g}$

- Room temperature density of oil: $\rho_{O}=0.87 \mathrm{~g} / \mathrm{mL}$

- Room temperature density of liquid R-22: $\rho_{R . L}=1.210 \mathrm{~g} / \mathrm{mL}$

- Total liquid removed in prior samplings: $m_{S}=292 \mathrm{~g}$

Oil and refrigerant portions: $m_{O, S}=247 \mathrm{~g} ; m_{R, S}=45 \mathrm{~g}$

- Contents remaining: $m_{O}=2128 \mathrm{~g} ; m_{R}=1605 \mathrm{~g}$

- Refrigerant distribution: $m_{R, L}=1500 \mathrm{~g} ; m_{R, V}=105 \mathrm{~g}$

Uncertainty of the mass of oil injected: The mass of oil injected is

$$
m_{O, i n j}=V_{O} \cdot \rho_{O}
$$

where $V_{O}$ is the volume of oil injected at room temperature and $\rho_{O}$ is the density of the pure oil at room temperature. The relative uncertainty of the mass of oil injected is

$$
\frac{W_{m_{O, i n j}}}{m_{O, i n j}}=\sqrt{\left(\frac{W_{V_{O}}}{V_{O}}\right)^{2}+\left(\frac{W_{\rho_{O}}}{\rho_{O}}\right)^{2}}
$$


Now $V_{O}=H \cdot F$, where $H$ is the total stroke, in inches, of the injection cylinder to give the full amount of oil injected, and $F$ is the calibrated volume displacement per inch of stroke. $F=51.15 \mathrm{~mL} /$ inch for the cylinder used for the oil injection. The uncertainty of the volume of oil injected is $W_{V_{O}}=F \cdot W_{H}$, where $W_{H}$ is the uncertainty of $H$. For this example, $2375 \mathrm{~g}(2730 \mathrm{~mL})$ of oil are injected, requiring five separate fill-and-discharge cycles of the injection cylinder. The associated total uncertainty is

$$
W_{H}=\sqrt{5\left[\left(W_{h_{s}}\right)^{2}+\left(W_{h_{e}}\right)^{2}\right]}
$$

where $W_{h_{s}}$ and $W_{h_{e}}$ are the uncertainties of the positions of the injection cylinder piston at the start and at the end, respectively, of each of the five injection cycles. Since the scales used with the injection cylinders are calibrated in sixteenths of an inch, both $W_{h_{s}}$ and $W_{h_{e}}$ are about 0.031 inch. Therefore, $W_{H}$ is approximately 0.1 inch, and the resulting uncertainty of the volume of oil injected, $W_{V_{O}}$, is $5.1 \mathrm{~mL}$.

Further, it is estimated that $\rho_{O}$ at room temperature is known to within $W_{P_{O}}$ $=0.005 \mathrm{~g} / \mathrm{mL}$. Equation B.10 can now be solved to give $W_{m_{0, i n j}}=14.4 \mathrm{~g}$.

Uncertainty of the mass of refrigerant injected: The mass of refrigerant injected and the uncertainty of that mass arising from successive injections of refrigerant is calculated in a manner similar to that for the oil injection.

$$
\begin{gathered}
m_{R, i n j}=V_{R, i n j} \cdot \rho_{R, L} \\
\frac{W_{m_{R, i n j}}}{m_{R, i n j}}=\sqrt{\left(\frac{\left.W_{V_{R, i n j}}\right)^{2}+\left(\frac{W_{\rho_{R, L}}}{V_{R, i n j}}\right)^{2}}{\rho_{R, L}}\right.}
\end{gathered}
$$

For the example case, 5 fill-and-discharge cycles of the refrigerant injection cylinder are required to successively test the five different compositions from pure oil to $40 \%$ 
refrigerant. This fact results in a similar injection volume uncertainty as that for the oil. Thus, $W_{V_{R, i n j}}=5.1 \mathrm{~mL}$.

The uncertainty of the density of the refrigerant liquid (injected as slightly compressed liquid at room temperature) is conservatively estimated as $W_{P R, L}=0.002$ $\mathrm{g} / \mathrm{mL}$. For the example case, $\rho_{R, L}=1.210 \mathrm{~g} / \mathrm{mL}$ and $V_{R, i n j}=1364 \mathrm{~mL}$. The uncertainty of the total mass of refrigerant charged is calculated by substituting the above into Eq. B.13: $W_{m_{R, i n j}}=6.8 \mathrm{~g}$.

Uncertainty of the mass withdrawn in sampling: Most of the mass of liquid withdrawn from the test cell in an individual sampling is contained in the sampling chamber, but a small amount is also trapped in the short lengths of tubing between the pairs of isolation valves on either side of the sample chamber. When the sampling chamber is removed, this small amount of trapped liquid is decompressed, refrigerant vapor evolves from it, and the rest of the liquid is drained and "lost". The mass of liquid in the sample chamber is simply determined by subtracting the mass of the clean, evacuated sample chamber from the mass of the full chamber prior to venting the contents. Thus, the total amount of liquid removed from the test cell for each sampling operation is

$$
m_{s, i}=m_{\text {samp }, i}+m_{\text {lost }, i}=m_{f u l l, i}-m_{\text {evac }, i}+m_{\text {lost }, i}
$$

The uncertainty of the mass of liquid removed during each sampling is then

$$
W_{m_{s, i}}=\sqrt{\left(W_{m_{f u l l, i}}\right)^{2}+\left(W_{m_{\text {evac }, i}}\right)^{2}+\left(W_{m_{l o s t}, i}\right)^{2}}
$$

For the example case, a total of four samples have been withdrawn prior to the current test situation. The uncertainty of the total mass withdrawn from the test 
cell is therefore

$$
W_{m_{S}}=\sqrt{4\left[\left(W_{m_{f u l l, i}}\right)^{2}+\left(W_{m_{\text {evac }, i}}\right)^{2}+\left(W_{m_{\text {lost }, i}}\right)^{2}\right]}
$$

The electronic balance used in the tests is capable of determining mass to within $0.01 \mathrm{~g}$, so that $W_{m}$ full,i $=W_{m_{\text {evac }, i}}=0.01 \mathrm{~g}$ at most.

The mass of the "lost" fluid must be determined from the calculated density of the sample and the volume of liquid in the tubing between the two isolation valves on each side of the sampling chamber:

$$
m_{\text {lost }, i}=V_{\text {lost }} \cdot \rho_{\text {samp }, i}
$$

Thus,

$$
\frac{W_{m_{\text {lost }, i}}}{m_{\text {lost }, i}}=\sqrt{\left(\frac{W_{V_{\text {lost }}}}{V_{\text {lost }}}\right)^{2}+\left(\frac{W_{\rho_{\text {samp }, i}}}{\rho_{\text {samp }, i}}\right)^{2}}
$$

Now $V_{\text {lost }}$ is approximately $5 \mathrm{~mL}$ and $W_{V_{\text {lost }}}$ is estimated to be $0.5 \mathrm{~mL}$. The density of the sample is calculated from the mass and volume of the particular sample:

$$
\rho_{\text {samp }, i}=\frac{m_{\text {samp }, i}}{V_{\text {samp }, i}}
$$

The relative uncertainty of this liquid density is

$$
\frac{W_{\rho_{s a m p, i}}}{\rho_{\text {samp }, i}}=\sqrt{\left(\frac{W_{m_{s a m p, i}}}{m_{\text {samp }, i}}\right)^{2}+\left(\frac{W_{V_{s a m p, i}}}{V_{s a m p, i}}\right)^{2}}
$$

It can be inferred from Equations B.14 and B.15 that

$$
W_{m_{s a m p, i}}=\sqrt{\left(W_{m_{f u l l, i}}\right)^{2}+\left(W_{m_{\text {evac }, i}}\right)^{2}}
$$

so the uncertainty of the sample mass would be no more than $0.014 \mathrm{~g}$. $W_{V_{s a m p, i}}$ is estimated to be $0.2 \mathrm{~mL}$. If, for example, $V_{s a m p, i}$ is $75 \mathrm{~mL}$, and $m_{s a m p, i}$ is approximately $70 \mathrm{~g}$, then $\rho_{s a m p, i}$ is $0.93 \mathrm{~g} / \mathrm{mL}$. Thus, $W_{\rho_{s a m p, i}}=0.0025 \mathrm{~g} / \mathrm{mL}$. With 
these results, the liquid "lost" in the fittings is approximately $4.7 \mathrm{~g}$ and Eq. B.18 yields $W_{m_{l o s t, i}}$ approximately equal to $0.5 \mathrm{~g}$, conservatively estimated. An estimate of the uncertainty of the total mass withdrawn from the test cell after four sampling operations can now be estimated using Eq. B.16: $W_{m_{S}}=1.0 \mathrm{~g}$.

Uncertainty of the mass of the vapor: In the tests reported on in this work, the vapor above the oil-refrigerant solution is assumed to be pure refrigerant. The mass of the vapor can then be calculated from the volume of the vapor space. $V_{V}$, and the density of the pure refrigerant vapor, $\rho_{R, V}$, at the temperature and pressure of the vapor:

$$
m_{R, V}=V_{V} \cdot \rho_{R, V}
$$

The relative uncertainty of $m_{R, V}$ is

$$
\frac{W_{m_{R, V}}}{m_{R, V}}=\sqrt{\left(\frac{W_{V_{V}}}{V_{V}}\right)^{2}+\left(\frac{W_{\rho_{R, V}}}{\rho_{R, V}}\right)^{2}}
$$

Now $W_{V}$, the uncertainty of the vapor volume, is related to the uncertainty of the height of the liquid-vapor interface that was discussed previously in the subsection on liquid volume, i.e., $W_{V_{V}}=W_{V_{L}}=8.6 \mathrm{~mL}$.

The refrigerant vapor density is a function of temperature and pressure, and is calculated using a computerized property routine. An estimate of the uncertainty of the vapor density requires the partial derivatives of the vapor density with respect to both pressure and temperature, as follows:

$$
W_{\rho_{R, V}}=\sqrt{\left(\frac{\partial \rho_{R, V}}{\partial P} W_{P}\right)^{2}+\left(\frac{\partial \rho_{R, V}}{\partial T} W_{T}\right)^{2}}
$$


The partial derivatives were estimated numerically at the temperature and pressure of the vapor in the example case. They are

$$
\frac{\partial \rho_{R, V}}{\partial P}=0.055 \frac{(g / m L)}{M P a}
$$

and

$$
\frac{\partial \rho_{R, V}}{\partial T}=-0.0005 \frac{(g / m L)}{{ }^{\circ} \mathrm{C}} .
$$

As discussed earlier, the estimates of the uncertainty for pressure and temperature are $W_{P}=0.75 \mathrm{psia}=0.00517 \mathrm{MPa}$ and $W_{T}=0.1^{\circ} \mathrm{C}$. Thus, $W_{\rho_{R} . V}$ is 0.00029 $\mathrm{g} / \mathrm{mL}$. The vapor density, $\rho_{R, V}$, is $0.07410 \mathrm{~g} / \mathrm{mL}$ at these conditions. The mass of the vapor is then $104.7 \mathrm{~g}$. Now Eq. B.23 is employed to find $W_{m_{R, V}}=0.75 \mathrm{~g}$.

\section{Summary of the uncertainty of the liquid density}

The uncertainties estimated in the preceding four sections are returned to Eq. B.8 to determine that $W_{m}=16.0 \mathrm{~g}$. The component uncertainties are listed below for comparison.

- $W_{m_{O, i n j}}=14.4 \mathrm{~g}$

- $W_{m_{R, i n j}},=6.8 \mathrm{~g}$

- $W_{m}=1.0 \mathrm{~g}$

- $W_{m, V}=0.75 \mathrm{~g}$

It is clear that the major contributions to the uncertainty of the mass of the liquid are the uncertainties of the masses of oil and refrigerant injected. A review of the calculations shows that the predominant causes are the uncertainties of the densities of the oil and the refrigerant as injected. 
With the results from all of the foregoing discussion, it is now finally possible to solve for the uncertainty of the liquid density, $W_{\rho}$, the goal of this major section. For the example case, with $m_{L}=3628 \mathrm{~g}$ and $V_{L}=3774 \mathrm{~mL}$, Eq. B.5 gives a relative uncertainty of the liquid density of about 0.0050 , or one-half of one percent. Now $\rho_{L}$ $=0.961 \mathrm{~g} / \mathrm{mL}$ in this case, so $W_{\rho_{L}}=0.0048 \mathrm{~g} / \mathrm{mL}$.

It should be noted that this uncertainty will vary somewhat for each test condition, since its magnitude depends on both the test condition itself and also on the history of the test run prior to the condition of interest. To understand the significance of the magnitude of $W_{\rho_{L}}$, it is useful to compare this estimate to the total variation in the liquid density across the entire range of test conditions. The liquid density range is from $0.782 \mathrm{~g} / \mathrm{mL}$ (for pure oil at $148.4^{\circ} \mathrm{C}$ ) to $0.985 \mathrm{~g} / \mathrm{ml}$ (for this nominal $40 \%$ refrigerant mixture at $38.5^{\circ} \mathrm{C}$ ), for an overall variation of $0.203 \mathrm{~g} / \mathrm{mL}$. Thus, $W_{\rho_{L}}$ is only about $2 \%$ of the overall variation in the liquid density, and the "signal-to-noise" ratio is reasonably high.

\section{Uncertainty of the Liquid Composition}

In this work, the composition of the liquid is given in terms of refrigerant mass fraction. Though it is checked by sampling once at each nominal composition, the refrigerant mass fraction is calculated as follows for each data point:

$$
{ }^{x_{R}}=\frac{m_{R, L}}{{ }^{m} L}
$$

where the mass of refrigerant dissolved in the liquid is

$$
{ }^{m_{R, L}}=m_{R, i n j}-m_{R, V}-m_{R, S}
$$


Previous sections of this appendix have outlined the calculation of all of the above terms and their uncertainties, except for $m_{R, S}$, which is the refrigerant portion of $m_{S}$, the total mass withdrawn from the test cell due to prior sampling operations. Accordingly,

$$
m_{R, S}=\sum\left(m_{R, s}\right)_{i}=\sum\left(m_{s, i} \cdot x_{R, i}\right)
$$

with the subscript ' $\mathrm{i}$ ' referring to prior individual samples.

Now the relative uncertainty of the liquid composition is

$$
\frac{W_{x_{R}}}{x_{R}}=\sqrt{\left(\frac{W_{m_{R, L}}}{m_{R, L}}\right)^{2}+\left(\frac{W_{m_{L}}}{m_{L}}\right)^{2}}
$$

and the uncertainty of $m_{R, L}$ is

$$
W_{m_{R, L}}=\sqrt{\left(W_{m_{R, i n j}}\right)^{2}+\left(W_{m_{R, V}}\right)^{2}+\left(W_{m_{R, S}}\right)^{2}}
$$

The above two equations contain only one uncertainty term which has not been estimated in previous sections, i.e., $W_{m} R, S$. Referring to Eq. B.2T, this uncertainty can be calculated as:

$$
W_{m_{R, S}}=\sqrt{\sum\left(W_{m_{R, s}}\right)_{i}^{2}}
$$

Now for each prior sampling except for the first which contained no refrigerant,

$$
\left(\frac{W_{m_{R, s}}}{m_{R, s}}\right)_{i}=\sqrt{\left(\frac{W_{m_{s, i}}}{m_{s, i}}\right)^{2}+\left(\frac{W_{x} R, i}{x_{R, i}}\right)^{2}}
$$

The term $W_{m_{s, i}}$ has been discussed in a previous section (see Eq. B.15)and is approximately $0.5 \mathrm{~g}$. Now $W_{x_{R, i}}$ remains to be calculated for each of the prior samplings. Noting that

$$
{ }_{R, i}=m_{(R, s a m p), i} / m_{s a m p, i}
$$


where $m_{(R, s a m p) i}$ is the mass of refrigerant in the sample, the relative uncertainty of $x_{R, i}$ is then

$$
\left(\frac{W_{x_{R, i}}}{x_{R . i}}\right)=\sqrt{\left(\frac{W_{m_{R, s a m p}}}{m_{R, s a m p}}\right)_{i}^{2}+\left(\frac{W_{m_{\text {samp }}}}{m_{\text {samp }}}\right)_{i}^{2}}
$$

Both $W_{m}(R, s a m p), i$ and $W_{m_{s a m p, i}}$ involve uncertainties of the differences of masses. From previous discussion, $W_{m_{s a m p, i}}=0.014 \mathrm{~g}$. Since $m_{(R, s a m p), i}$ is determined in a similar manner, $W_{(R, s a m p), i}=0.014 \mathrm{~g}$ also.

Lising Equations B.31 and B.33, the contributing terms of Equation B.30 can be estimated for each prior sample (except the first, which contained no refrigerant) as summarized below:

- For sample 2: $x_{R, 2}=0.10, m_{s a m p, 2}=67 \mathrm{~g}, m_{(R, s a m p), 2}=6.7 \mathrm{~g}$, and $W_{x_{R, 2}}=0.00021$. Now $m_{s, 2}=71 \mathrm{~g}, m_{(R, s), 2}=7.1 \mathrm{~g}$, and thus, $W_{m_{(R, s), 2}}$ $=0.052 \mathrm{~g}$.

- For sample $3: x_{R, 3}=0.20, m_{s a m p, 3}=70 \mathrm{~g}, m_{(R, s a m p), 3}=14 \mathrm{~g}$, and $W_{x_{R, 3}}$ $=0.00020$. Now $m_{s, 3}=74.2 \mathrm{~g}, m_{(R, s), 3}=14.8 \mathrm{~g}$, and thus, $W_{(R, s), 3}=$ $0.101 \mathrm{~g}$.

- For sample $4: x_{R, 4}=0.30, m_{s a m p, 4}=72 \mathrm{~g}, m_{(R, s a m p), 4}=21.6 \mathrm{~g}$, and $W_{x_{R, 4}}=0.00020$. Now $m_{s, 4}=76.3 \mathrm{~g}, m_{(R, s), 4}=22.9 \mathrm{~g}$, and thus, $W_{m_{(R . s), 4}}$ $=0.151 \mathrm{~g}$.

Equations B.30, B.29, and B.28 are then used in turn to give $W_{m}, S=0.189 \mathrm{~g}$, $W_{m_{R, L}}=6.84 \mathrm{~g}$, and $W_{x_{R}}=0.0026$, respectively, for this example test case.

As is the case for the uncertainty of the liquid density, the influence of the history of prior sampling and injection operations is evident. Similar calculations for 
the other liquid compositions tested prior to the current condition in this example would show that the uncertainties in the compositions are smaller. 


\section{APPENDIX C. LISTING OF EXPERIMENTAL DATA}

Experimental results of the oil/refrigerant property studies are provided in the following tables. These data have been reduced from the actual "raw" test run data as outlined in Chapter 3 and in Appendix B. They form the bases upon which the empirical correlations discussed in Chapters 4 and 5 are derived.

As noted in chapter 4 , the temperature at which the solubilities (pressures) are recorded is an estimated liquid-vapor interface temperature that is an average of the vapor temperature and the average liquid temperature. This was done because of some non-uniformity in temperatures throughout the test cell, even at steady conditions. Viscosities are reported at the operating temperature of the viscometer and the average liquid temperature is used to report the liquid densities.

Tables C.1, C..2, and C.3 list the solubility, viscosity, and density data, respectively, for solutions of R-22 in a 150 SUS napthenic oil. These are the earliest data taken in the project. The numbers of solubility, viscosity, and density data points are different, because of early variations in data collection procedures. These procedures were later made more concise. Thus, for the other oil/refrigerant pairs, the solubility (pressure) and the viscosity and density of the liquid were evaluated at the same test conditions, and for each of these solutions the numbers of solubility, viscosity, and density data points are the same. Tables C..4, C.5, and C.6 list the data for solutions 
of R-22 and a 150 SU'S alkylbenzene. Similarly, Tables C.T through C'.12 provide this information for solutions of R-502 in these same lubricants. 
Table C.1: Experimental solubility (vapor pressure) data for R-22/150 SLiS naphthenic oil solutions

\begin{tabular}{|c|c|c|}
\hline $\begin{array}{c}\text { Temperature } \\
\text { (C) }\end{array}$ & $\begin{array}{l}\text { Pressure } \\
\text { (MPa) }\end{array}$ & $\begin{array}{l}\text { Concentration } \\
\text { (mass fraction } \mathrm{R}-22 \text { ) }\end{array}$ \\
\hline 57.5 & 0.000 & 0.000 \\
\hline 104.0 & 0.000 & 0.000 \\
\hline 104.3 & 0.000 & 0.000 \\
\hline 117.8 & 0.000 & 0.000 \\
\hline 134.1 & 0.000 & 0.000 \\
\hline 135.8 & 0.000 & 0.000 \\
\hline 143.9 & 0.000 & 0.000 \\
\hline 144.4 & 0.000 & 0.000 \\
\hline 115.0 & 0.000 & 0.000 \\
\hline 108.7 & 0.000 & 0.000 \\
\hline 73.2 & 0.000 & 0.000 \\
\hline 51.7 & 0.000 & 0.000 \\
\hline 40.7 & 0.685 & 0.093 \\
\hline 60.2 & 0.780 & 0.092 \\
\hline 84.4 & 1.031 & 0.087 \\
\hline 84.5 & 1.033 & 0.087 \\
\hline 107.7 & 1.297 & 0.082 \\
\hline 135.8 & 1.613 & 0.078 \\
\hline 62.8 & 0.849 & 0.090 \\
\hline 62.1 & 0.825 & 0.091 \\
\hline 62.0 & 0.821 & 0.091 \\
\hline 38.9 & 0.638 & 0.114 \\
\hline 47.2 & 0.734 & 0.113 \\
\hline 47.9 & 0.743 & 0.112 \\
\hline 68.8 & 1.007 & 0.109 \\
\hline 86.2 & 1.234 & 0.107 \\
\hline 102.3 & 1.455 & 0.105 \\
\hline 101.5 & 1.469 & 0.104 \\
\hline 112.1 & 1.625 & 0.103 \\
\hline 131.4 & 1.943 & 0.101 \\
\hline 140.2 & 2.073 & 0.100 \\
\hline
\end{tabular}


Table C.1 (C'ontinued)

$\begin{array}{ccc}\begin{array}{c}\text { Temperature } \\ (\mathrm{C})\end{array} & \begin{array}{c}\text { Pressure } \\ \text { (MPa) }\end{array} & \begin{array}{c}\text { Concentration } \\ \text { (mass fraction } \mathrm{R}-22)\end{array} \\ 62.5 & & \\ 76.9 & 1.452 & 0.181 \\ 95.3 & 1.766 & 0.175 \\ 95.3 & 2.184 & 0.168 \\ 49.2 & 2.184 & 0.168 \\ 85.4 & 1.177 & 0.187 \\ 46.1 & 1.949 & 0.172 \\ 85.8 & 1.115 & 0.189 \\ 114.3 & 1.964 & 0.172 \\ 128.2 & 2.630 & 0.161 \\ 97.8 & 2.956 & 0.156 \\ 96.0 & 2.254 & 0.166 \\ 48.5 & 2.201 & 0.167 \\ 44.8 & 1.152 & 0.188 \\ 39.7 & 1.096 & 0.189 \\ 58.0 & 1.039 & 0.202 \\ 59.0 & 1.431 & 0.198 \\ 76.6 & 1.469 & 0.198 \\ 79.0 & 1.899 & 0.195 \\ 87.1 & 1.998 & 0.194 \\ 89.4 & 2.211 & 0.192 \\ 96.6 & 2.289 & 0.192 \\ 104.5 & 2.494 & 0.191 \\ 113.9 & 2.712 & 0.189 \\ 123.6 & 3.009 & 0.188 \\ 37.0 & 3.314 & 0.186 \\ 38.6 & 1.170 & 0.336 \\ 47.6 & 1.256 & 0.335 \\ 48.2 & 1.456 & 0.334 \\ 50.3 & 1.519 & 0.333 \\ 55.6 & 1.541 & 0.333 \\ 55.6 & 1.728 & 0.333 \\ 56.5 & 1.732 & 0.332 \\ 56.4 & 1.731 & 0.331 \\ 56.5 & 1.732 & 0.331 \\ 56.8 & 1.738 & 0.331 \\ 60.5 & 1.778 & 0.331 \\ 61.0 & 1.846 & 0.330 \\ & 1.859 & 0.330\end{array}$


Table C.1 (Continued)

$\begin{array}{ccc}\begin{array}{c}\text { Temperature } \\ (\mathrm{C})\end{array} & \begin{array}{c}\text { Pressure } \\ (\mathrm{MPa})\end{array} & \begin{array}{c}\text { Concentration } \\ \text { (mass fraction R-22) }\end{array} \\ 64.9 & 2.046 & 0.330 \\ 65.0 & 2.049 & 0.330 \\ 65.1 & 2.049 & 0.330 \\ 72.9 & 2.179 & 0.328 \\ 70.6 & 2.192 & 0.328 \\ 73.1 & 2.349 & 0.328 \\ 75.1 & 2.439 & 0.325 \\ 93.3 & 3.211 & 0.321 \\ 44.1 & 1.476 & 0.387 \\ 48.9 & 1.637 & 0.383 \\ 58.0 & 1.942 & 0.376 \\ 58.7 & 1.969 & 0.375 \\ 67.1 & 2.283 & 0.368 \\ 67.7 & 2.330 & 0.366 \\ 76.6 & 2.672 & 0.358 \\ 88.0 & 3.143 & 0.346 \\ 88.1 & 3.150 & 0.346\end{array}$


Table C'.2: Experimental viscosity data for R-22/150 SL'S naphthenic oil solutions

$\begin{array}{rrr}\begin{array}{r}\text { Temperature } \\ (\mathrm{C})\end{array} & \begin{array}{c}\text { Viscosity } \\ (\mathrm{CP})\end{array} & \begin{array}{l}\text { Concentration } \\ \text { (mass fraction R-22) }\end{array} \\ 59.9 & & \\ 104.0 & 10.99 & 0.000 \\ 104.3 & 3.37 & 0.000 \\ 117.8 & 3.34 & 0.000 \\ 134.1 & 2.57 & 0.000 \\ 135.8 & 1.92 & 0.000 \\ 143.9 & 1.87 & 0.000 \\ 144.4 & 1.64 & 0.000 \\ 115.0 & 1.62 & 0.000 \\ 108.7 & 2.57 & 0.000 \\ 74.6 & 3.02 & 0.000 \\ 54.4 & 7.08 & 0.000 \\ 44.0 & 13.48 & 0.000 \\ 58.8 & 10.48 & 0.093 \\ 81.7 & 6.18 & 0.092 \\ 81.8 & 3.37 & 0.087 \\ 103.5 & 3.38 & 0.087 \\ 129.4 & 2.07 & 0.082 \\ 62.9 & 1.19 & 0.078 \\ 62.1 & 5.73 & 0.090 \\ 62.1 & 5.84 & 0.091 \\ 98.8 & 5.85 & 0.091 \\ 107.0 & 1.86 & 0.104 \\ 126.0 & 1.60 & 0.103 \\ 133.8 & 1.22 & 0.101 \\ 63.3 & 1.10 & 0.100 \\ 76.9 & 2.90 & 0.181 \\ 94.0 & 2.16 & 0.175 \\ 94.0 & 1.54 & 0.168 \\ 50.8 & 1.55 & 0.168 \\ 84.6 & 3.99 & 0.187 \\ 47.9 & 1.86 & 0.172 \\ 84.6 & 4.39 & 0.189 \\ 112.4 & 1.93 & 0.172 \\ & 0.97 & 0.161 \\ & & \end{array}$


Table C .2 (Continued)

$\begin{array}{ccc}\begin{array}{c}\text { Temperature } \\ (\mathrm{C})\end{array} & \begin{array}{c}\text { Viscosity } \\ (\mathrm{cP})\end{array} & \begin{array}{l}\text { Concentration } \\ \text { (mass fraction R-22) }\end{array} \\ 125.7 & & \\ 96.9 & 0.76 & 0.156 \\ 95.2 & 1.56 & 0.166 \\ 49.8 & 1.65 & 0.167 \\ 47.0 & 4.10 & 0.188 \\ 75.3 & 4.52 & 0.189 \\ 78.3 & 2.24 & 0.195 \\ 86.3 & 1.96 & 0.194 \\ 88.7 & 1.74 & 0.192 \\ 95.3 & 1.64 & 0.192 \\ 102.1 & 1.48 & 0.191 \\ 110.9 & 1.32 & 0.189 \\ 120.2 & 1.18 & 0.188 \\ 39.5 & 1.05 & 0.186 \\ 46.7 & 2.18 & 0.335 \\ 48.0 & 1.91 & 0.334 \\ 49.0 & 1.83 & 0.333 \\ 54.7 & 1.84 & 0.333 \\ 55.3 & 1.65 & 0.331 \\ 55.3 & 1.72 & 0.331 \\ 57.4 & 1.61 & 0.331 \\ 58.3 & 1.57 & 0.330 \\ 66.0 & 1.55 & 0.330 \\ 45.4 & 1.37 & 0.328 \\ 50.0 & 1.69 & 0.387 \\ 58.1 & 1.47 & 0.383 \\ 59.5 & 1.31 & 0.376 \\ 66.5 & 1.35 & 0.375 \\ 68.3 & 1.22 & 0.368 \\ 75.9 & 1.18 & 0.366 \\ 86.2 & 1.03 & 0.358 \\ 86.4 & 0.95 & 0.346 \\ & 0.96 & 0.346 \\ & & \end{array}$


Table C'.3: Experimental density data for R-22/150 SL'S naphthenic oil solutions

$\begin{array}{rrl}\begin{array}{r}\text { Temperature } \\ (\mathrm{C})\end{array} & \begin{array}{r}\text { Density } \\ (\mathrm{g} / \mathrm{mL})\end{array} & \begin{array}{l}\text { Concentration } \\ \text { (mass fraction } \mathrm{R}-22)\end{array} \\ 57.5 & 0.876 & 0.000 \\ 104.0 & 0.849 & 0.000 \\ 104.3 & 0.849 & 0.000 \\ 117.8 & 0.841 & 0.000 \\ 134.1 & 0.832 & 0.000 \\ 135.8 & 0.831 & 0.000 \\ 143.9 & 0.826 & 0.000 \\ 144.4 & 0.826 & 0.000 \\ 115.0 & 0.843 & 0.000 \\ 108.7 & 0.846 & 0.000 \\ 73.2 & 0.866 & 0.000 \\ 51.7 & 0.878 & 0.000 \\ 41.0 & 0.945 & 0.093 \\ 58.6 & 0.931 & 0.092 \\ 81.7 & 0.914 & 0.087 \\ 81.8 & 0.914 & 0.087 \\ 104.2 & 0.898 & 0.082 \\ 131.2 & 0.879 & 0.078 \\ 61.0 & 0.929 & 0.090 \\ 60.5 & 0.930 & 0.091 \\ 60.4 & 0.930 & 0.091 \\ 112.9 & 0.915 & 0.181 \\ 112.9 & 0.915 & 0.181 \\ 101.9 & 0.924 & 0.183 \\ 101.9 & 0.924 & 0.183 \\ 91.3 & 0.933 & 0.185 \\ 91.3 & 0.933 & 0.185 \\ 91.3 & 0.933 & 0.185 \\ 81.1 & 0.942 & 0.188 \\ 81.0 & 0.942 & 0.188 \\ 67.6 & 0.952 & 0.191 \\ 67.4 & 0.952 & 0.191 \\ 54.3 & 0.964 & 0.194 \\ 42.6 & 0.973 & 0.197 \\ & & \end{array}$


Table C.3 (C'ontinued)

$\begin{array}{ccc}\begin{array}{c}\text { Temperature } \\ (\mathrm{C})\end{array} & \begin{array}{r}\text { Density } \\ (\mathrm{g} / \mathrm{mL})\end{array} & \begin{array}{l}\text { Concentration } \\ \text { (mass fraction R-22) }\end{array} \\ 83.7 & 0.962 & 0.288 \\ 75.2 & 0.970 & 0.290 \\ 75.2 & 0.970 & 0.290 \\ 66.4 & 0.978 & 0.292 \\ 66.4 & 0.978 & 0.292 \\ 57.4 & 0.987 & 0.294 \\ 57.4 & 0.987 & 0.294 \\ 45.8 & 0.997 & 0.297 \\ 45.5 & 0.998 & 0.297\end{array}$


Table C.4: Experimental solubility (vapor pressure) data for R-22/150 SLS alkylbenzene solutions

$\begin{array}{rcc}\begin{array}{c}\text { Temperature } \\ (\mathrm{C})\end{array} & \begin{array}{c}\text { Pressure } \\ \text { (MPa) }\end{array} & \begin{array}{c}\text { Concentration } \\ \text { (mass fraction R-22) }\end{array} \\ 43.7 & 0.000 & 0.000 \\ 44.0 & 0.000 & 0.000 \\ 44.0 & 0.000 & 0.000 \\ 70.9 & 0.000 & 0.000 \\ 72.6 & 0.000 & 0.000 \\ 98.9 & 0.000 & 0.000 \\ 99.5 & 0.000 & 0.000 \\ 81.2 & 0.000 & 0.000 \\ 81.2 & 0.000 & 0.000 \\ 117.6 & 0.000 & 0.000 \\ 117.6 & 0.000 & 0.000 \\ 135.3 & 0.000 & 0.000 \\ 135.3 & 0.000 & 0.000 \\ 148.4 & 0.000 & 0.000 \\ 148.4 & 0.000 & 0.000 \\ 148.4 & 0.000 & 0.000 \\ 66.7 & 0.628 & 0.089 \\ 67.0 & 0.632 & 0.089 \\ 86.0 & 0.806 & 0.087 \\ 104.3 & 1.041 & 0.085 \\ 117.3 & 1.173 & 0.084 \\ 128.0 & 1.277 & 0.083 \\ 132.8 & 1.334 & 0.083 \\ 136.2 & 1.406 & 0.082 \\ 136.5 & 1.419 & 0.082 \\ 150.1 & 1.583 & 0.081 \\ 150.2 & 1.590 & 0.081 \\ 144.6 & 1.538 & 0.082 \\ 143.7 & 1.529 & 0.082 \\ 137.2 & 1.441 & 0.082 \\ 137.1 & 1.438 & 0.082 \\ 118.2 & 1.207 & 0.083 \\ 110.7 & 1.147 & 0.084 \\ 105.7 & 1.081 & 0.084 \\ & & \end{array}$


Table C'.4 (C'ontinued)

$\begin{array}{rcc}\begin{array}{c}\text { Temperature } \\ (\mathrm{C})\end{array} & \begin{array}{c}\text { Pressure } \\ \text { (MPa) }\end{array} & \begin{array}{c}\text { Concentration } \\ \text { (mass fraction R-22) }\end{array} \\ 104.7 & 1.059 & 0.085 \\ 95.5 & 0.975 & 0.085 \\ 91.2 & 0.905 & 0.086 \\ 78.6 & 0.778 & 0.087 \\ 77.5 & 0.757 & 0.087 \\ 63.7 & 0.626 & 0.089 \\ 62.8 & 0.620 & 0.089 \\ 61.8 & 0.602 & 0.089 \\ 53.3 & 1.048 & 0.199 \\ 53.5 & 1.055 & 0.199 \\ 66.3 & 1.310 & 0.197 \\ 90.0 & 1.890 & 0.193 \\ 90.1 & 1.892 & 0.193 \\ 104.0 & 2.277 & 0.191 \\ 104.0 & 2.277 & 0.191 \\ 117.9 & 2.682 & 0.190 \\ 118.0 & 2.681 & 0.190 \\ 129.2 & 2.994 & 0.189 \\ 136.9 & 3.236 & 0.188 \\ 136.3 & 3.227 & 0.188 \\ 136.3 & 3.225 & 0.188 \\ 127.1 & 2.965 & 0.189 \\ 122.7 & 2.812 & 0.189 \\ 122.5 & 2.805 & 0.189 \\ 108.5 & 2.417 & 0.191 \\ 105.2 & 2.304 & 0.191 \\ 104.4 & 2.280 & 0.191 \\ 90.2 & 1.892 & 0.193 \\ 90.1 & 1.892 & 0.193 \\ 81.7 & 1.751 & 0.194 \\ 81.3 & 1.670 & 0.195 \\ 80.6 & 1.656 & 0.195 \\ & & \end{array}$


Table C..4 (C'ontinued)

\begin{tabular}{|c|c|c|}
\hline $\begin{array}{l}\text { Temperature } \\
\text { (C) }\end{array}$ & $\begin{array}{l}\text { Pressure } \\
(\mathrm{MPa})\end{array}$ & $\begin{array}{l}\text { Concentration } \\
\text { (mass fraction } \mathrm{R}-22 \text { ) }\end{array}$ \\
\hline 70.9 & 1.455 & 0.196 \\
\hline 67.5 & 1.349 & 0.197 \\
\hline 67.4 & 1.347 & 0.197 \\
\hline 35.3 & 0.964 & 0.327 \\
\hline 43.8 & 1.145 & 0.324 \\
\hline 53.0 & 1.418 & 0.320 \\
\hline 75.3 & 2.098 & 0.310 \\
\hline 83.5 & 2.372 & 0.306 \\
\hline 94.8 & 2.839 & 0.299 \\
\hline 103.8 & 3.184 & 0.295 \\
\hline 90.2 & 2.657 & 0.302 \\
\hline 90.2 & 2.658 & 0.302 \\
\hline 83.9 & 2.429 & 0.305 \\
\hline 75.5 & 2.134 & 0.309 \\
\hline 75.5 & 2.133 & 0.309 \\
\hline 63.6 & 1.747 & 0.315 \\
\hline 63.6 & 1.746 & 0.315 \\
\hline 53.3 & 1.446 & 0.319 \\
\hline 53.3 & 1.446 & 0.319 \\
\hline 35.7 & 1.147 & 0.419 \\
\hline 40.6 & 1.276 & 0.418 \\
\hline 41.6 & 1.311 & 0.418 \\
\hline 62.8 & 2.009 & 0.412 \\
\hline 71.7 & 2.367 & 0.409 \\
\hline 87.8 & 3.126 & 0.403 \\
\hline 81.9 & 2.817 & 0.406 \\
\hline 79.2 & 2.711 & 0.407 \\
\hline 74.4 & 2.485 & 0.409 \\
\hline 60.2 & 1.898 & 0.413 \\
\hline 59.8 & 1.886 & 0.413 \\
\hline 58.3 & 1.846 & 0.414 \\
\hline
\end{tabular}


Table C'.5: Experimental viscosity data for R-22/150 SUS alkylbenzene solutions

$\begin{array}{ccc}\begin{array}{c}\text { Temperature } \\ (\mathrm{C})\end{array} & \begin{array}{c}\text { Viscosity } \\ (\mathrm{CP})\end{array} & \begin{array}{l}\text { Concentration } \\ \text { (mass fraction } \mathrm{R}-22)\end{array} \\ 47.0 & & \\ 47.2 & 17.21 & 0.000 \\ 46.6 & 16.68 & 0.000 \\ 72.5 & 17.26 & 0.000 \\ 74.0 & 6.91 & 0.000 \\ 98.9 & 6.56 & 0.000 \\ 99.5 & 3.52 & 0.000 \\ 82.1 & 3.46 & 0.000 \\ 82.1 & 5.21 & 0.000 \\ 117.6 & 5.22 & 0.000 \\ 117.6 & 2.39 & 0.000 \\ 135.3 & 2.40 & 0.000 \\ 135.3 & 1.79 & 0.000 \\ 148.4 & 1.78 & 0.000 \\ 148.4 & 1.46 & 0.000 \\ 148.4 & 1.47 & 0.000 \\ 67.2 & 1.46 & 0.000 \\ 67.5 & 4.43 & 0.089 \\ 85.1 & 4.43 & 0.089 \\ 102.3 & 2.92 & 0.087 \\ 114.9 & 2.08 & 0.085 \\ 124.4 & 1.67 & 0.084 \\ 129.9 & 1.44 & 0.083 \\ 133.3 & 1.32 & 0.083 \\ 133.5 & 1.25 & 0.082 \\ 146.7 & 1.25 & 0.082 \\ 146.9 & 1.04 & 0.081 \\ 141.8 & 1.04 & 0.081 \\ 140.7 & 1.09 & 0.082 \\ 134.1 & 1.12 & 0.082 \\ 134.0 & 1.24 & 0.082 \\ 115.7 & 1.25 & 0.082 \\ 108.3 & 1.67 & 0.083 \\ 103.4 & 1.86 & 0.084 \\ & 2.05 & 0.084 \\ & & \end{array}$


Table C $.5 \quad$ (C'ontinued)

$\begin{array}{ccc}\begin{array}{c}\text { Temperature } \\ (\mathrm{C})\end{array} & \begin{array}{c}\text { Viscosity } \\ (\mathrm{CP})\end{array} & \begin{array}{c}\text { Concentration } \\ \text { (mass fraction } \mathrm{R}-22)\end{array} \\ 102.6 & & \\ 93.5 & 2.08 & 0.085 \\ 89.9 & 2.47 & 0.085 \\ 78.4 & 2.70 & 0.086 \\ 77.6 & 3.34 & 0.087 \\ 65.3 & 3.42 & 0.087 \\ 63.9 & 4.75 & 0.089 \\ 62.5 & 4.91 & 0.089 \\ 55.4 & 4.98 & 0.089 \\ 55.6 & 2.86 & 0.199 \\ 67.2 & 2.90 & 0.199 \\ 88.6 & 2.28 & 0.197 \\ 88.6 & 1.58 & 0.193 \\ 101.7 & 1.56 & 0.193 \\ 101.7 & 1.19 & 0.191 \\ 115.3 & 1.20 & 0.191 \\ 115.5 & 0.96 & 0.190 \\ 126.1 & 0.95 & 0.190 \\ 134.1 & 0.82 & 0.189 \\ 133.4 & 0.75 & 0.188 \\ 133.4 & 0.75 & 0.188 \\ 124.3 & 0.75 & 0.188 \\ 120.1 & 0.85 & 0.189 \\ 119.9 & 0.90 & 0.189 \\ 105.9 & 0.91 & 0.189 \\ 102.9 & 1.13 & 0.191 \\ 102.2 & 1.18 & 0.191 \\ 88.8 & 1.19 & 0.191 \\ 88.7 & 1.51 & 0.193 \\ 80.9 & 1.51 & 0.193 \\ 80.6 & 1.68 & 0.194 \\ 79.8 & 1.75 & 0.195 \\ 70.8 & 1.78 & 0.195 \\ & 2.13 & 0.196 \\ & & \end{array}$


Table C $.5 \quad$ (C'ontinued)

$\begin{array}{ccc}\begin{array}{c}\text { Temperature } \\ (\mathrm{C})\end{array} & \begin{array}{c}\text { Viscosity } \\ (\mathrm{CP})\end{array} & \begin{array}{l}\text { Concentration } \\ \text { (mass fraction R-22) }\end{array} \\ 67.9 & 2.25 & 0.197 \\ 67.8 & 2.25 & 0.197 \\ 37.6 & 2.17 & 0.327 \\ 45.0 & 1.78 & 0.324 \\ 54.4 & 1.45 & 0.320 \\ 74.5 & 1.08 & 0.310 \\ 81.6 & 0.99 & 0.306 \\ 92.5 & 0.83 & 0.299 \\ 100.8 & 0.80 & 0.295 \\ 88.2 & 0.89 & 0.302 \\ 88.2 & 0.89 & 0.302 \\ 82.6 & 1.03 & 0.305 \\ 75.0 & 1.09 & 0.309 \\ 75.0 & 1.10 & 0.309 \\ 64.3 & 1.26 & 0.315 \\ 64.3 & 1.27 & 0.315 \\ 55.0 & 1.53 & 0.319 \\ 55.0 & 1.53 & 0.319 \\ 39.6 & 1.13 & 0.419 \\ 43.9 & 1.04 & 0.418 \\ 44.7 & 1.02 & 0.418 \\ 63.8 & 0.79 & 0.412 \\ 71.8 & 0.71 & 0.409 \\ 61.0 & 0.84 & 0.413 \\ 60.8 & 0.84 & 0.413 \\ 59.8 & 0.82 & 0.414\end{array}$


Table C.6: Experimental density data for R-22/150 SLiS alkylbenzene solutions

$\begin{array}{ccc}\begin{array}{c}\text { Temperature } \\ (\mathrm{C})\end{array} & \begin{array}{r}\text { Density } \\ (\mathrm{g} / \mathrm{mL})\end{array} & \begin{array}{l}\text { Concentration } \\ \text { (mass fraction } \mathrm{R}-22)\end{array} \\ 43.7 & 0.852 & 0.000 \\ 44.0 & 0.852 & 0.000 \\ 44.0 & 0.852 & 0.000 \\ 70.9 & 0.834 & 0.000 \\ 72.6 & 0.833 & 0.000 \\ 98.9 & 0.815 & 0.000 \\ 99.5 & 0.815 & 0.000 \\ 81.2 & 0.827 & 0.000 \\ 81.2 & 0.827 & 0.000 \\ 117.6 & 0.803 & 0.000 \\ 117.6 & 0.803 & 0.000 \\ 135.3 & 0.791 & 0.000 \\ 135.3 & 0.791 & 0.000 \\ 148.4 & 0.782 & 0.000 \\ 148.4 & 0.782 & 0.000 \\ 148.4 & 0.782 & 0.000 \\ 65.3 & 0.866 & 0.089 \\ 65.6 & 0.864 & 0.089 \\ 84.4 & 0.854 & 0.087 \\ 102.3 & 0.841 & 0.085 \\ 114.9 & 0.832 & 0.084 \\ 124.4 & 0.825 & 0.083 \\ 129.9 & 0.821 & 0.083 \\ 133.3 & 0.819 & 0.082 \\ 133.5 & 0.819 & 0.082 \\ 146.7 & 0.811 & 0.081 \\ 146.9 & 0.811 & 0.081 \\ 141.8 & 0.814 & 0.082 \\ 140.7 & 0.814 & 0.082 \\ 134.1 & 0.820 & 0.082 \\ 134.0 & 0.820 & 0.082 \\ 115.7 & 0.832 & 0.083 \\ 108.3 & 0.837 & 0.084 \\ 103.4 & 0.840 & 0.084 \\ & & \end{array}$


134

Table C..6 (Continued)

\begin{tabular}{|c|c|c|}
\hline $\begin{array}{l}\text { Temperature } \\
\text { (C) }\end{array}$ & $\begin{array}{r}\text { Density } \\
(\mathrm{g} / \mathrm{mL})\end{array}$ & $\begin{array}{l}\text { Concentration } \\
\text { (mass fraction } R-22 \text { ) }\end{array}$ \\
\hline 102.6 & 0.840 & 0.085 \\
\hline 93.4 & 0.848 & 0.085 \\
\hline 89.5 & 0.850 & 0.086 \\
\hline 77.2 & 0.858 & 0.087 \\
\hline 76.4 & 0.860 & 0.087 \\
\hline 63.2 & 0.869 & 0.089 \\
\hline 61.8 & 0.869 & 0.089 \\
\hline 60.3 & 0.870 & 0.089 \\
\hline 52.7 & 0.892 & 0.199 \\
\hline 52.9 & 0.892 & 0.199 \\
\hline 65.3 & 0.883 & 0.197 \\
\hline 88.1 & 0.864 & 0.193 \\
\hline 88.2 & 0.864 & 0.193 \\
\hline 101.7 & 0.853 & 0.191 \\
\hline 101.7 & 0.853 & 0.191 \\
\hline 115.3 & 0.843 & 0.190 \\
\hline 115.5 & 0.843 & 0.190 \\
\hline 126.1 & 0.833 & 0.189 \\
\hline 134.1 & 0.828 & 0.188 \\
\hline 133.4 & 0.829 & 0.188 \\
\hline 133.4 & 0.829 & 0.188 \\
\hline 124.3 & 0.836 & 0.189 \\
\hline 120.1 & 0.839 & 0.189 \\
\hline 119.9 & 0.839 & 0.189 \\
\hline 105.9 & 0.850 & 0.191 \\
\hline 102.9 & 0.853 & 0.191 \\
\hline 102.2 & 0.854 & 0.191 \\
\hline 88.3 & 0.864 & 0.193 \\
\hline 88.2 & 0.864 & 0.193 \\
\hline 80.0 & 0.871 & 0.194 \\
\hline 79.7 & 0.872 & 0.195 \\
\hline 78.7 & 0.872 & 0.195 \\
\hline 69.2 & 0.881 & 0.196 \\
\hline
\end{tabular}


Table C.6 (C'ontinued)

$\begin{array}{ccc}\begin{array}{c}\text { Temperature } \\ (\mathrm{C})\end{array} & \begin{array}{r}\text { Density } \\ (\mathrm{g} / \mathrm{mL})\end{array} & \begin{array}{l}\text { Concentration } \\ \text { (mass fraction } \mathrm{R}-22)\end{array} \\ 66.0 & 0.882 & 0.197 \\ 66.0 & 0.882 & 0.197 \\ 33.7 & 0.960 & 0.327 \\ 41.6 & 0.951 & 0.324 \\ 51.7 & 0.939 & 0.320 \\ 73.1 & 0.917 & 0.310 \\ 80.7 & 0.911 & 0.306 \\ 92.3 & 0.898 & 0.299 \\ 100.8 & 0.890 & 0.295 \\ 87.7 & 0.903 & 0.302 \\ 87.7 & 0.903 & 0.302 \\ 81.8 & 0.909 & 0.305 \\ 73.7 & 0.918 & 0.309 \\ 73.7 & 0.918 & 0.309 \\ 62.2 & 0.930 & 0.315 \\ 62.2 & 0.930 & 0.315 \\ 52.3 & 0.942 & 0.319 \\ 52.3 & 0.942 & 0.319 \\ 35.8 & 0.985 & 0.419 \\ 40.4 & 0.978 & 0.418 \\ 41.3 & 0.977 & 0.418 \\ 61.7 & 0.955 & 0.412 \\ 70.3 & 0.945 & 0.409 \\ 58.7 & 0.960 & 0.413 \\ 58.4 & 0.959 & 0.413 \\ 57.4 & 0.961 & 0.414\end{array}$


Table ('.7: Experimental solubility (vapor pressure) data for R-502/1.50 SUS naphthenic oil solutions

\begin{tabular}{rcc}
$\begin{array}{r}\text { Temperature } \\
(\mathrm{C})\end{array}$ & $\begin{array}{c}\text { Pressure } \\
\text { (MPa) }\end{array}$ & $\begin{array}{c}\text { Concentration } \\
\text { (mass fraction } \mathrm{R}-502)\end{array}$ \\
57.5 & & \\
104.0 & 0.000 & 0.000 \\
104.3 & 0.000 & 0.000 \\
117.8 & 0.000 & 0.000 \\
134.1 & 0.000 & 0.000 \\
135.8 & 0.000 & 0.000 \\
143.9 & 0.000 & 0.000 \\
144.4 & 0.000 & 0.000 \\
115.0 & 0.000 & 0.000 \\
108.7 & 0.000 & 0.000 \\
73.2 & 0.000 & 0.000 \\
51.7 & 0.000 & 0.000 \\
150.0 & 0.000 & 0.000 \\
139.3 & 2.225 & 0.087 \\
128.3 & 2.045 & 0.087 \\
117.2 & 1.868 & 0.088 \\
106.2 & 1.694 & 0.089 \\
95.0 & 1.531 & 0.090 \\
84.6 & 1.371 & 0.091 \\
74.1 & 1.233 & 0.092 \\
61.9 & 1.104 & 0.093 \\
55.0 & 0.963 & 0.094 \\
44.5 & 0.901 & 0.094 \\
42.0 & 0.776 & 0.096 \\
113.6 & 0.743 & 0.096 \\
104.5 & 3.228 & 0.180 \\
95.6 & 2.946 & 0.181 \\
86.3 & 2.684 & 0.182 \\
77.2 & 2.408 & 0.184 \\
68.1 & 2.148 & 0.186 \\
59.7 & 1.899 & 0.188 \\
49.2 & 1.685 & 0.190 \\
45.6 & 1.407 & 0.193 \\
40.0 & 1.339 & 0.194 \\
& 1.217 & 0.195 \\
\hline 50 & &
\end{tabular}


Table C.T (C'ontinued)

$\begin{array}{ccc}\begin{array}{c}\text { Temperature } \\ \text { (C) }\end{array} & \begin{array}{c}\text { Pressure } \\ \text { (MPa) }\end{array} & \begin{array}{c}\text { Concentration } \\ \text { (mass fraction R-502) }\end{array} \\ 35.7 & 1.342 & 0.294 \\ 41.1 & 1.535 & 0.289 \\ 47.7 & 1.754 & 0.284 \\ 47.7 & 1.757 & 0.284 \\ 57.0 & 2.069 & 0.276 \\ 57.1 & 2.073 & 0.276 \\ 65.5 & 2.354 & 0.270 \\ 65.5 & 2.355 & 0.270 \\ 74.0 & 2.645 & 0.264 \\ 74.1 & 2.650 & 0.263 \\ 83.2 & 2.982 & 0.256 \\ 83.2 & 2.982 & 0.256 \\ 92.3 & 3.319 & 0.250 \\ 92.3 & 3.318 & 0.250\end{array}$


Table C.8: Experimental viscosity data for R-502/1.50 SUS naphthenic oil solutions

$\begin{array}{ccc}\begin{array}{c}\text { Temperature } \\ (\mathrm{C})\end{array} & \begin{array}{c}\text { Viscosity } \\ (\mathrm{CP})\end{array} & \begin{array}{l}\text { Corcentration } \\ \text { (mass fraction R-502) }\end{array} \\ 59.9 & & \\ 104.0 & 10.99 & 0.000 \\ 104.3 & 3.37 & 0.000 \\ 117.8 & 3.34 & 0.000 \\ 134.1 & 2.57 & 0.000 \\ 135.8 & 1.92 & 0.000 \\ 143.9 & 1.87 & 0.000 \\ 144.4 & 1.64 & 0.000 \\ 115.0 & 1.62 & 0.000 \\ 108.7 & 2.57 & 0.000 \\ 74.6 & 3.02 & 0.000 \\ 54.4 & 7.08 & 0.000 \\ 146.1 & 13.48 & 0.000 \\ 135.6 & 1.09 & 0.087 \\ 124.9 & 1.26 & 0.087 \\ 114.2 & 1.48 & 0.088 \\ 103.6 & 1.75 & 0.089 \\ 92.8 & 2.08 & 0.090 \\ 83.5 & 2.55 & 0.091 \\ 73.9 & 3.12 & 0.092 \\ 62.9 & 3.95 & 0.093 \\ 56.5 & 5.50 & 0.094 \\ 47.3 & 6.35 & 0.094 \\ 45.2 & 8.57 & 0.096 \\ 111.3 & 9.25 & 0.096 \\ 102.3 & 1.31 & 0.180 \\ 93.8 & 1.50 & 0.181 \\ 85.3 & 1.76 & 0.182 \\ 77.1 & 1.93 & 0.184 \\ 68.9 & 2.26 & 0.186 \\ 61.1 & 2.70 & 0.188 \\ 51.7 & 3.31 & 0.190 \\ 48.3 & 4.26 & 0.193 \\ 43.2 & 4.55 & 0.194 \\ & 5.37 & 0.195 \\ & & \end{array}$


Table C.8 (Continued)

$\begin{array}{ccc}\begin{array}{c}\text { Temperature } \\ (\mathrm{C})\end{array} & \begin{array}{c}\text { Viscosity } \\ (\mathrm{CP})\end{array} & \begin{array}{c}\text { Concentration } \\ \text { (mass fraction R-502) }\end{array} \\ 38.6 & 3.23 & 0.294 \\ 44.5 & 3.18 & 0.289 \\ 50.5 & 2.48 & 0.284 \\ 50.5 & 2.48 & 0.284 \\ 60.2 & 2.21 & 0.276 \\ 59.1 & 2.22 & 0.276 \\ 66.8 & 1.87 & 0.270 \\ 66.6 & 1.84 & 0.270 \\ 74.0 & 1.53 & 0.264 \\ 74.2 & 1.58 & 0.263 \\ 82.2 & 1.45 & 0.256 \\ 82.4 & 1.42 & 0.256 \\ 90.4 & 1.29 & 0.250 \\ 90.7 & 1.26 & 0.250\end{array}$


Table C.9: Experimental density data for R-502/150 SUS naphthenic oil solutions

$\begin{array}{rrr}\begin{array}{r}\text { Temperature } \\ (\mathrm{C})\end{array} & \begin{array}{r}\text { Density } \\ (\mathrm{g} / \mathrm{mL})\end{array} & \begin{array}{l}\text { Concentration } \\ \text { (mass fraction } \mathrm{R}-502)\end{array} \\ 57.5 & 0.876 & 0.000 \\ 104.0 & 0.849 & 0.000 \\ 104.3 & 0.849 & 0.000 \\ 117.8 & 0.841 & 0.000 \\ 134.1 & 0.832 & 0.000 \\ 135.8 & 0.831 & 0.000 \\ 143.9 & 0.826 & 0.000 \\ 144.4 & 0.826 & 0.000 \\ 115.0 & 0.843 & 0.000 \\ 108.7 & 0.846 & 0.000 \\ 73.2 & 0.866 & 0.000 \\ 51.7 & 0.878 & 0.000 \\ 146.1 & 0.856 & 0.087 \\ 135.6 & 0.865 & 0.087 \\ 124.9 & 0.873 & 0.088 \\ 114.2 & 0.881 & 0.089 \\ 103.6 & 0.888 & 0.090 \\ 92.7 & 0.897 & 0.091 \\ 82.7 & 0.904 & 0.092 \\ 72.4 & 0.912 & 0.093 \\ 60.7 & 0.920 & 0.094 \\ 53.9 & 0.926 & 0.094 \\ 44.1 & 0.932 & 0.096 \\ 41.8 & 0.933 & 0.096 \\ 111.3 & 0.911 & 0.180 \\ 102.3 & 0.918 & 0.181 \\ 93.7 & 0.925 & 0.182 \\ 84.7 & 0.933 & 0.184 \\ 75.8 & 0.939 & 0.186 \\ 67.1 & 0.946 & 0.188 \\ 58.8 & 0.954 & 0.190 \\ 48.8 & 0.961 & 0.193 \\ 45.2 & 0.964 & 0.194 \\ 39.7 & 0.968 & 0.195 \\ & & \end{array}$


Table C..9 (C'ontinued)

$\begin{array}{ccc}\begin{array}{c}\text { Temperature } \\ (\mathrm{C})\end{array} & \begin{array}{r}\text { Density } \\ (\mathrm{g} / \mathrm{mL})\end{array} & \begin{array}{l}\text { Concentration } \\ \text { (mass fraction } \mathrm{R}-502)\end{array} \\ 34.8 & 0.979 & 0.294 \\ 41.1 & 0.975 & 0.289 \\ 47.5 & 0.968 & 0.284 \\ 47.5 & 0.968 & 0.284 \\ 56.6 & 0.959 & 0.276 \\ 56.7 & 0.959 & 0.276 \\ 64.7 & 0.951 & 0.270 \\ 64.7 & 0.950 & 0.270 \\ 72.6 & 0.943 & 0.264 \\ 72.7 & 0.943 & 0.263 \\ 81.4 & 0.934 & 0.256 \\ 81.4 & 0.934 & 0.256 \\ 90.1 & 0.926 & 0.250 \\ 90.1 & 0.926 & 0.250\end{array}$


Table ('.10: Experimental solubility (vapor pressure) data for R-.502/150 SUS alkylbenzene solutions

$\begin{array}{rcc}\begin{array}{r}\text { Temperature } \\ (\mathrm{C})\end{array} & \begin{array}{c}\text { Pressure } \\ (\mathrm{MPa})\end{array} & \begin{array}{l}\text { Concentration } \\ \text { (mass fraction } \mathrm{R}-502)\end{array} \\ 43.7 & & \\ 44.0 & 0.000 & 0.000 \\ 44.0 & 0.000 & 0.000 \\ 70.9 & 0.000 & 0.000 \\ 72.6 & 0.000 & 0.000 \\ 98.9 & 0.000 & 0.000 \\ 99.5 & 0.000 & 0.000 \\ 81.2 & 0.000 & 0.000 \\ 81.2 & 0.000 & 0.000 \\ 117.6 & 0.000 & 0.000 \\ 117.6 & 0.000 & 0.000 \\ 135.3 & 0.000 & 0.000 \\ 135.3 & 0.000 & 0.000 \\ 148.4 & 0.000 & 0.000 \\ 148.4 & 0.000 & 0.000 \\ 148.4 & 0.000 & 0.000 \\ 151.7 & 0.000 & 0.000 \\ 137.1 & 1.983 & 0.092 \\ 137.0 & 1.788 & 0.092 \\ 136.8 & 1.785 & 0.092 \\ 122.7 & 1.782 & 0.092 \\ 122.6 & 1.590 & 0.093 \\ 109.4 & 1.589 & 0.093 \\ 109.3 & 1.427 & 0.093 \\ 95.6 & 1.424 & 0.094 \\ 82.2 & 1.246 & 0.095 \\ 68.3 & 1.079 & 0.096 \\ 56.3 & 0.916 & 0.097 \\ 49.2 & 0.806 & 0.098 \\ 47.0 & 0.740 & 0.099 \\ 140.9 & 0.695 & 0.100 \\ 141.0 & 3.238 & 0.181 \\ 127.6 & 3.239 & 0.181 \\ 127.5 & 2.891 & 0.182 \\ & 2.889 & 0.182 \\ & & \end{array}$


Table C.10 (C'ontinued)

$\begin{array}{ccc}\begin{array}{c}\text { Temperature } \\ (\mathrm{C})\end{array} & \begin{array}{c}\text { Pressure } \\ \text { (MPa) }\end{array} & \begin{array}{l}\text { Concentration } \\ \text { (mass fraction R-502) }\end{array} \\ 113.7 & 2.535 & 0.183 \\ 113.6 & 2.534 & 0.183 \\ 100.2 & 2.212 & 0.185 \\ 100.1 & 2.209 & 0.185 \\ 86.6 & 1.897 & 0.187 \\ 86.4 & 1.889 & 0.187 \\ 68.9 & 1.503 & 0.190 \\ 68.6 & 1.492 & 0.190 \\ 58.6 & 1.279 & 0.192 \\ 49.1 & 1.092 & 0.193 \\ 41.6 & 0.968 & 0.195 \\ 103.6 & 3.177 & 0.262 \\ 103.6 & 3.178 & 0.262 \\ 94.9 & 2.882 & 0.266 \\ 94.9 & 2.882 & 0.266 \\ 86.3 & 2.602 & 0.270 \\ 86.2 & 2.598 & 0.270 \\ 77.1 & 2.303 & 0.275 \\ 76.9 & 2.295 & 0.275 \\ 68.2 & 2.029 & 0.280 \\ 68.0 & 2.024 & 0.280 \\ 59.4 & 1.775 & 0.284 \\ 59.2 & 1.767 & 0.284 \\ 49.8 & 1.503 & 0.289 \\ 41.5 & 1.285 & 0.293 \\ 82.1 & 3.371 & 0.428 \\ 76.6 & 3.078 & 0.431 \\ 67.8 & 2.631 & 0.436 \\ 59.5 & 2.253 & 0.440 \\ 49.4 & 1.839 & 0.444 \\ 49.3 & 1.837 & 0.444 \\ 39.3 & 1.485 & 0.447 \\ & & \end{array}$


Table C..11: Experimental viscosity data for R-502/150 SUS alkylbenzene solutions

$\begin{array}{rcc}\begin{array}{r}\text { Temperature } \\ (\mathrm{C})\end{array} & \begin{array}{c}\text { Viscosity } \\ (\mathrm{cP})\end{array} & \begin{array}{c}\text { Concentration } \\ \text { (mass fraction R-502) }\end{array} \\ 47.0 & & \\ 47.2 & 17.21 & 0.000 \\ 46.6 & 16.68 & 0.000 \\ 72.5 & 17.26 & 0.000 \\ 74.0 & 6.91 & 0.000 \\ 98.9 & 6.56 & 0.000 \\ 99.5 & 3.52 & 0.000 \\ 82.1 & 3.46 & 0.000 \\ 82.1 & 5.21 & 0.000 \\ 117.6 & 5.22 & 0.000 \\ 117.6 & 2.39 & 0.000 \\ 135.3 & 2.40 & 0.000 \\ 135.3 & 1.79 & 0.000 \\ 148.4 & 1.78 & 0.000 \\ 148.4 & 1.46 & 0.000 \\ 148.4 & 1.47 & 0.000 \\ 148.3 & 1.46 & 0.000 \\ 133.8 & 0.96 & 0.092 \\ 119.9 & 1.18 & 0.092 \\ 106.8 & 1.46 & 0.093 \\ 93.6 & 1.82 & 0.094 \\ 81.4 & 2.27 & 0.095 \\ 68.9 & 3.03 & 0.096 \\ 58.1 & 4.09 & 0.097 \\ 51.8 & 5.49 & 0.098 \\ 49.7 & 6.84 & 0.099 \\ 137.9 & 7.25 & 0.100 \\ 124.8 & 0.83 & 0.181 \\ 111.2 & 0.99 & 0.182 \\ 98.0 & 1.22 & 0.183 \\ 85.4 & 1.50 & 0.185 \\ 69.3 & 1.89 & 0.187 \\ 60.3 & 2.64 & 0.190 \\ 44.8 & 3.52 & 0.192 \\ & 5.51 & 0.195 \\ & & \end{array}$


Table C'.11 (C'ontinued)

$\begin{array}{ccc}\begin{array}{c}\text { Temperature } \\ (\mathrm{C})\end{array} & \begin{array}{c}\text { Viscosity } \\ (\mathrm{CP})\end{array} & \begin{array}{l}\text { Concentration } \\ \text { (mass fraction R-502) }\end{array} \\ 100.6 & 1.01 & 0.262 \\ 92.6 & 1.21 & 0.266 \\ 84.9 & 1.34 & 0.270 \\ 76.5 & 1.56 & 0.275 \\ 68.6 & 1.74 & 0.280 \\ 60.7 & 1.98 & 0.284 \\ 52.2 & 2.39 & 0.289 \\ 44.6 & 2.85 & 0.293 \\ 80.2 & 0.74 & 0.428 \\ 75.5 & 0.80 & 0.431 \\ 67.7 & 0.91 & 0.436 \\ 60.5 & 1.01 & 0.440 \\ 50.9 & 1.18 & 0.444 \\ 50.5 & 1.19 & 0.444 \\ 40.8 & 1.40 & 0.447\end{array}$


Table C..12: Experimental density data for R-502/150 SUS alkylbenzene solutions

$\begin{array}{ccc}\begin{array}{c}\text { Temperature } \\ (\mathrm{C})\end{array} & \begin{array}{r}\text { Density } \\ (\mathrm{g} / \mathrm{mL})\end{array} & \begin{array}{c}\text { Concentration } \\ \text { (mass fraction R-502) }\end{array} \\ 43.7 & 0.852 & 0.000 \\ 44.0 & 0.852 & 0.000 \\ 44.0 & 0.852 & 0.000 \\ 70.9 & 0.834 & 0.000 \\ 72.6 & 0.833 & 0.000 \\ 98.9 & 0.815 & 0.000 \\ 99.5 & 0.815 & 0.000 \\ 81.2 & 0.827 & 0.000 \\ 81.2 & 0.827 & 0.000 \\ 117.6 & 0.803 & 0.000 \\ 117.6 & 0.803 & 0.000 \\ 135.3 & 0.791 & 0.000 \\ 135.3 & 0.791 & 0.000 \\ 148.4 & 0.782 & 0.000 \\ 148.4 & 0.782 & 0.000 \\ 148.4 & 0.782 & 0.000 \\ 148.3 & 0.815 & 0.092 \\ 133.8 & 0.826 & 0.092 \\ 119.9 & 0.835 & 0.093 \\ 106.8 & 0.844 & 0.094 \\ 93.6 & 0.854 & 0.095 \\ 80.4 & 0.863 & 0.096 \\ 67.2 & 0.873 & 0.097 \\ 55.6 & 0.880 & 0.098 \\ 48.9 & 0.885 & 0.099 \\ 46.6 & 0.887 & 0.100 \\ 137.9 & 0.856 & 0.181 \\ 124.8 & 0.866 & 0.182 \\ 111.2 & 0.878 & 0.183 \\ 98.0 & 0.888 & 0.185 \\ 84.8 & 0.898 & 0.187 \\ 67.5 & 0.914 & 0.190 \\ 57.9 & 0.921 & 0.192 \\ 41.4 & 0.935 & 0.195 \\ & & \end{array}$


Table C.12 (Continued)

$\begin{array}{ccc}\begin{array}{c}\text { Temperature } \\ (\mathrm{C})\end{array} & \begin{array}{r}\text { Density } \\ (\mathrm{g} / \mathrm{mL})\end{array} & \begin{array}{l}\text { Concentration } \\ \text { (mass fraction } \mathrm{R}-502)\end{array} \\ 100.6 & 0.887 & 0.262 \\ 92.5 & 0.896 & 0.266 \\ 84.2 & 0.905 & 0.270 \\ 75.3 & 0.914 & 0.275 \\ 66.8 & 0.922 & 0.280 \\ 58.4 & 0.931 & 0.284 \\ 49.3 & 0.939 & 0.289 \\ 41.2 & 0.948 & 0.293 \\ 80.3 & 0.951 & 0.428 \\ 75.1 & 0.957 & 0.431 \\ 66.6 & 0.967 & 0.436 \\ 58.5 & 0.975 & 0.440 \\ 48.8 & 0.986 & 0.444 \\ 48.8 & 0.986 & 0.444 \\ 39.1 & 0.999 & 0.447\end{array}$

